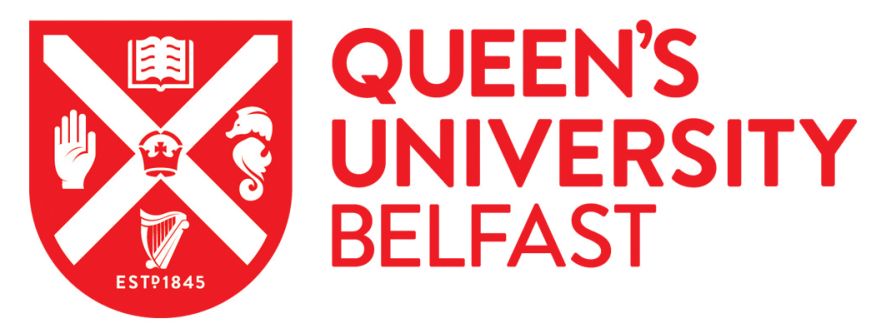

\title{
Simulation of the Mechanical Response of Thin-Ply Composites: From Computational Micro-Mechanics to Structural Analysis
}

Arteiro, A., Catalanotti, G., Reinoso, J., Linde, P., \& Camanho, P. P. (2018). Simulation of the Mechanical Response of Thin-Ply Composites: From Computational Micro-Mechanics to Structural Analysis. Archives of Computational Methods in Engineering, 1-43. https://doi.org/10.1007/s11831-018-9291-2

Published in:

Archives of Computational Methods in Engineering

Document Version:

Peer reviewed version

Queen's University Belfast - Research Portal:

Link to publication record in Queen's University Belfast Research Portal

Publisher rights

Copyright 2018 Springer. This work is made available online in accordance with the publisher's policies. Please refer to any applicable terms of use of the publisher.

\section{General rights}

Copyright for the publications made accessible via the Queen's University Belfast Research Portal is retained by the author(s) and / or other copyright owners and it is a condition of accessing these publications that users recognise and abide by the legal requirements associated with these rights.

Take down policy

The Research Portal is Queen's institutional repository that provides access to Queen's research output. Every effort has been made to ensure that content in the Research Portal does not infringe any person's rights, or applicable UK laws. If you discover content in the Research Portal that you believe breaches copyright or violates any law, please contact openaccess@qub.ac.uk. 


\title{
Simulation of the mechanical response of thin-ply composites: from computational micro-mechanics to structural analysis
}

\author{
Albertino Arteiro - Giuseppe Catalanotti • José Reinoso • Peter Linde • \\ Pedro P. Camanho
}

Received: date / Accepted: date

\begin{abstract}
This work was funded by AIRBUS under project 2 genComp - second generation Composites; the authors gratefully acknowledge the support provided by AIRBUS. The first author would also like to thank the financial support provided by FCT - Fundação para a Ciência e a Tecnologia through National Funds in the scope of project MITPTB/PFM/0005/2013. The third author is grateful to the support of the research projects funded by the Spanish Ministry of Economy and Competitiveness/FEDER (Projects DPI2012-37187, MAT2015-71036-P and MAT2015-71309-P) and the Andalusian Government (Projects of Excellence No. P11-TEP-7093 and P12-TEP-1050), and to the financial support of the European Research Council (ERC), Grant No. 306622 through the ERC Starting Grant "Multi-field and multi-scale Computational Approach to Design and Durability of PhotoVoltaic Modules" - CA2PVM. The last author gratefully acknowledges the funding of Project NORTE-010145-FEDER-000022 - SciTech - Science and Technology for Competitive and Sustainable Industries, co-financed by Programa Operacional Regional do Norte (NORTE2020), Fundo Europeu de Desenvolvimento Regional (FEDER).
\end{abstract}

\section{A. Arteiro}

DEMec, Faculdade de Engenharia, Universidade do Porto, Rua Dr. Roberto Frias, s/n, 4200-465 Porto, Portugal

Tel.: +351 220414049

Fax: +351225081440

E-mail: aarteiro@fe.up.pt

G. Catalanotti

Advanced Composites Research Group (ACRG), School of Mechanical and Aerospace Engineering, Queen's University Belfast, Belfast BT9 5AH, UK

\section{J. Reinoso}

Elasticity and Strength of Materials Group, School of Engineering, Universidad de Sevilla, Camino de los Descubrimientos s/n, 41092 Seville, Spain

P. Linde

AIRBUS Operations GmbH, Kreetslag 10, 21129 Hamburg, Germany

P.P. Camanho

DEMec, Faculdade de Engenharia, Universidade do Porto, Rua Dr. Roberto Frias, s/n, 4200-465 Porto, Portugal

\begin{abstract}
This paper provides an overview of the current approaches to predict damage and failure of composite laminates at the micro- (constituent), meso- (ply), and macro- (structural) levels, and their application to understand the underlying physical phenomena that govern the mechanical response of thin-ply composites. In this context, computational micro-mechanics is used in the analysis of ply thickness effects, with focus on the prediction of in-situ strengths. At the mesoscale, to account for ply thickness effects, theoretical results are presented related with the implementation of failure criteria that account for the in-situ strengths. Finally, at the structural level, analytical and computational fracture approaches are proposed to predict the strength of composite structures made of thin plies. While computational mechanics models at the lower (micro- and meso-) length-scales already show a sufficient level of maturity, the strength prediction of thin-ply composite structures subjected to complex loading scenarios is still a challenge. The former (micro- and meso-models) provide already interesting bases for in-silico material design and virtual testing procedures, with most of current and future research focused on reducing the computational cost of such strategies. In the latter (structural level), analytical Finite Fracture Mechanics models - when closed-form solutions can be used, or the phase field approach to brittle fracture seem to be the most promising techniques to predict structural failure of thin-ply composite structures.
\end{abstract}

Keywords Fibre-reinforced composites - Thin plies . Damage $\cdot$ Strength prediction

INEGI, Instituto de Ciência e Inovação em Engenharia Mecânica e Engenharia Industrial, Rua Dr. Roberto Frias, 400, 4200-465 Porto, Portugal 


\section{Introduction}

As the name indicates, a composite material arises from the macroscopic combination of two or more different materials, resulting in a material with superior properties than those corresponding to the individual constituent materials alone $[61,80]$. Particularly, a composite may consist of polymers that have continuous fibres embedded in them; these are usually termed fibrereinforced polymers (FRPs).

Carbon fibre-reinforced polymers (CFRPs) are characterised by high specific properties (strength-to-weight and stiffness-to-weight ratios), high fatigue resistance, high corrosion resistance, and good thermal stability, making them well suited for advanced structures especially when weight is an important variable in the design process. However, in spite of the improved specific properties of CFRPs and recent technological developments $[1,15,60,66,82,109,127,129,166]$, their heterogeneity at the ply-scale still poses some limitations on the mechanical performance. In fact, the damage behaviour of CFRPs can be quite different from that of commonly used materials such as metals, generally more complicated, and dependent on several factors, such as the properties of the constituent materials, the fibre orientation, the stacking sequence, or the nature of loading, to mention just a few.

Typical damage mechanisms of composite laminates include delamination between plies, matrix cracking parallel to the fibres, and fibre breakage - brittle fracture and pull-out failure in tension, or shear-driven fracture and fibre kinking in compression. Matrix-dominated damage mechanisms — delamination and matrix cracking - are often the first-ply failure (FPF) modes. In some cases (e.g. with sufficiently thick plies), multidirectional composite laminates can lose their structural integrity only due to matrix-dominated damage, before any fibre breakage. Fibre-dominated damage mechanisms, on the other hand, typically lead to composite ultimate failure (or last-ply failure (LPF)), which occur most of the times in a catastrophic manner. The development of matrix cracking and delamination can sometimes promote fibre-dominated damage, leading to premature laminate failure when subjected to smooth stress distributions or cyclic loading $[5,151]$.

Even though the use of CFRPs has increased drastically in the last few years, in order to ensure safe operation, currently large safety margins are still used in the design of composite structures when compared with alternative materials, limiting the full exploitation of the benefits of CFRPs. This is due to the high susceptibility of CFRPs to subcritical damage mechanisms, which degrade their mechanical performance. This is also due to the lack of knowledge and predictive capability of both the mechanical response and the complex failure behaviour of composite materials.

To avoid early composite failure, thin plies can be used to delay matrix-dominated damage mechanisms. Thin-ply laminates, composed by flat and straight plies with a dry ply thickness as low as $0.015 \mathrm{~mm}$, are a new class of advanced composite materials [99, 100]. Due to an in-situ effect on the ply strengths [33, 49, 67], matrix cracking can be substantially reduced. In addition, the laminae fine dispersion of thin-ply laminates leads to lower interlaminar stresses, delaying delamination onset, even in the presence of ply-drops (stepped, non-uniform free edges) [35]. These two features combined make thin-ply laminates particularly strong and fatigue insensitive $[5,151]$.

However, with the aim of taking advantage of all benefits of thin plies, it is important to understand how to efficiently and accurately model the mechanical response of thin-ply laminates, which show features that are unique to this new class of composite laminates. The present review article covers the formulation and application of models established at the different length-scales of composite damage representation (Fig. 1) to the understanding and prediction of the mechanical response of thin-ply laminates, providing a comprehensive coverage of the existing predictive solutions for this class of composite laminates. At the scale of the constituents (or microscale), computational micro-mechanical models are used to investigate the in-situ effect on the strengths of an embedded ply. To take this in-situ effect into account at the ply scale (or mesoscale) in a ply-by-ply discretization, a strategy is described that ensures advanced failure criteria can consistently capture in their FPF envelopes the strength increase with ply thinness; new solutions are defined for the in-situ strengths in the framework of a fully three-dimensional (3D) invariant-based failure criterion and validated by micro-mechanical simulations. Finally, because thin-ply laminates are characterised by a high degree of homogeneity, models at the laminate scale (or macroscale) can be used to accurately represent laminate failure. For relatively simple geometries and boundary conditions, coupled energy-stress Finite Fracture Mechanics (FFMs) criteria are used to predict the strength of notched thin-ply laminates. For more complex scenarios, when closed-form solutions for the stress field and energy release rate are not readily available, a computational model becomes more versatile. In this regard, numerical simulations at structural level are performed using the novel phase field (PF) approach to brittle fracture, which is employed to represent macroscopic damage onset and growth in thin-ply laminates. 

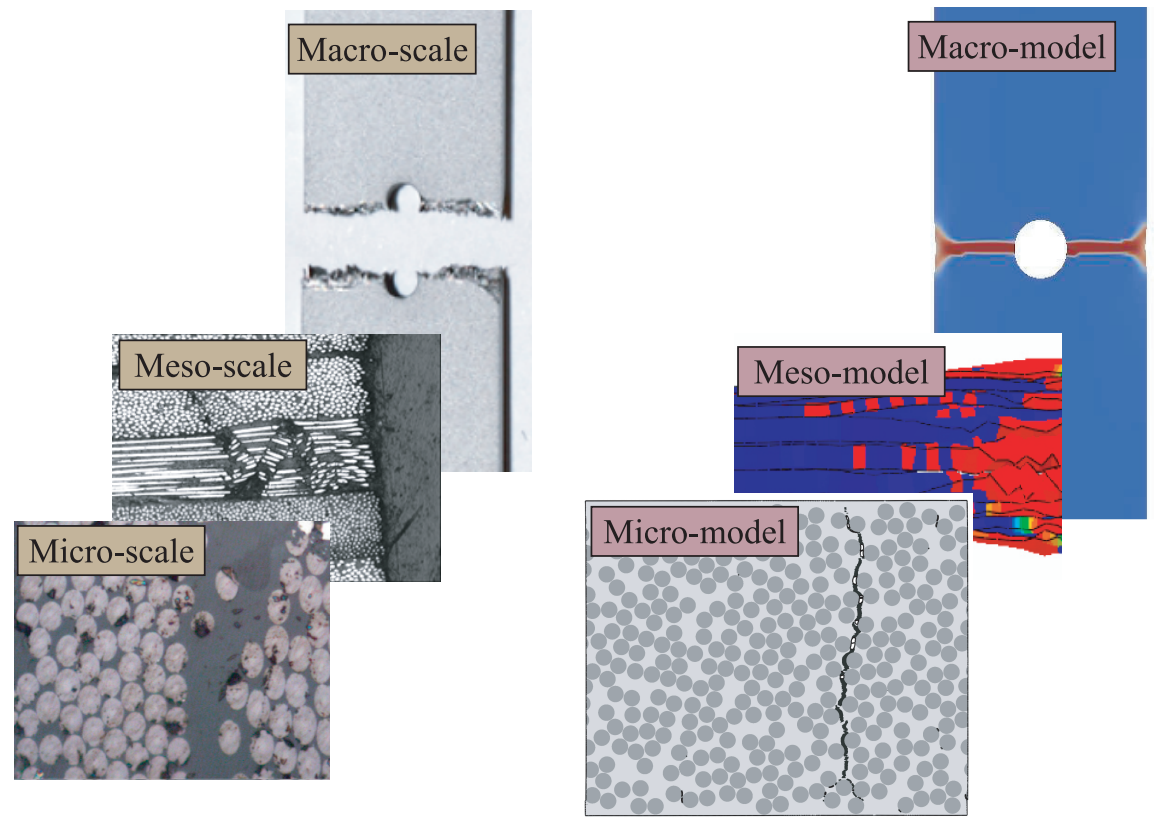

Fig. 1: Composite damage at different length-scales [7, 28] and corresponding representations [10, 143].

\section{Prediction of the mechanical response of fibre-reinforced composites: a multi-scale problem}

When composites are used in structural parts, a design development programme is generally implemented where the performance of the structure is assessed prior to use, in the case of aero-structures relying on a "buildingblock" approach (Fig. 2) [55]. The process of validating the structural performance and durability of these composite parts generally consists of a combination of tests and analyses.

While testing alone is prohibitively expensive and time consuming, analysis techniques currently need additional validation procedures in order to show their predictive capabilities to reproduce the structural response of composites under complex loading conditions within a reasonable amount of time. This is of especial relevance whether the interest is to predict the mechanical response of composite laminates or to assess the structural integrity of composite structures. In the absence of accurate and computationally efficient analysis techniques, the design process of composite parts will keep relying on mechanical tests based on a large number of coupons and empirical knock-down factors, undermining the benefits of advanced composite laminates. The ability to obtain reliable predictions for the onset and propagation of damage in composite laminates is, therefore, key to a more effective use of polymer composite materials in load carrying structures.

\subsection{Microscale}

Macroscopic fracture in composite systems is usually a result of the evolution of discrete damage events at lower length-scales, acting together under complex combinations. Some of the involved damage mechanisms are fibre-matrix debonding and subsequent fibre pull-out, matrix yielding and matrix cracking, fibre breakage (in tension) or fibre kinking/micro-buckling (in compression), fibre-matrix splitting, and delamination between plies, resulting in an inter-connected multi-scale failure behaviour.

To predict the complex damage behaviour of composite materials, progressive loss of stiffness and strength needs to be taken into account. This usually leads either to too simplistic analytical solutions or computationally demanding numerical models. However, the recent computational advances allowed numerous published demonstrations of successful representations of the initiation and propagation of damage in composite materials at different length-scales, from detailed constituents (micro-mechanical) representations $[12,17,41,81,95$, 119-122, 166, 169-171, 184, 185], to homogenised models at the ply-level (mesoscale) $[2,34,37,94,111,112$, $154,179,180,198]$ and at the laminate-level (macroscale) $[6,57,58,143]$.

At the microscale, damage idealisations have higher resolution, higher kinematic freedom and are able to recreate all kinds of damage mechanisms involving each individual constituent - fibres, matrix and their interfaces - captured with appropriate separate consti- 


\section{Experimental test pyramid}

\section{Virtual test pyramid}

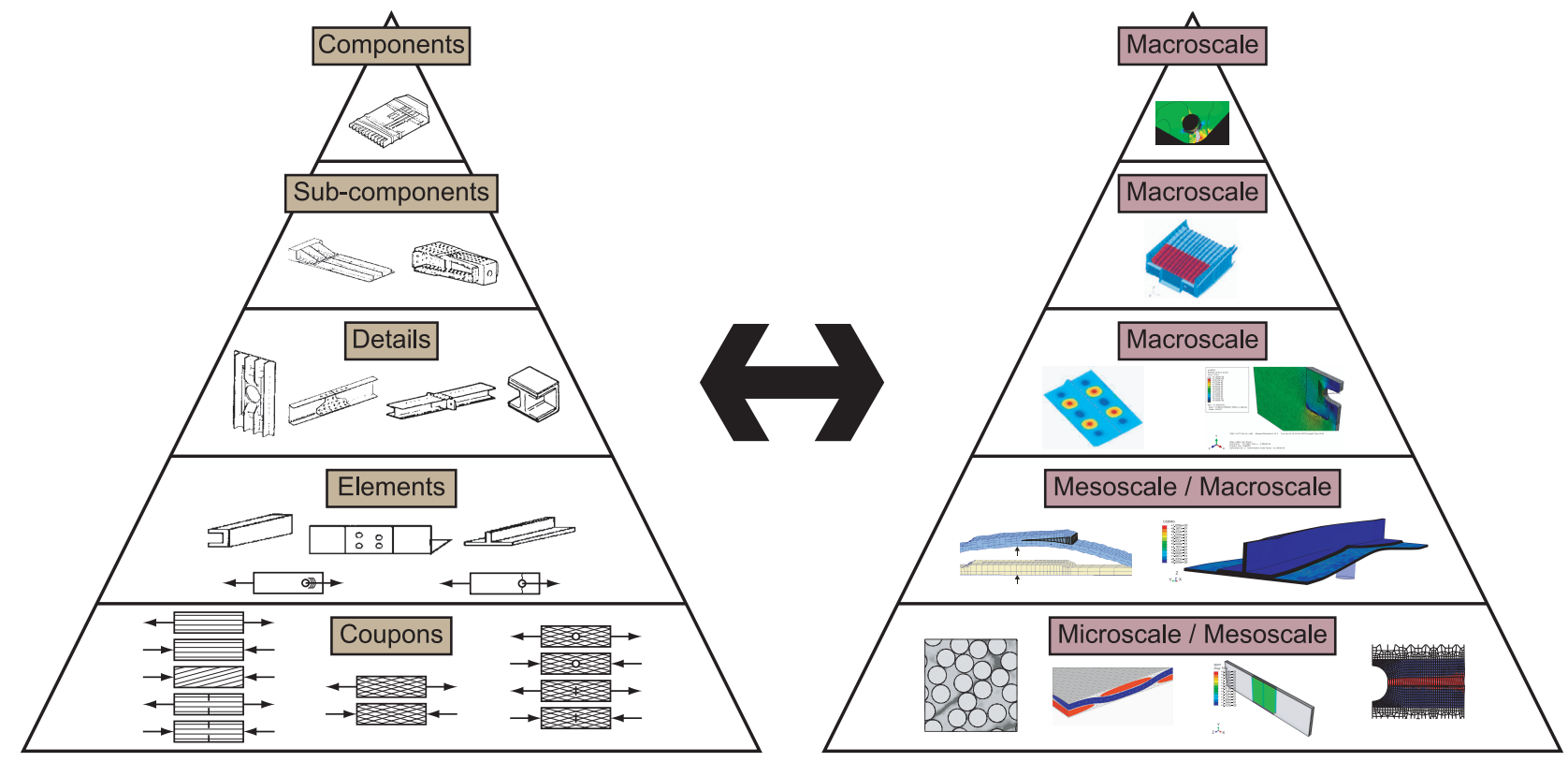

Fig. 2: Building-block approach: experimental and virtual test pyramids (after Refs. [34, 37, 54, 55, 62, 64, 120, $122])$.

tutive laws [17, 121, 122, 166]. Experimental data of the properties of the constituents, which are modelled as individual homogeneous materials, and their interfaces, and a truthful geometrical representation of the arrangement of reinforcements are the basis to study the constitutive behaviour of a composite lamina using a micro-mechanical modelling approach. Detailed microscopic damage mechanisms, such as fibre-matrix decohesion, matrix plasticity and damage, and fibre failure can be easily represented by means of the numerical simulation of the deformation of a representative volume element (RVE) of the microstructure. Hence, the generation of virtual RVEs statistically and materially equivalent to real microstructures, and the use of constitutive models that are able to capture the nature of deformation and damage of each of the constituent materials of advanced FRPs are key in the definition of reliable micro-mechanical models (Fig. 3). Even though these models can be computationally expensive, the sophistication of the modelling techniques and the everincreasing computational power has allowed computational micro-mechanics to emerge as a reliable tool to study the mechanical response of composite materials.

The size of the RVE and the spatial arrangement and volume fraction of reinforcements can have a strong influence on the response of the composite system. RVEs must be sufficiently large to ensure that their homogenised response is representative of the global mechanical performance of the system, without compromising the possibility to numerically analyse it. Regarding the reinforcements distribution, even though periodic models can be used in the determination of effective elastic properties, for statistical and reliability analysis, or for prediction of local phenomena and failure, random models must be used [173]. However, obtaining a truthful representation of a composite microstructure is still a challenging task.

For this purpose, on one hand, one possibility is to rely on digital image analysis of real composite crosssections [172, 183, 196]. These techniques can provide perfect replicas of the transverse section of polymer composites. However, they can be extremely time and resource consuming as they require specific software and hardware for image acquisition and processing, and properly treated material to be analysed.

Alternatively, virtual random RVE generators can be used. However, problems in generating distributions with fibre volume fractions greater than $50 \%[27,70$, $130,131]$, in guaranteeing non-overlapping fibres [141], in achieving a random pattern [98], the lack of statistical analyses [195], or a very high computational effort even for moderate fibre volume fractions (i.e. lower than 


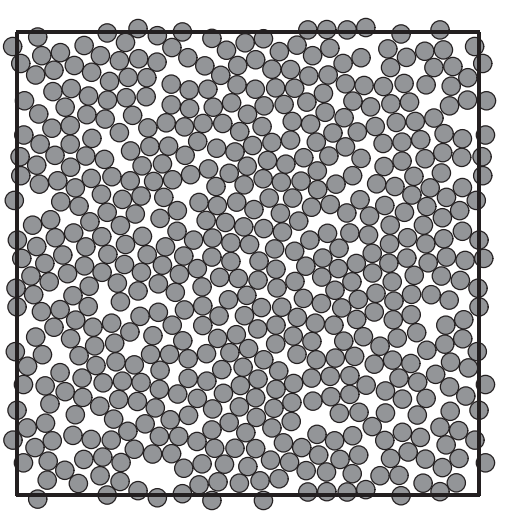

Generation of virtual RVEs statistically and materially equivalent to real microstructures

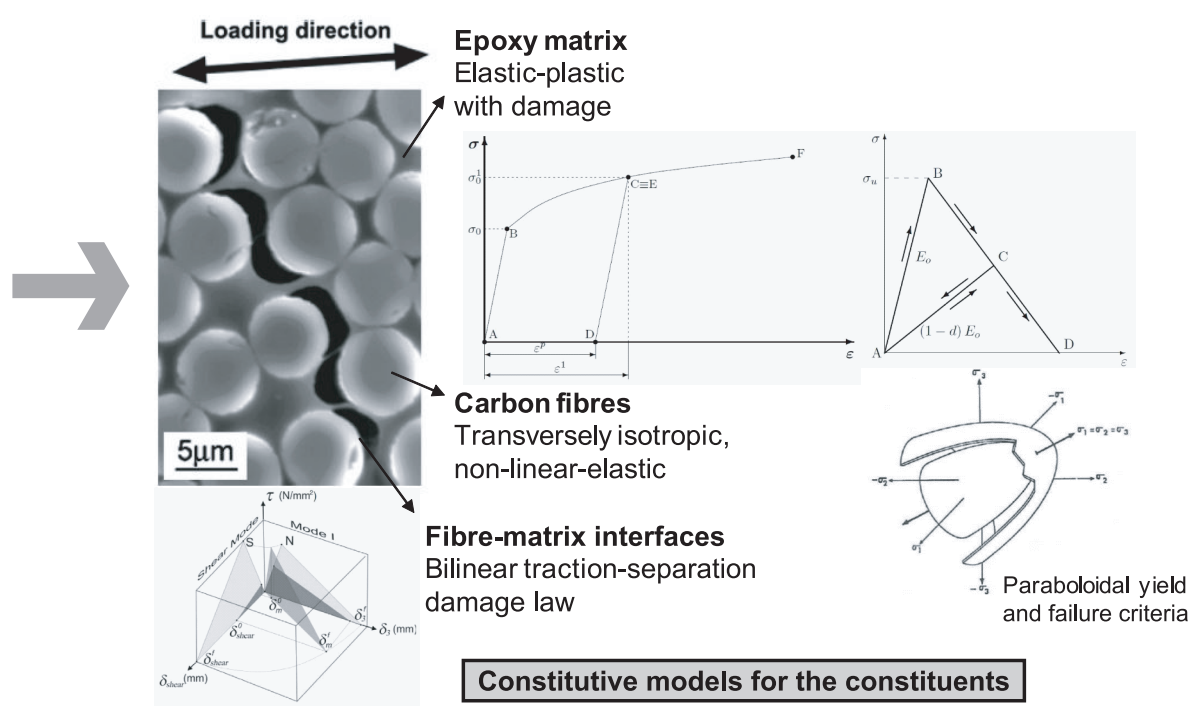

$\downarrow$
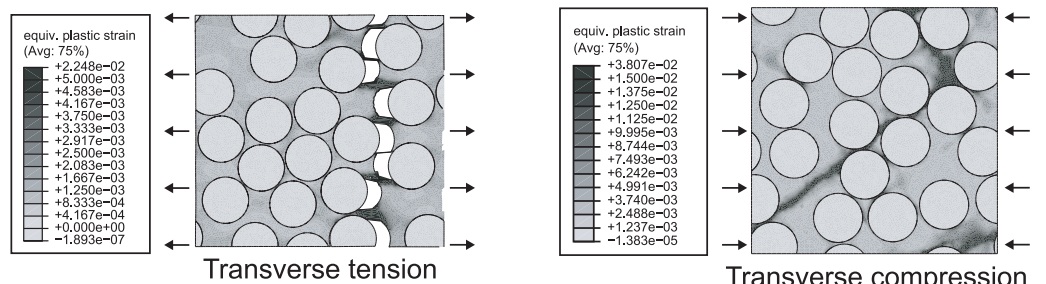

Transverse compression

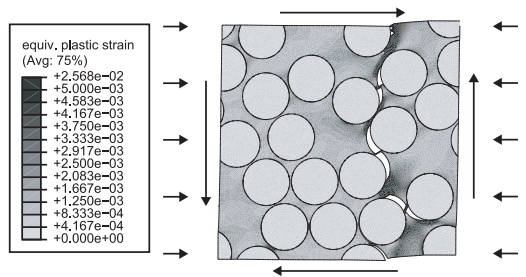

Combined transverse compression and transverse shear

Generation of the FE model, application of boundary conditions, analysis and results interpretation

Fig. 3: Main components of computational micro-mechanical models (after Refs. [32, 93, 118, 121, 122]).

$60 \%)$ [172] have been found. To overcome these problems, more sophisticated methodologies have been recently proposed $[45,118]$ and successfully applied in the prediction of the micro-mechanical response of FRPs $[10,12,17,39,119,122,158-160,162,163,166,167$, $181]$.

Nevertheless, the ability to accurately predict the failure response of composite materials at the microscale does not depend solely on the geometrical definition of the RVEs, but also on the definition of appropriate con- stitutive models for each of the constituents. In the case of FRPs, this includes an appropriate definition of plasticity and damage in the resin, non-linear elasticity and fracture in the fibres, and decohesion at the interface between the fibres and matrix.

The polymer resins typically used in advanced FRPs are known to be pressure dependent and extremely ductile under shear loading, features that standard nonlinear models, such as the Von Mises elastic-plastic models, cannot properly capture. Hence, pressure depen- 
dent, elastic-plastic formulations with damage capabilities, which model the pressure dependency on the yield and failure behaviour of polymer resins, and their shear non-linear-almost perfectly plastic behaviour, have been proposed $[17,121]$ and used in micro-mechanical models to predict the matrix inelastic response in RVEs subjected to transverse $[10,12,122]$, longitudinal [166], and interlaminar [181] failure.

In the analysis of matrix-dominated damage mechanisms [10, 12, 17, 39, 81, 122, 169-171, 181, 184, 185], the reinforcing fibres are usually assumed linear-elastic solids. However, in the prediction of fibre-dominated failure modes $[160,161,163,166,167]$, fibre fracture needs to be accounted for. Simpler micro-mechanical models tend to rely on simple maximum stress criteria [160-163, 167]. But for high-fidelity micro-mechanical analysis, thermodynamically consistent damage models must be employed [166]. To account for the stochastic nature of the tensile strength of the fibres, random strength distributions can be assigned to the fibres, usually based on a Weibull distribution or on modified versions of it $[160,161,163,166,167]$.

For accurate micro-mechanical representation of local phenomena, also the interface between fibres and matrix cannot be neglected, as it can significantly affect the composite mechanical response, in particular under transverse tensile and combined stress states [122]. Fibre/matrix interfaces are often represented using cohesive formulations $[10,12,39,81,122,166,169-171$, $181,184,185]$, typically defined by bilinear tractionseparation laws. It is noted that, in general, the values of the interface fracture toughness are assumed relatively low to capture the brittle behaviour in transverse tension exhibited by polymer composites, an assumption justified not only by experimental evidence [182], but also by previous micro-mechanical numerical analyses $[10,39,122,184,185]$.

If successfully applied, computational micro-mechanics has the potential to predict the effects of material changes, the influence of the geometry and spatial distribution of the constituents (e.g. fibre volume fraction and fibre clustering), the effect of micro-mechanical defects such as voids and microcracking induced during the curing process, and the effects of adding new constituents (e.g. thermoplastic particles or doping agents), setting the path for in-silico material design of improved composite systems.

\subsection{Mesoscale}

The high computational cost of micro-mechanical models makes them currently unsuitable for the prediction of damage localisation and ultimate failure in composite laminates and structures. Alternatively, meso-mechanical models based on a ply-by-ply discretization, where the laminate layers are taken as the basic homogeneous building blocks, become more appropriate to predict the behaviour of the whole laminate. Each layer is represented by its orthotropic material properties. These material properties can be determined experimentally from characterisation tests at the lamina level, or from micro-mechanical models using the properties of the constituents.

To predict the onset of the different, discrete damage modes observed in FRPs using meso-models, phenomenological failure criteria based on the homogenised stress (or strain) state at the ply level become the most appropriate approach. However, few criteria represent satisfactorily several relevant aspects of the failure process of laminated composites. Accordingly, the development of accurate, fully-benchmarked failure criteria that predict the onset of ply damage mechanisms in FRPs is extremely important [92].

Important aspects that failure criteria for FRPs should be able to capture include the increase on apparent shear strength when applying moderate values of transverse compression, the effect of ply thickness on the strengths of each ply (in-situ effect), the detrimental effect of the in-plane shear stresses due to fibre misalignment under longitudinal compressive failure by fibre kinking, or the ability to predict failure under hydrostatic pressure. Until very recently [38, 39], many of the available failure criteria used to predict the onset of matrix cracking and fibre fracture [47, 63, 87, 91, 138, 153] did not address all these issues.

But, with the exception of unidirectional (UD) laminates, the onset of failure at a given ply — or FPF rarely coincides with ultimate failure of the laminate - or LPF. The ability to represent the evolution of the different damage mechanisms at the ply level (Fig. 4) is therefore crucial to obtain accurate predictions of laminate failure. This is typically addressed using damage models $[4,26,29,34,44,51,52,94,97,105,107,110$, $144,179,180,188,194]$.

\subsection{Macroscale}

In spite of providing a detailed representation of the initiation and propagation of the different damage mechanisms occurring at the ply level and their interaction, the required discretization usually leads to computationally expensive meso-models. Moreover, this computational cost increases rapidly with the number of plies in the laminate and with the size of the structure, as these models typically require a minimum element size 


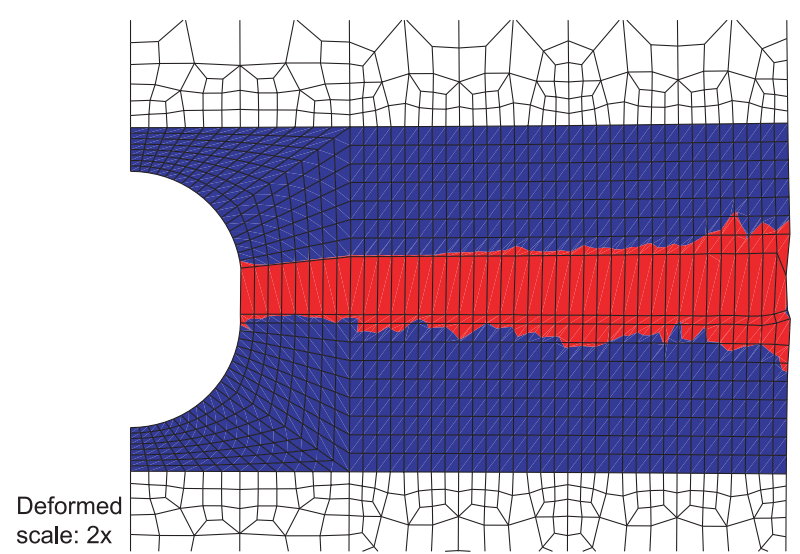

Fig. 4: Damage localisation in a continuum damage mechanics model. Example of fibre fracture in the $0^{\circ}$ ply of an open-hole quasi-isotropic laminated plate (after Camanho et al [34]).

to ensure not only numerical objectivity but also physical representativeness of the modelled damage mechanisms. Damage meso-models are, therefore, unsuitable for preliminary design and optimisation of composite structures, or for large-scale numerical simulations in the absence of global-local coupling analysis. In these situations, macro-mechanical models formulated at the laminate level are required.

In structural-level (macro-mechanical) damage models, the basic building block is the laminate. Stress patterns and stress concentration regions in a component can be studied assuming the composite to be a homogeneous material and representing the effects of the constituent materials and stacking sequence by averaged apparent properties of the laminate.

Laminate damage can be represented either as a hard discontinuity [6] or using a continuum damage approach [57, 58, 143] (e.g. Fig. 5). However, structurallevel crack propagation criteria are strongly dependent on the material system and laminate configuration. A new set of material properties must be determined for each new material system and laminate stacking sequence, either through direct experimental testing, or through virtual testing using suitable meso-models and experimental data at the ply level.

For simple geometries and loading scenarios, analytical models can satisfactorily predict failure of composite laminates with smooth geometries [174, 175, 177] or notched configurations $[11,16,31,36,46,69,76$, $115,116,191,193]$, as long as delamination is not the predominant failure mechanism. These models are particularly suited for material and lay-up screening and for preliminary design and optimisation of composite structures. They do not require complex modelling tools

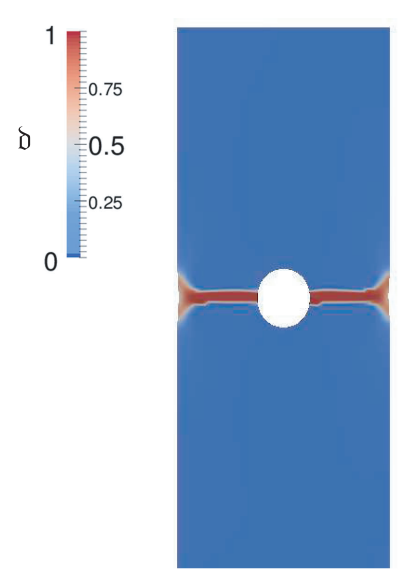

Fig. 5: Crack pattern of an open-hole tension test on a quasi-isotropic laminate obtained using a PF approach to brittle fracture - contour plot of phase field variable (after Reinoso et al [143]).

and provide predictions and design charts for parametric analyses in a very small fraction of the time required by FE models.

In addition to fast computations, it is also desirable to minimise the number of material properties required by the analysis models, and thus reduce the material testing requirements at the material screening and preliminary design stages [55, 192]. However, the most commonly used analytical models for the prediction of the notched strength of laminates [191, 193] use empirical "characteristic distances" that, in practice, are determined from notched strength data. They are often thought as correction factors that account for apparent changes in the stress distribution or in the fracture toughness with increasing crack size, with limited physical meaning [192]. Unless virtual testing is used to calibrate these empirical factors, a considerable amount of tests on laminates with different stacking sequences may be required.

To overcome this limitation of the classical analysis methods, physically-based criteria [11, 36, 46, 116] provide accurate predictions of the notched response of composite laminates without requiring fitting parameters or complex Finite Element Analyses (FEA). Only independently measured material properties are necessary, the laminate strength and the laminate fracture toughness or crack resistance curve. These properties can be easily obtained from the experimental characterisation programmes that are often carried out in the composites industry. Moreover, physically-based analysis methods such as the FFMs model can be combined with suitable models to estimate the laminate strength $[174,175,177]$ and the laminate fracture toughness [30] 
using only properties measured at the ply level [76]. With this approach, the number of tests required in the early stages of design and optimisation can be significantly reduced, and more efficient experimental programmes can be established, resulting in lower costs associated with preliminary material and lay-up characterisation.

However, in macro-mechanical models formulated at the laminate-level, the characteristics of the damage process zone or the complex interactions between micro- and macro-failures associated with the process of crack extension cannot be properly captured, particularly when subcritical diffuse damage is present. The laminate damage process zone is lumped into an "effective" crack-tip area that is assumed to grow in a self-similar manner. In many cases, though, self-similar crack growth is not observed (e.g. laminates showing delamination failure), and the lack of resolution in the damage mechanisms often renders structural-level damage models inaccurate after a short damage extension [65].

\subsection{Discussion and remarks}

It is clear that the development of reliable damage models at the different length-scales is important for the improved design development of composite structures. With accurate and computationally efficient analysis techniques in hand, the large number of coupons required during development of composite structures can be complemented, and, in some cases, replaced by virtual tests - see Fig. 2 - making application of polymer composite materials in load carrying structures more efficient and cost-effective.

It is also noted that, as an alternative to perform several simulations at different length-scales to obtain first the homogenised lamina (microscale) or laminate (mesoscale) properties - by means of virtual testing - and only then the structural response (macroscale) using virtual allowables, it is possible to link the different scale idealisations using multi-scale approaches (Fig. 6). These consider the various aspects of the entire structural problem at different levels of observation. The different levels at which analyses are carried out are then connected either through length-scale transitions, where the structural behaviour at a given level is homogenised to provide information about the mechanical response for a next higher level - hierarchical methods, or through FEA conducted at two different levels simultaneously (or concurrently), connected by matching the boundary conditions at both levels (usually invoking periodicity to reduce the amount of computations that need to be performed) - concurrent methods [19]. Hence, multi-scale analyses can be performed by using the best out of each level of analysis. For instance, in an information passing (or hierarchical) multi-scale approach, analyses on unit cells at the microscale can determine the mechanical behaviour of the UD composite through homogenisation techniques, which are transferred to a meso-mechanical model that accounts for the response of the individual plies in a laminate and predicts its structural behaviour (including lay-up and stacking sequence effects), providing the laminate response for computations at the macroscale [146]. Consequently, changes at the constituent-level can be reflected on the macro-response by means of a well-established framework, without having to conduct unnecessary analysis or verifications. Nevertheless, the reliability of such frameworks is dependent on the effectiveness of the damage models available for each lengthscale, whose application to the understanding and failure prediction of a new class of composite materials is explored in the remaining of this paper.

\section{Mechanics of thin-ply laminates}

To satisfy the stringent requirements for advanced composite materials, new technologies are being developed to improve the performance of FRP-based composite structures. One of this technologies - the spread-tow thin-ply technology [99, 100] — is able to continuously and stably open fibre tows and cost-effectively produce flat and straight plies with dry ply areal weights lower than $125 \mathrm{~g} / \mathrm{m}^{2}$ without damaging the filament fibres ${ }^{1}$. This leads to unique features that can make thin-ply composites stronger, and consequently thinner and lighter. This includes woven [13] and non-crimp fabric reinforcements $[8,11,14]$, which exhibit enhanced mechanical properties over conventional fabrics, allowing the development of advanced laminated composites using more competitive manufacturing techniques. Moreover, thin plies make laminate design more flexible. For a given laminate thickness, the use of thin plies allows smaller relative fibre orientations to be accommodated, reducing the interlaminar stresses [165], and thus contributing for the mitigation of the initiation and propagation of interlaminar fracture events between plies. This is especially important in applications with significant out-of-plane stresses (e.g. L-shaped structures, typical of box structures such as wings or wind turbine blades) where application of conventional composite laminates is generally restrict due to their low through-thickness strength. Thin plies also motivate the

$1125 \mathrm{~g} / \mathrm{m}^{2}$ is typically regarded as the minimum dry ply areal weight of conventional low-grade CFRPs. 


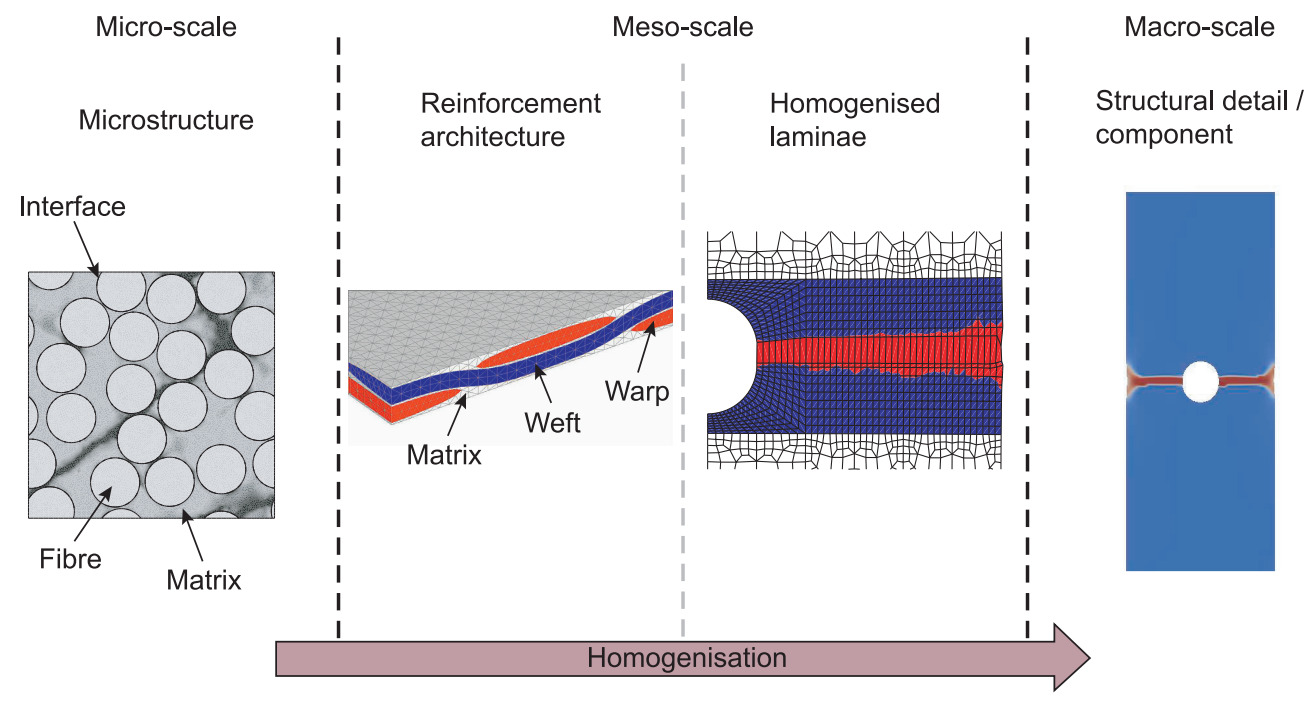

Fig. 6: Illustration of a multi-scale approach applied to composite materials (after Refs. $[3,34,120,122,143]$ ).

integration of simpler lay-up rules, such as laminate asymmetry and more flexible ply drops, due to easier laminate homogenisation, which can contribute to notable reductions in production times. This makes thinply composites particularly attractive for the industries relying on high-performance FRPs.

To take full advantage of the potential mechanical and design benefits of thin plies, it is important to understand their unique features and how they can be accounted for in the analysis models.

The improved fibre dispersion resulting from tow spreading has motivated the study of the effect of ply thickness on the mechanical response of UD laminae. Amacher et al [5] performed an extensive experimental characterisation of the mechanical response of thin-ply laminates, including testing of UD carbon fibre-epoxy composites with ply areal weights ranging from ultrathin to very high grades, all produced from the same batch of fibre and matrix. No significant influence of the ply thickness on the elastic and strength properties of the UD composites was observed, except for longitudinal compression, where an increase of approximately $20 \%$ was observed. This was attributed to the more uniform microstructure of spread tow thin plies, which reduces the presence of the weak zones and fibre misalignments that trigger the initiation of longitudinal compressive failure [190]. This improved ply compressive strength parallel to the fibre direction is behind the superior plain and notched laminate compressive strengths found in thin-ply composites [5, 13, 197].

Moreover, due to the constraining effect exerted by the adjacent plies with the fibres aligned along different orientations, the mechanical response of an embedded ply in a multidirectional laminate can be significantly different from the behaviour of a UD lamina, and ply thickness can have a great influence on this mechanical response. By delaying damage propagation in the matrix, an in-situ effect on the ply strengths is observed, characterised by an increase of the resistance to matrix cracking as ply thickness decreases [33, 49, 67, 148]. This means that the actual ply strengths are not only higher than those measured in UD laminae, but they reportedly increase with decreasing ply thickness $[23,33$, $49,67,72,79,135,136,148,150]$. Hence, the effect of ply thickness on the onset of ply damage (matrix cracking) finds particular significance when dealing with the most recent spread-tow, ultra-thin grades.

However, the available analytical models for the insitu effect [33, 67], which are based on Fracture Mechanics, yield asymptotic results when the ply thickness tends to zero. For example, the relation between the $i n$ situ transverse tensile strength $Y_{T}^{i s}$, the ply thickness $t$, its UD transverse tensile strength $Y_{T}$, and its mode I intralaminar fracture toughness parallel to the fibre direction $\mathcal{G}_{\text {Ic }}$ can be written, for a thin embedded ply, as [33]:

$\frac{Y_{T}^{i s}}{Y_{T}}=\lambda^{-1 / 2}$

with:

$\lambda=\frac{\pi t \Lambda_{22}^{0}}{8 \mathcal{G}_{I c} Y_{T}^{2}}$ 
and [113]:

$\Lambda_{22}^{0}=2\left(\frac{1}{E_{22}}-\frac{\nu_{12}^{2}}{E_{11}}\right)$

where $E_{11}, E_{22}$ and $\nu_{12}$ are the ply elastic properties. For a thick ply ${ }^{2}[33]$ :

$\frac{Y_{T}^{i s}}{Y_{T}}=1.12 \sqrt{2}$

Fig. 7 shows a dimensionless representation of the $i n$ situ effect on the transverse tensile strength of an embedded ply. As can be observed, as the ply thickness decreases, the in-situ strength asymptotically tends to infinity. Therefore, an understanding of the in-situ effect on thin plies is of crucial importance, namely for validation and/or development of physically meaningful analytical models applicable at this scale. However, experimental analysis based on in-situ observations of very thin plies [148] are extremely difficult, not only because it is hard to identify any transverse damage at this scale, but also because the applied strains needed to develop such damage mechanisms are so high that may lead to failure (or severe damage) of the surrounding plies [21]. A possible way through for the understanding of the in-situ effect is the use of computational micro-mechanics - this is the subject of Sect. 4. In fact, the delay of other ply matrix-dominated failure mechanisms in multidirectional laminates, such as shear and wedge transverse compressive fracture, can also be attributed to an in-situ effect. Computational micromechanics provides the flexibility to assess ply thickness effects at the microscale for any devisable loading scenario.

While computational micro-mechanics can be extremely helpful in the understanding of the phenomena at the lower length-scales whose interaction can lead to structural damage, its application in the prediction

2 The distinction between thin- and thick-ply behaviour in Eqs. (1) and (4), respectively, separates the cases of stable crack propagation in the longitudinal direction (crack tunnelling) after through-thickness propagation (thin-ply case), and unstable through-thickness propagation of the transverse crack without stable crack tunnelling, as longitudinal propagation occurs immediately after but at a lower applied stress (thick-ply case) [33, 67, 178]. The theory shows that the transverse stress level at which unstable though-thickness crack propagation occurs is independent of the ply thickness thick-ply case, Eq. (4). However, stable propagation parallel to the fibres occurs at higher stress levels as the ply thickness decreases - thin-ply case, Eq. (1). Hence, for a ply thickness at which the stress level needed for stable propagation in the longitudinal direction is higher than for unstable throughthickness propagation, increasing strength with decreasing ply thickness is observed (Fig. 7).

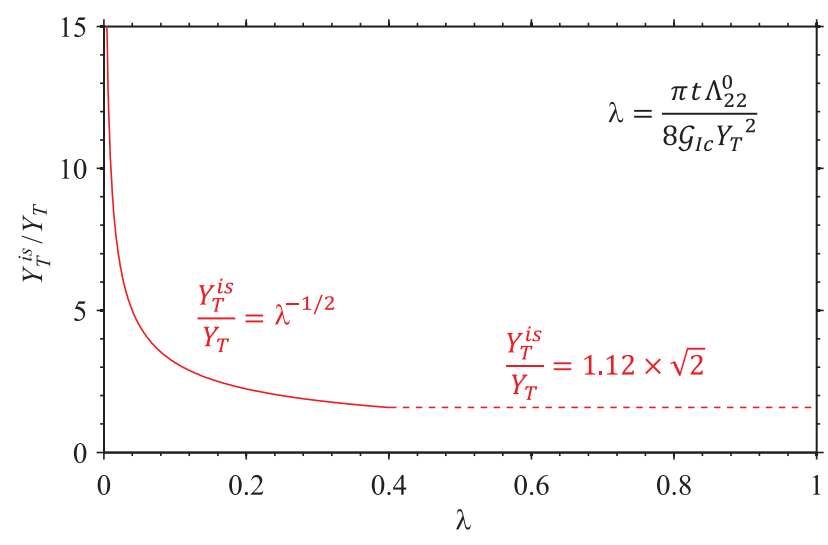

Fig. 7: Dimensionless representation of the in-situ effect on the transverse tensile strength of an embedded ply.

of the inelastic response of composite laminates or as a design tool is not feasible. For a detailed prediction of lay-up and ply thickness effects on multidirectional laminates, meso-models become a more attractive solution.

The accurate determination of the in-situ effect is crucial for the implementation of any physically-based failure criteria for transverse damage initiation [37, 38, $47,50,63,71,111,117,138]$. It has been shown that using as ply properties those measured directly from UD plies to predict the strength of multidirectional laminates results in very conservative predictions that could differ substantially from the experimental results [49, 59, 78, 140].

For the in-situ transverse tensile and in-plane shear strengths ${ }^{3}$, Fracture Mechanics solutions have been proposed $[33,67]$ and successfully applied to the prediction of the initiation of ply damage $[37,111]$. To account for the in-situ effect on other matrix-dominated ply damage mechanisms, such as transverse compression and transverse shear cracking, the extension of phenomenological failure criteria for a consistent representation of failure of an embedded ply has been proposed by Catalanotti et al [47]. The implementation of these failure criteria as damage activation functions in a damage model [37] allows their application to the prediction of the inelastic response of multidirectional laminates subjected to general stress states, while accounting for lay-up and ply thickness effects. In Sect. 5, a similar strategy to that proposed in Ref. [46] is adopted to account for the in-situ effect, but in the framework of

\footnotetext{
3 It is noted that, in the case of in-plane shear, Linear Elastic Fracture Mechanics alone is not able to accurately predict the in-situ strength, and the non-linear shear response typically observed in laminated composites must be included in the models [33].
} 
new invariant-based phenomenological failure criteria for FRPs [39]. These new failure criteria are not only simpler, but due to their invariant formulation, a priori knowledge of the angle of the fracture plane is not required. Moreover, due to their fully $3 \mathrm{D}$ character, they can also predict failure under the most general stress states, including failure under hydrostatic pressure, to which polymer matrices, and their composites, are sensitive [90].

As a consequence of matrix cracking suppression, the localised delaminations induced at the tips of the transverse cracks when these approach the interlaminar area can be precluded as well [74, 83, 151]. Furthermore, due to the laminae fine dispersion, the interlaminar stresses between thin plies with different orientations are substantially lower, delaying the onset and propagation of delamination at the laminate free edges [151]. Thus, the initiation of subcritical, matrixdominated damage mechanisms, or FPF occurrence, is delayed until very close to fibre-dominated LPF, contributing for the high plain strengths, enhanced fatigue life, and improved impact resistance of thin-ply laminates $[5,8,147,151]$. The absence of early subcritical damage mechanisms also means that multidirectional thin-ply laminates can be macroscopically represented as homogeneous materials, and their failure characterised by the onset and growth of a macro-crack (Fig. 8). Therefore, failure analysis tools and damage models that take the laminate as a homogeneous material must be able to capture the physics behind macroscopic failure of thin-ply laminates without requiring complex ply-by-ply analysis. This will be the subject of Sect. 6. When the geometry and boundary conditions allow an accurate analytical representation of the stress field and energy release rate, simple LPF analyses [5, 76] and coupled energy-stress FFMs criteria $[11,36,76,143]$ can be used to predict failure of notched thin-ply laminates with good accuracy. For more complex geometries and/or loading scenarios, a computational model based on a PF approach to brittle fracture [143] is used instead, providing a more versatile tool when analytical representations of the stress field and energy release rate are not readily available. Moreover, this approach provides additional information such as the stress-strain response and the crack path before ultimate failure, which cannot be obtained by analytical criteria.

\section{Micro-mechanical analysis of ply thickness effects}

Ply thickness effects on transverse matrix cracking of thin-ply cross-ply laminates were thoroughly analysed

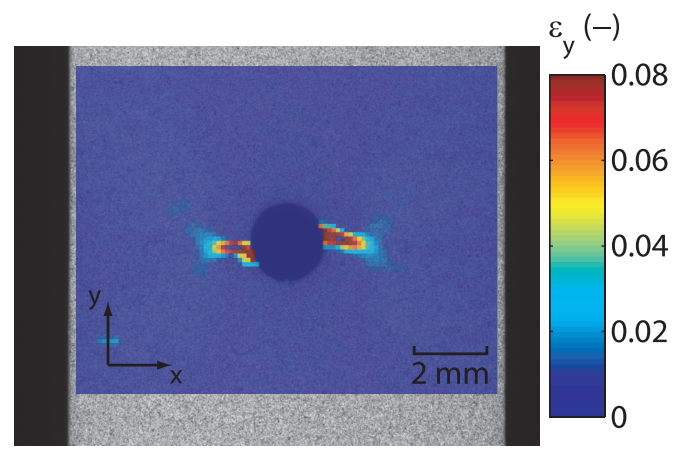

(a) Open-hole specimen with a hole diameter of $2 \mathrm{~mm}[75]$.

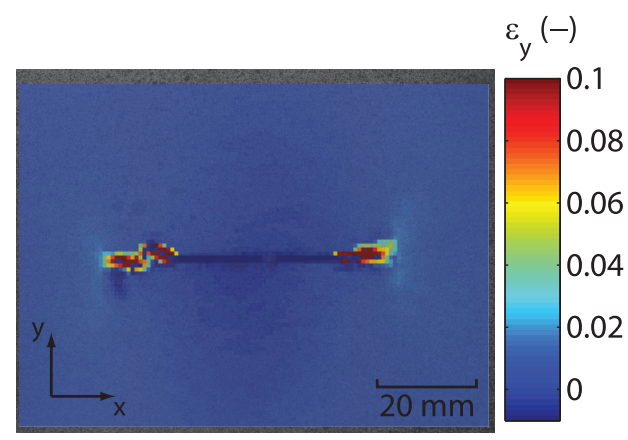

(b) Large damage capability centre-notched specimen with a notch length of $36 \mathrm{~mm}$ [11].

Fig. 8: Experimental surface longitudinal strain fields $\left(\varepsilon_{y}\right)$ obtained with digital image correlation just before ultimate failure in notched quasi-isotropic thin-ply laminates subjected to tensile loading ( $y$-direction). Clear through-thickness macro-cracking from the notch tips, including stable intralaminar fibre fracture, can be observed in small open-hole (a) and large centre-notched specimens (b). It is important to note that in neither case the fibre direction of the outer ply is perpendicular to the applied tensile load.

by Saito et al [148]. Their experimental in-situ observations showed that, due to the constraining effect caused by the stiff $0^{\circ}$ plies adjacent to the inner $90^{\circ}$ ply, thinner plies have a much lower crack-opening displacement when compared with $90^{\circ}$-ply blocks of two and four plies. While matrix crack extension occurs suddenly when the inner ply is relatively thick, causing high stress relaxation, matrix cracking extends gradually in thin plies, eventually without penetrating completely through the thickness, making stress relaxation more difficult. The higher stress field maintained in the thinner plies cause new fibre-matrix decohesions, increasing the crack density.

To clarify the mechanisms of transverse damage suppression in thin-ply laminates, Saito et al [149] numerically investigated matrix cracking constraining in 
the inner transverse ply of thin-ply cross-ply laminates. They relied on a two-dimensional micro-mechanical modelling strategy, including an RVE of a cross-ply laminate with homogenised outer plies and an embedded $90^{\circ}$ ply with fibres and matrix discretely represented. The distribution of fibres in the $90^{\circ}$ ply discretization was obtained from in-situ observations of real composite crosssections [148]. These direct experimental observations were also used to define the width of the RVEs using the crack density information, ensuring that the represented area contained only one transverse crack. To model the mechanical behaviour of the polymer matrix, a bilinear elastic-plastic constitutive model was used. Failure was assumed to occur when the tensile or shear strains in the matrix reached their critical values, reducing the moduli of the failed matrix to $10 \%$ of their original values. As usual in the analysis of matrix-dominated damage mechanisms, the fibres were assumed linearelastic. The interface between matrix and fibres was modelled using cohesive elements. Standard boundary conditions were applied to the RVE, and an initial thermal step was performed to account for the residual stresses of the curing process. In spite of the simplicity of the modelling strategy adopted, the numerical results presented were consistent with the experimental observations [148], capturing the faster penetration of the transverse cracks as the thickness of the $90^{\circ}$ ply increased.

Saito et al [149] also assessed the effect of the stiffness of the adjacent plies, replacing the homogenised outer $0^{\circ}$ plies by $45^{\circ}$ plies. Faster matrix cracking propagation was predicted in the case of outer $45^{\circ}$ plies, confirming the effect of the stiffness of the adjacent plies on the constraining effect imposed to embedded $90^{\circ}$ plies [72].

To improve the analysis of the in-situ effect on thin embedded plies at the micro-level, a 3D computational micro-mechanics framework $[121,122]$ was employed by Arteiro et al [10, 12], giving particular emphasis to the characteristics of the RVEs under analysis and to the constitutive behaviour of the constituents.

\subsection{RVE and constitutive models}

A micro-mechanical FE model of a thin-ply carbon/epoxy sub-laminate, consisting of an RVE of a $90^{\circ}$ ply inbetween homogenised $0^{\circ}$ plies, was used to study microdamage development on an embedded ply. An adaptation of the algorithm proposed by Melro et al [118] was used to generate the distribution of reinforcements in the $90^{\circ}$ ply RVEs, without relying on empirical observations. This random fibre generator is based on a hard-core model [141], which corresponds to the first of three steps on each iteration of the algorithm. Two heuristics are then introduced, which allow the generation of RVEs with high fibre volume fractions in a relatively short amount of time. The first heuristic is used to create matrix-rich areas in the RVE by stirring the fibres in the direction of one of the closest (not necessarily the closest) fibres. The second heuristic is used to stir the fibres positioned in the outskirts of the RVE towards its interior. These fibre movements generate matrix-rich areas that increase the success rate of the hard-core model in allocating new fibres every new iteration.

Based on statistical analysis, Melro et al [118] showed that this algorithm is able to generate random fibre distributions, even for high values of the fibre volume fraction, that are materially and statistically equivalent to real distributions in the transverse cross-section of laminated composites.

For implementation of Periodic Boundary Conditions (PBCs), a condition of material periodicity is imposed along opposite edges of the RVE [118]. A minimum distance between fibres is also specified to avoid regions of poor mesh quality between the fibres when generating the FE model [118]. Fig. 9 shows an RVE of a sub-laminate with an embedded $0.020 \mathrm{~mm}$ thick $90^{\circ}$ ply. PBCs are applied to the sub-laminate RVEs in the $x$ - and $y$-directions by means of linear multi-point constraints, i.e., kinematic constraints imposed on the degrees of freedom of each pair of nodes belonging to opposite faces, edges or vertices of the RVE [122].

To appropriately capture the inelastic behaviour of epoxy resins, the pressure dependent, elastic-plastic model with damage proposed by Melro et al [121] was used to model the mechanical response of the matrix. This constitutive model is based on paraboloidal yield and failure criteria, and uses a thermodynamically consistent damage model to predict damage growth.

The paraboloidal yield criterion, defined as a function of the stress tensor and of the tensile and compressive yield strengths, $\sigma_{y m}^{t}$ and $\sigma_{y m}^{c}$ respectively, can be written as:

$\Phi=6 J_{2}+2 I_{1}\left(\sigma_{y m}^{c}-\sigma_{y m}^{t}\right)-2 \sigma_{y m}^{t} \sigma_{y m}^{c}$

where $J_{2}=1 / 2 \mathbf{s}: \mathbf{s}$ is the second invariant of the deviatoric stress tensor $\mathbf{s}=\boldsymbol{\sigma}-1 / 3 I_{1} \mathbf{I}, I_{1}=\operatorname{tr}(\boldsymbol{\sigma})$ is the first invariant of the stress tensor, $\sigma_{y m}^{t}$ and $\sigma_{y m}^{c}$ are respectively the tensile and compressive yield strengths of the resin, and $\mathbf{I}$ is the second order identity tensor. For a correct definition of the volumetric deformation along the plastic evolution, the paraboloidal yield criterion in Eq. (5) is used together with a non-associative flow rule. Because the tensile and compressive yield strengths are 


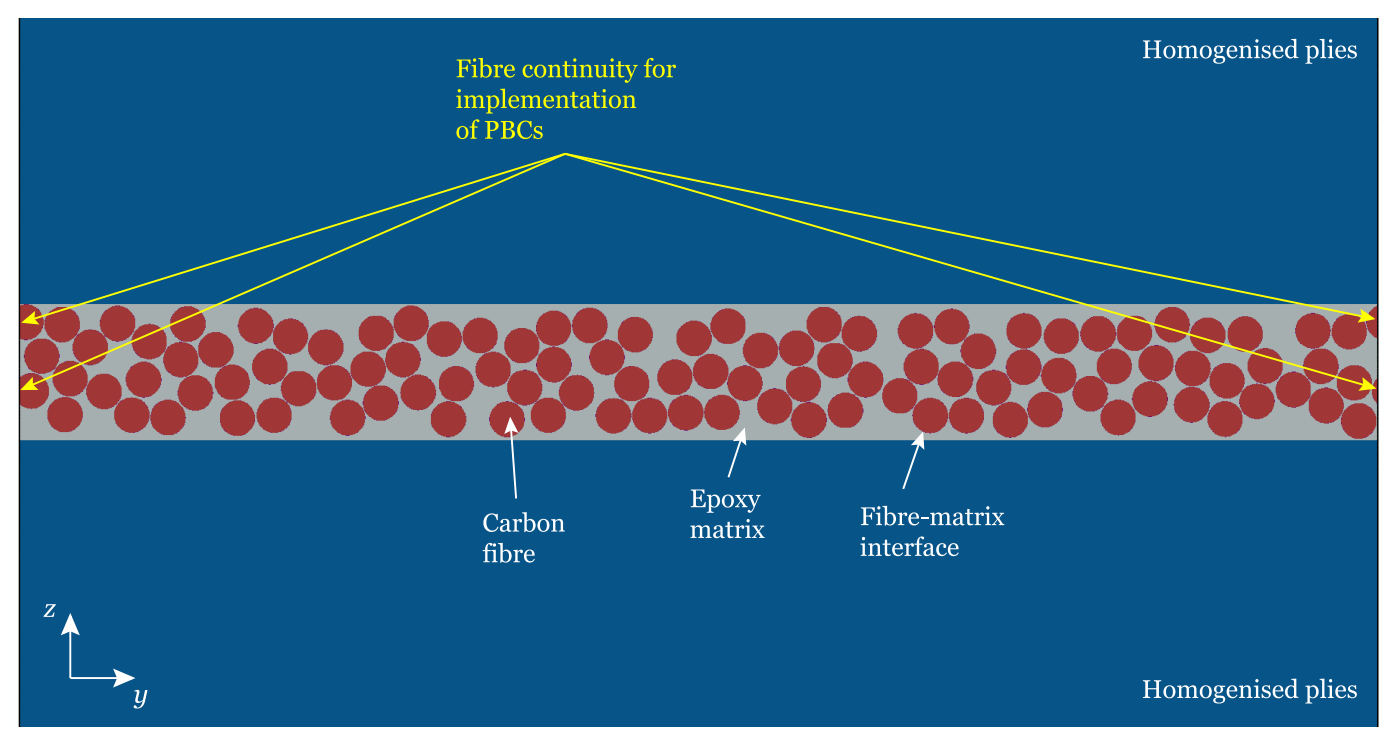

Fig. 9: RVE of a cross-ply sub-laminate with an embedded $0.020 \mathrm{~mm} 90^{\circ}$ ply [12].

used to define the yield surface, hardening is considered to affect these two values. The corresponding hardening laws are defined as a function of the equivalent plastic strain $\varepsilon_{e}^{p}$, provided as piecewise functions. Due to its fully differentiable character, the paraboloidal yield function can be integrated by means of a general return mapping algorithm [121]. The details of the integration of the constitutive model are presented in Ref. [121].

Matrix damage onset is defined by a damage activation function similar to the paraboloidal yield criterion, but using the final tensile and compressive strengths of the epoxy resin $\left(X_{m}^{c}\right.$ and $X_{m}^{t}$ respectively) instead of the yield strengths. The damage activation function can be defined as [121]:

$F_{m}^{d}=\phi_{m}^{d}-r_{m} \leq 0$

where $\phi_{m}^{d}$ is the loading function [121]:

$\phi_{m}^{d}=\frac{3 \tilde{J}_{2}+\tilde{I}_{1}\left(X_{m}^{c}-X_{m}^{t}\right)}{X_{m}^{t} X_{m}^{c}}$

and $r_{m}$ is an internal variable related with the damage variable $d_{m}$. The invariants $\tilde{J}_{2}$ and $\tilde{I}_{1}$ are determined using the effective stress tensor $\tilde{\boldsymbol{\sigma}}$, i.e., the stress tensor calculated using the undamaged stiffness tensor. The internal variable is defined as [121]:

$r_{m}=\max \left\{1, \max _{t \rightarrow \infty}\left\{\phi_{m, t}^{d}\right\}\right\}$

The relation between the internal variable $r_{m}$ and the damage variable $d_{m}$ is given by the damage evolution law [121]:
$d_{m}=1-\frac{e^{A_{m}\left(3-\sqrt{7+2 r_{m}^{2}}\right)}}{\sqrt{7+2 r_{m}^{2}}-2}$

The parameter $A_{m}$ needs to be determined by means of the regularisation of the computed dissipated energy [121]. To avoid damage localization (mesh size dependency), an approach based on the crack band model [18] is applied, which makes use of the characteristic length of the finite element $\left(l^{*}\right)$ and the fracture toughness of the epoxy resin $\left(\mathcal{G}_{c m}\right)$ to regularize the computed dissipated energy [121].

Because the analysis presented in this Section is concerned with matrix-dominated mechanisms, to simulate the individual reinforcing carbon fibres a transversely isotropic, linear-elastic behaviour was assumed.

To model the interface between fibres and matrix, cohesive elements were used [32]. A bilinear tractionseparation law, which relates the displacement jump across the interface with the tractions acting on it, is chosen. Before damage onset, the response of the interface is considered linear-elastic, with a high initial stiffness $(K)$. The onset of cohesive damage is assumed mode dependent, and defined by the corresponding strengths in mode I $\left(\tau_{3}^{0}\right)$ and mode II $\left(\tau_{1}^{0}=\tau_{2}^{0}\right)$. A quadratic nominal stress criterion is used to predict interface damage initiation. Damage evolution is controlled by a linear softening law. A scalar damage variable, $d$, is used to represent the interface damage.

To describe the evolution of damage under a combination of normal and shear deformation across the interface, an effective displacement jump, $\omega_{m}$, is defined 
as the norm of the displacement jump vector across the interface [32]:

$\omega_{m}=\sqrt{\omega_{1}^{2}+\omega_{2}^{2}+\left\langle\omega_{3}\right\rangle^{2}}$

where $\omega_{3}$ is the displacement jump in mode I, and $\omega_{1}$ and $\omega_{2}$ are the displacement jumps in mode II and in mode III, respectively. The rate of damage progression is controlled by the fracture toughness in mode I $\left(\mathcal{G}_{I c}\right)$, mode II $\left(\mathcal{G}_{I I c}\right)$, or mixed-mode, according to the Benzeggagh-Kenane law [20]:

$\mathcal{G}_{I c}+\left(\mathcal{G}_{I I c}-\mathcal{G}_{I c}\right)\left(\frac{\mathcal{G}_{\text {shear }}}{\mathcal{G}_{T}}\right)^{\eta}=\mathcal{G}_{c}$

where $\mathcal{G}_{T}=\mathcal{G}_{I}+\mathcal{G}_{I I}+\mathcal{G}_{I I I}$ and $\mathcal{G}_{\text {shear }}=\mathcal{G}_{I I}+\mathcal{G}_{I I I}$ are respectively the total and the shear contributions of the energy release rate, $\eta$ is a material parameter and $\mathcal{G}_{c}$ is the critical value of the total energy release rate. The evolution of the damage variable is defined as a function of the maximum value of the effective displacement jump $\omega_{m}^{\max }$ attained during the loading history [32]:

$d=\frac{\omega_{m}^{f}\left(\omega_{m}^{\max }-\omega_{m}^{0}\right)}{\omega_{m}^{\max }\left(\omega_{m}^{f}-\omega_{m}^{0}\right)}$

where $\omega_{m}^{0}$ is the effective displacement jump at the initiation of damage, and $\omega_{m}^{f}$ is the effective displacement jump at complete failure, given as [32]:

$\omega_{m}^{f}=\frac{2 \mathcal{G}_{c}}{\tau_{\text {eff }}^{0}}$

$\tau_{\text {eff }}^{0}$ is the effective traction at damage initiation, given by the norm of the traction tensor:

$\tau_{\text {eff }}^{0}=\sqrt{\left(\tau_{1}^{0}\right)^{2}+\left(\tau_{2}^{0}\right)^{2}+\left\langle\tau_{3}^{0}\right\rangle^{2}}$

\subsection{Analysis of the in-situ effect}

Varying the thickness of the $90^{\circ}$ ply in the sub-laminate RVE (Fig. 9), it is possible to assess the in-situ effect on the mechanical response of the embedded lamina. The thickness of the outer plies are kept constant and equal to $0.150 \mathrm{~mm}$ throughout the analysis. The width of the sub-laminate RVEs ( $y$-direction) was defined to ensure that any diffuse damage that might occur before a transverse crack has grown entirely through the thickness of the ply can be captured $[10,12]$. The length of the RVEs ( $x$-direction) is kept constant and approximately equal to two times the average element size of the mesh of the $90^{\circ}$ ply, with a discretization of two elements along the $x$-direction.

Fig. 10 shows the strain field along the transverse $\left(y\right.$-) direction of an RVE with a $0.080 \mathrm{~mm}$ thick $90^{\circ}$ ply subjected to transverse compression. In agreement with the experimental observations carried out by Canal et al [40], fibres are characterised by a very homogeneous strain field, while the matrix shows a very inhomogeneous strain distribution.

Figs. 11-17 depict the contour plots of the matrix damage variable on representative RVEs of embedded $90^{\circ}$ laminae with thicknesses between $0.020 \mathrm{~mm}$ and $0.140 \mathrm{~mm}$ at applied remote strains ranging from $0.6 \%$ to $8.0 \%$. Although only one random distribution of fibres is presented for each case, it is representative of other random distributions in terms of damage localisation.

As observed experimentally from in-situ observations [148], matrix cracks develop perpendicularly to the applied load. Independently of the embedded ply thickness, damage starts in the narrower portions of matrix between the closest adjacent fibres aligned with the loading direction at approximately the same applied remote strain following two basic stages: (i) starting as fibre-matrix decohesions (Fig. 18), and (ii) propagating into the matrix as matrix cracks.

In the thicker embedded $90^{\circ}$ plies (Figs. 15-17), once a transverse crack is formed, it rapidly penetrates through the thickness. But as the embedded ply thickness decreases, crack extension remarkably slows down (Figs. 11-14).

Figs. 12-17 also show that once through-thickness transverse cracking has saturated, damage localisation occurs close to the straight transverse cracks, starting near the interface between the embedded $90^{\circ}$ ply and the surrounding constraining plies; this does not happen in the thinner $0.020 \mathrm{~mm} 90^{\circ}$ plies (Fig. 11). The oblique cracks in Figs. 12-17, which were also observed experimentally [96], are not perpendicular to the loading direction and propagate towards the straight transverse cracks, without joining them. These simulations also show that the oblique cracks typically do not penetrate through the ply thickness, except when joining with oblique cracks growing in the opposite direction in sufficiently thin plies, as can be observed in Fig. 19.

In the sub-laminates with the thinner $0.020 \mathrm{~mm}$ and $0.040 \mathrm{~mm} 90^{\circ}$ plies, transverse failure can be described as a distributed damage mechanism. In the case of $0.040 \mathrm{~mm} 90^{\circ}$ plies (Fig. 12), transverse fracture is characterised by progressive fragmentation and multiple matrix cracking, with reduced spacing between 


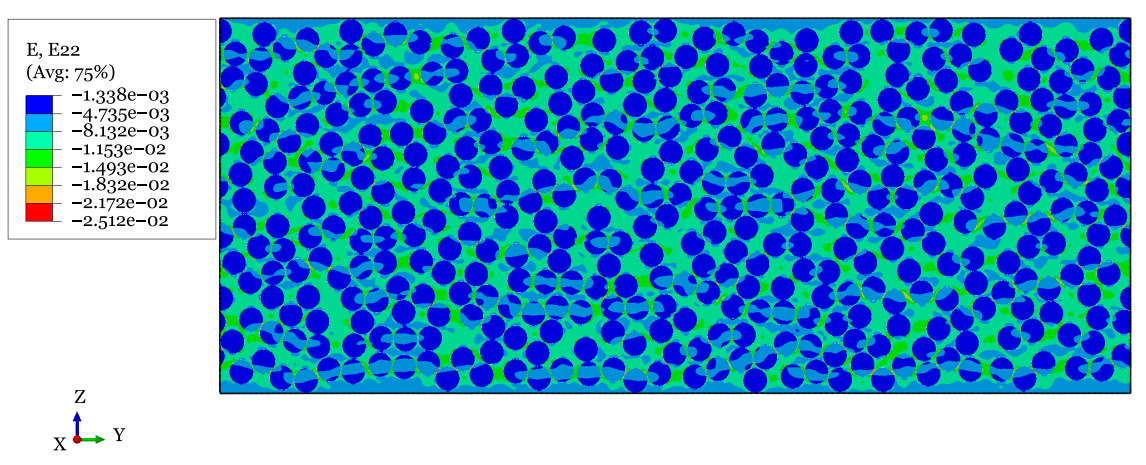

Fig. 10: Strain distribution along the transverse $(y-)$ direction of an RVE with a 0.080 mm thick $90^{\circ}$ ply subjected to transverse compression, at an applied remote strain of $0.66 \%$ [12].

transverse cracks, followed by additional decohesions that form the onset sites for the development of oblique cracking close to the interface with the constraining plies. By reducing further the thickness of the $90^{\circ}$ plies (Fig. 11), damage is characterised by many decohesions occurring without extending completely through the ply thickness, similar to a continuous damage event, and leading to overall failure of the matrix material between the fibres, as shown in Figs. 11f-g. Hence, damage progression and failure of very thin plies can be represented at the mesoscale by simple material degradation schemes, without the need to address discrete crack formation, or embedded in laminate damage models that take the homogenised laminate as the basic material building block. This makes analysis of thin-ply laminates considerably simpler.

The sudden matrix crack extension in the thicker embedded plies leads to significant stress relaxation, as shown in Fig. 20 and reported experimentally by Saito et al [148]. The thinner transverse laminae show a gradual extension of the transverse cracks, eventually without penetrating completely through the thickness, and therefore the stress relaxation is much more difficult to occur, as shown in Fig. 21. In this case, a higher stress field leads to an increase of the crack density, as can be observed in Figs. 11-14, and confirmed experimentally [148]. In fact, as reported in the literature [21], the maximum crack density typically observed experimentally corresponds to a crack spacing of the order of the embedded $90^{\circ}$ ply thickness. This is accurately captured in the simulations (Figs. 11-14).

These predictions are also useful in understanding how transverse cracking can be detrimental to the integrity of a laminate with thick transverse plies, and how thin plies can minimise the risk of failure of the adjacent, load carrying plies. In fact, once transverse damage initiates in a thick ply, it quickly penetrates through the thickness, resulting in high local stress relaxation in the $90^{\circ}$ ply, and consequently in a local stress concentration at the adjacent plies. This local increase of the stress level can induce delamination at the interface or, in some cases, cause premature failure of the adjacent ply. By reducing the $90^{\circ}$ ply thickness, transverse damage growth is suppressed, resulting in low stress relaxation, and consequently in a lower stress concentration at the adjacent plies, pushing their load carrying capability closer to that of intact laminae. This is one of the reasons why simple, analytical ply-by-ply [5] or laminate failure analysis [76], without complex degradation schemes, can predict with accuracy ultimate failure of multidirectional thin-ply laminates (Sect. 6).

Another interesting result of the current numerical simulations, also confirmed by experimental evidence [148], is the formation of thin necks of matrix material in the regions where fibre-matrix debonding is more pronounced. The prediction of this phenomenon was also reported by Melro et al [122]. The in-situ observations presented by Saito et al [148] suggest that this phenomenon is more pronounced in the case of thicker plies, since it is barely seen in the thinner embedded $90^{\circ}$ plies. The micro-mechanical simulations suggest the same (Figs. 22-23).

Figs. 24-27 show the contour plots of the equivalent plastic strain in the matrix of representative RVEs of cross-ply sub-laminates with thin and standard embedded $90^{\circ}$ plies subjected to transverse compressive remote strains ranging from $2.0 \%$ to $4.0 \%$. As can be observed, failure caused by transverse compressive loading is dominated by fibre/matrix interface cracking and large localised plastic deformation of the matrix, forming a localised band of damage in a plane not aligned with the loading direction. This wedge shaped transverse fracture is in agreement with what has been described in the literature for the UD case $[122,140]$. 


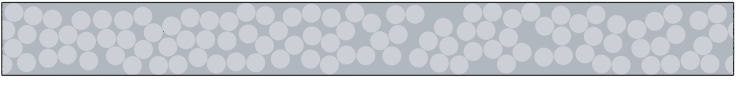

(a) Applied remote strain of $0.6 \%$.

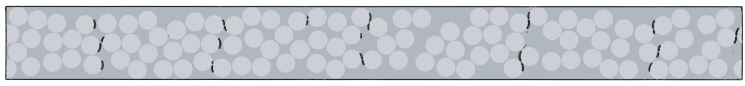

(b) Applied remote strain of $1.2 \%$.

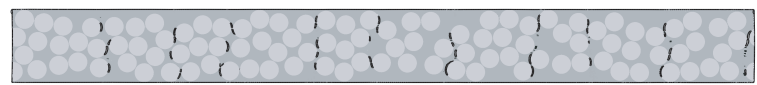

(c) Applied remote strain of $2.0 \%$.

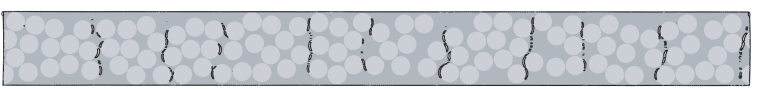

(d) Applied remote strain of $2.6 \%$.

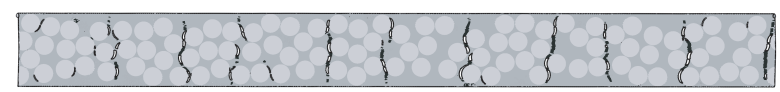

(e) Applied remote strain of $4.0 \%$.

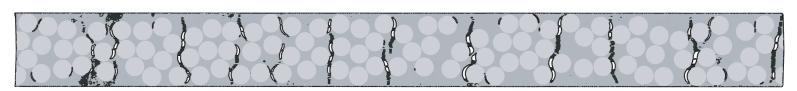

(f) Applied remote strain of $5.5 \%$.

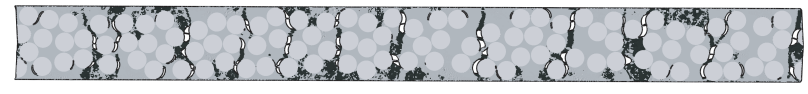

(g) Applied remote strain of $8.0 \%$.

Fig. 11: Contour plots of the matrix damage variable on a representative RVE of an embedded $0.020 \mathrm{~mm} 90^{\circ}$ ply (only the embedded $90^{\circ}$ ply is presented).

Although the damage pattern is very similar, in the case of cross-ply sub-laminates with very thin plies (Figs. 24-25) the wedge cracks develop at higher applied remote strains; a transverse crack suppression effect can be clearly identified when compared with standard plies (Figs. 26-27). As the ply thickness decreases, damage progression slows down, and through-thickness wedge transverse cracking is delayed. This fact indicates that an in-situ effect in transverse compression exists.

Before the first through-thickness wedge crack is fully developed, localised bands of damage start prop-

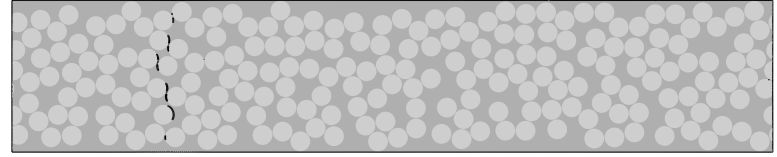

(a) Applied remote strain of $0.6 \%$.

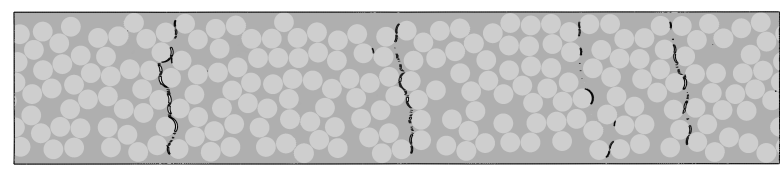

(b) Applied remote strain of $1.2 \%$.

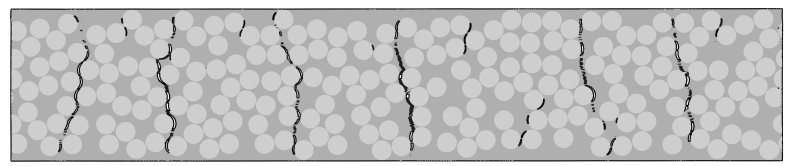

(c) Applied remote strain of $2.0 \%$.

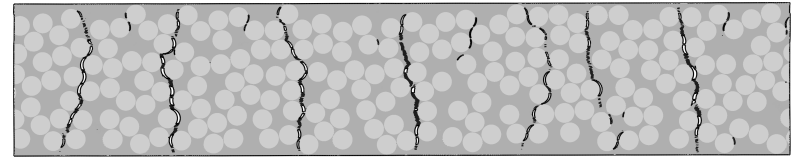

(d) Applied remote strain of $2.6 \%$.

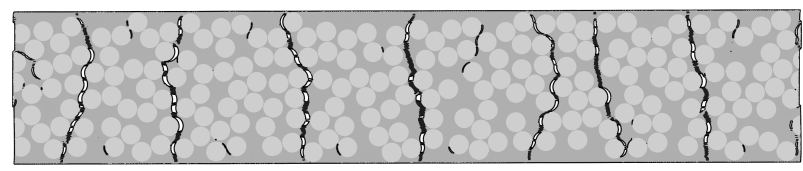

(e) Applied remote strain of $4.0 \%$.

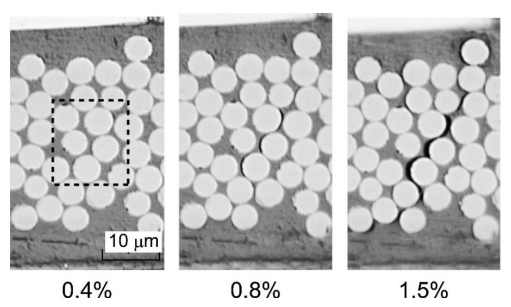

(f) In-situ observations [148].

Fig. 12: Contour plots of the matrix damage variable on a representative RVE of an embedded $0.040 \mathrm{~mm} 90^{\circ}$ ply (only the embedded $90^{\circ}$ ply is presented), and $i n$ situ observations of a $0.040 \mathrm{~mm}$ embedded $90^{\circ}$ ply in a cross-ply laminate. 


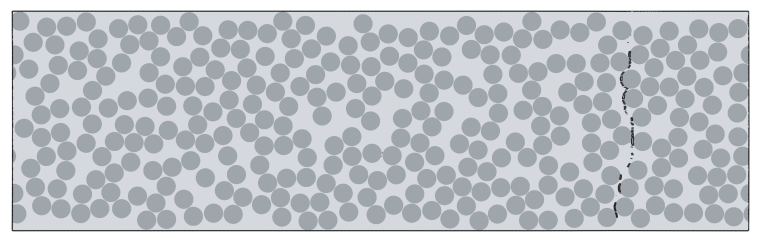

(a) Applied remote strain of $0.6 \%$.

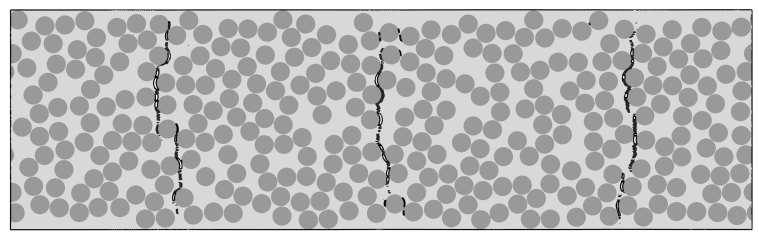

(b) Applied remote strain of $1.2 \%$.

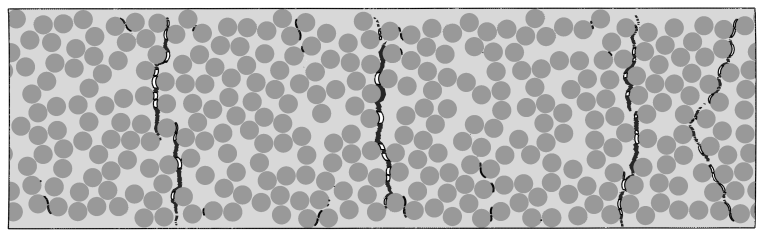

(c) Applied remote strain of $2.0 \%$.

Fig. 13: Contour plots of the matrix damage variable on a representative RVE of an embedded $0.060 \mathrm{~mm} 90^{\circ}$ ply (only the embedded $90^{\circ}$ ply is presented).

agating along other locations. As the ply thickness decreases, the number of localised bands increases. Once the first band penetrates through the thickness, the remaining will also penetrate progressively.

As the ply thickness decreases further, the main failure mechanism gradually changes from wedge shaped transverse cracking to a dispersed damage mechanism, including ply fragmentation/separation, as shown in Fig. 28. In line with the tensile case, this dispersed damage pattern in thin-ply sub-laminates is the result of a less pronounced stress relaxation due to the constraining effect imposed by the surrounding plies (Fig. 29). This causes the development of progressive, overall ply damage instead of discrete transverse cracking.

\subsection{Comparison with analytical models and discussion}

In laminate analysis, the in-situ effect is typically taken into account by using analytical Fracture Mechanics models $[33,67]$ and through application of 3D phenomenological failure criteria [38, 47]. Fig. 30 shows the in-situ transverse tensile strength as a function of the embedded $90^{\circ}$ ply thickness determined using computational micro-mechanics, and a comparison with the

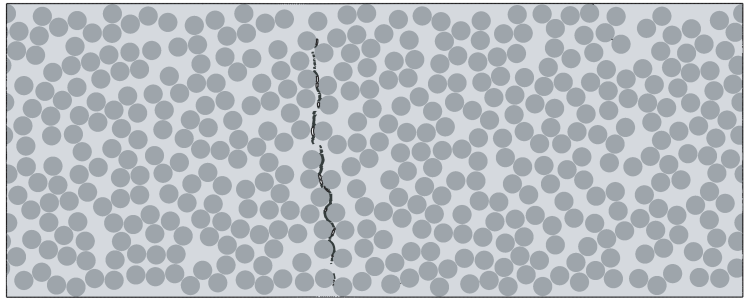

(a) Applied remote strain of $0.6 \%$.

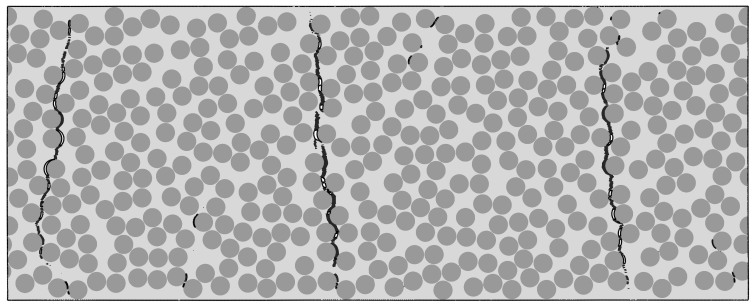

(b) Applied remote strain of $1.2 \%$.

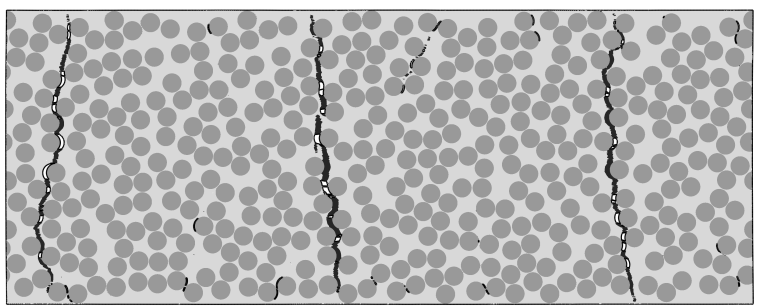

(c) Applied remote strain of $2.0 \%$.

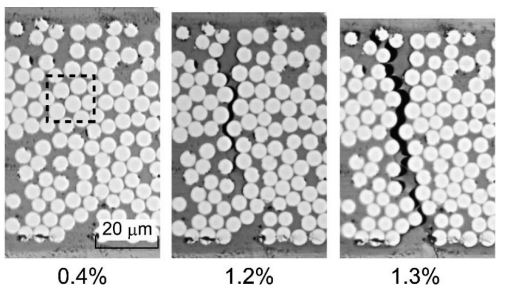

(d) In-situ observations [148].

Fig. 14: Contour plots of the matrix damage variable on a representative RVE of an embedded $0.080 \mathrm{~mm} 90^{\circ}$ ply (only the embedded $90^{\circ}$ ply is presented), and insitu observations of a $0.080 \mathrm{~mm}$ embedded $90^{\circ}$ ply in a cross-ply laminate.

predictions of the Fracture Mechanics model proposed by Camanho et al [33]:

$Y_{T}^{i s}=1.12 \sqrt{2} Y_{T}$

for a thick ply, or:

$Y_{T}^{i s}=\sqrt{\frac{8 \mathcal{G}_{I c}}{\pi t \Lambda_{22}^{0}}}$ 


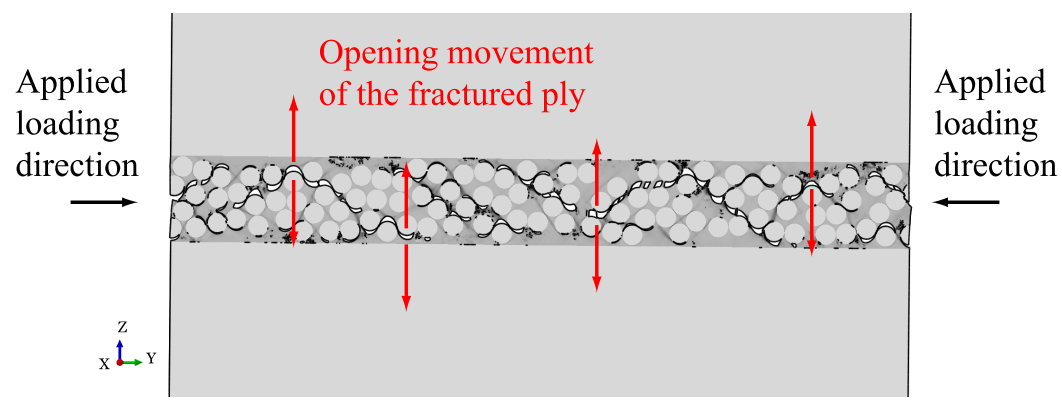

Fig. 28: Fragmentation/ply separation of a representative RVE with an embedded 0.020 mm $90^{\circ}$ ply subjected to an applied transverse compressive strain of $4.9 \%$ [12].

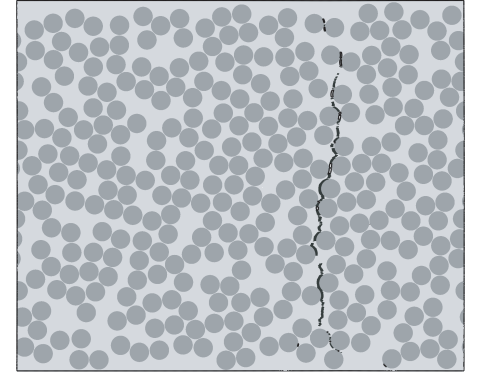

(a) Applied remote strain of $0.6 \%$.

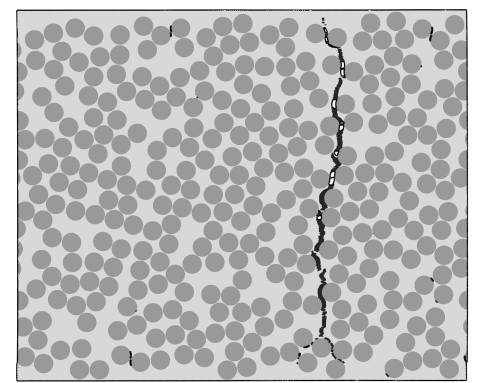

(b) Applied remote strain of $1.2 \%$.

Fig. 15: Contour plots of the matrix damage variable on a representative RVE of an embedded $0.100 \mathrm{~mm} 90^{\circ}$ ply (only the embedded $90^{\circ}$ ply is presented).

for a thin embedded ply. Fig. 31 shows the in-situ transverse compressive strength, $Y_{C}^{i s}$, as a function of the embedded $90^{\circ}$ ply thickness determined using the micromechanical models, and a comparison with the predictions of the models proposed by Catalanotti et al [47] and Camanho et al [38]. According to Catalanotti et al [47], the in-situ transverse compressive strength is given explicitly as:

$Y_{C}^{i s}=\frac{S_{L}^{i s}\left(2 \cos ^{2} \alpha_{0}-1\right)}{\eta_{L} \cos ^{2} \alpha_{0}}$

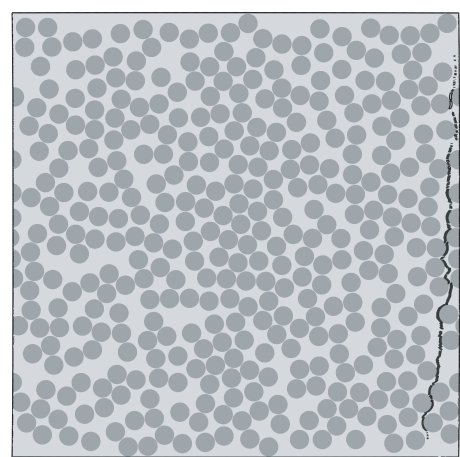

(a) Applied remote strain of $0.6 \%$

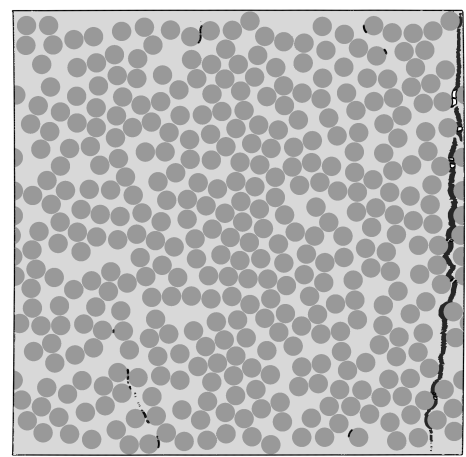

(b) Applied remote strain of $1.2 \%$.

Fig. 16: Contour plots of the matrix damage variable on a representative RVE of an embedded $0.120 \mathrm{~mm} 90^{\circ}$ ply (only the embedded $90^{\circ}$ ply is presented).

where $\alpha_{0}$ is the fracture angle under pure transverse compression, and $\eta_{L}$ is a friction coefficient [47]. The in-situ in-plane shear strength, $S_{L}^{i s}$, is calculated from the Fracture Mechanics model proposed by Camanho et al [33]:

$S_{L}^{i s}=\sqrt{\frac{\left(1+\beta \phi G_{12}^{2}\right)^{1 / 2}-1}{3 \beta G_{12}}}$ 


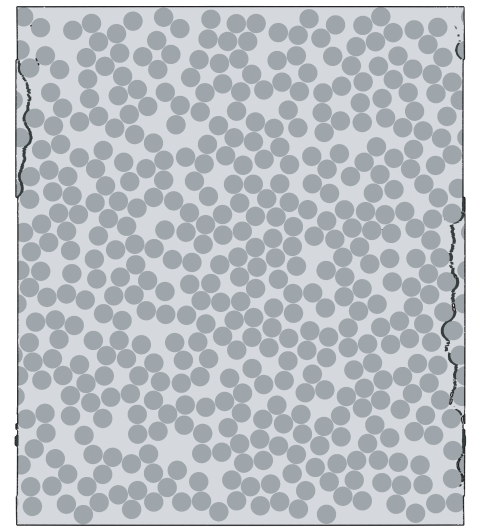

(a) Applied remote strain of $0.6 \%$.

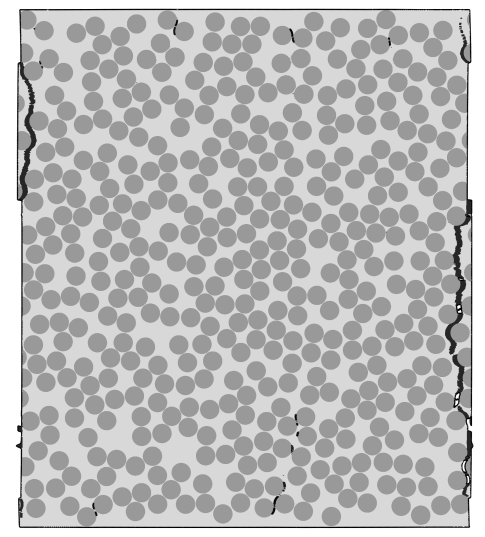

(b) Applied remote strain of $1.2 \%$.
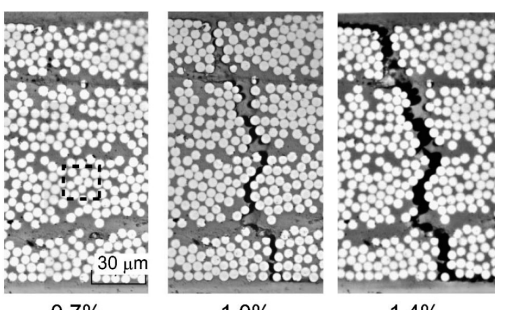

(c) In-situ observations [148].

Fig. 17: Contour plots of the matrix damage variable on a representative RVE of an embedded $0.140 \mathrm{~mm} 90^{\circ}$ ply (only the embedded $90^{\circ}$ ply is presented), and $i n$ situ observations of a $0.160 \mathrm{~mm}$ embedded $90^{\circ}$ ply in a cross-ply laminate.

where $\beta$ is a parameter that defines the nonlinearity of the shear stress-shear strain relation [86], $G_{12}$ is the shear modulus and the parameter $\phi$ is defined according to the configuration of a given ply. For a thick ply [33]:

$\phi=\frac{12 S_{L}^{2}}{G_{12}}+18 \beta S_{L}^{4}$

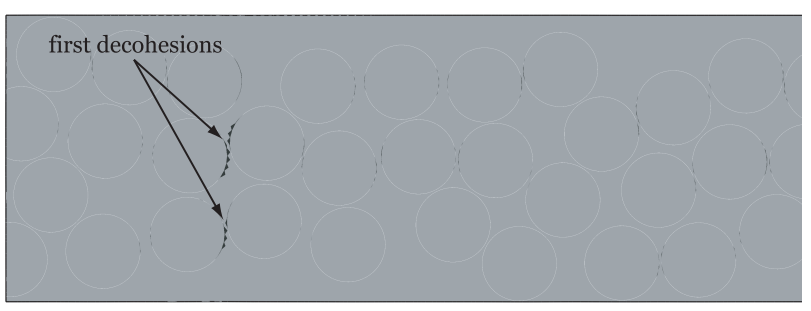

Fig. 18: Damage variable of the cohesive elements at the interface between fibres and matrix of an embedded $0.020 \mathrm{~mm} 90^{\circ}$ ply at an applied remote strain of $0.6 \%$ [10].

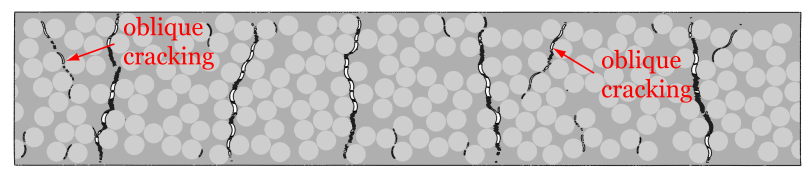

(a) Applied remote strain of $3.0 \%$.

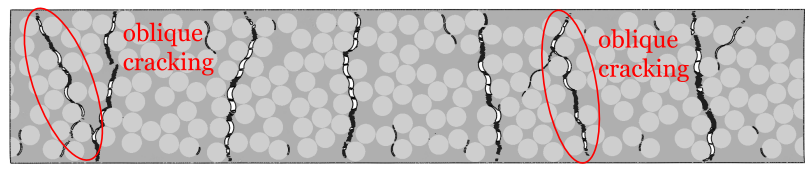

(b) Applied remote strain of $4.0 \%$.

Fig. 19: Oblique cracking captured by the micromechanical analysis of a representative RVE of an embedded $0.040 \mathrm{~mm} 90^{\circ}$ ply (only the $90^{\circ}$ ply is presented).

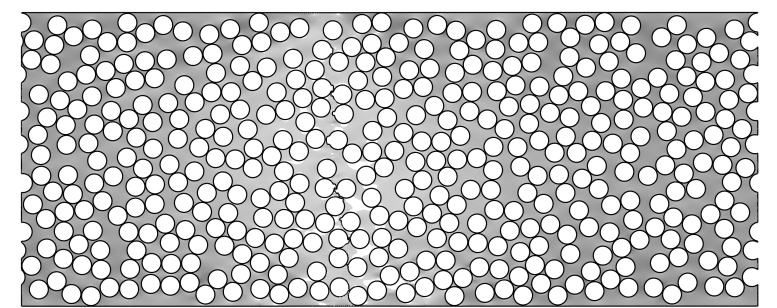

(a) Applied remote strain of $0.6 \%$.

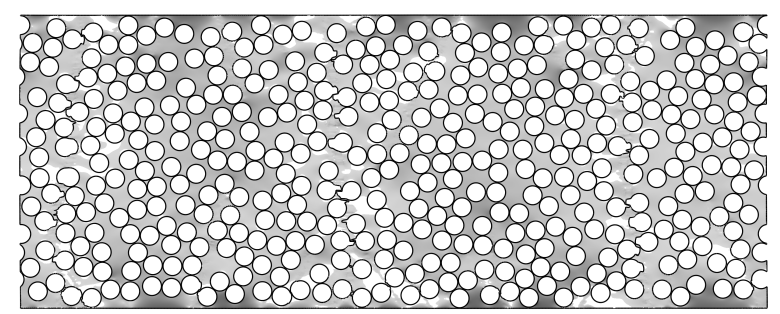

(b) Applied remote strain of $2.0 \%$.

Fig. 20: Transverse stress field $\left(\sigma_{22}\right)$ in a damaged $0.080 \mathrm{~mm}$ embedded $90^{\circ}$ ply (only the matrix of the embedded $90^{\circ}$ ply is presented) [10].

whereas for a thin ply [33]: 


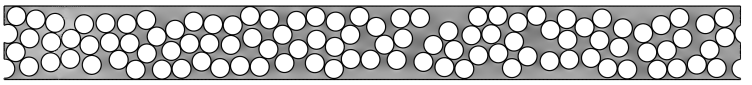

(a) Applied remote strain of $0.6 \%$.

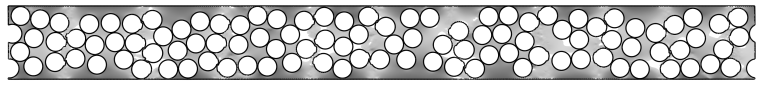

(b) Applied remote strain of $2.0 \%$.

Fig. 21: Transverse stress field $\left(\sigma_{22}\right)$ in a damaged $0.020 \mathrm{~mm}$ embedded $90^{\circ}$ ply (only the matrix of the embedded $90^{\circ}$ ply is presented) [10].

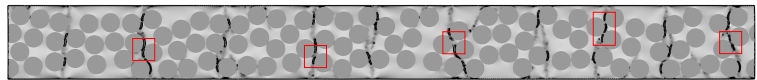

(a) $0.020 \mathrm{~mm}$ embedded $90^{\circ}$ ply.

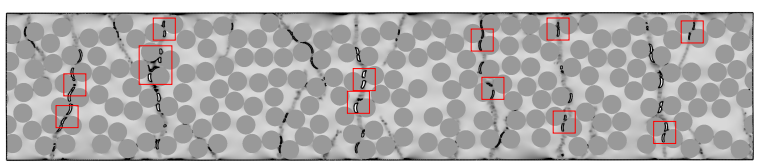

(b) $0.040 \mathrm{~mm}$ embedded $90^{\circ}$ ply.

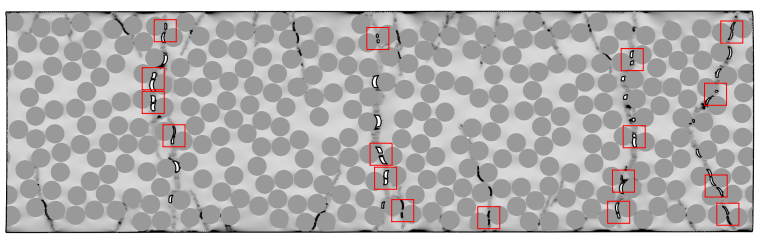

(c) $0.060 \mathrm{~mm}$ embedded $90^{\circ}$ ply.

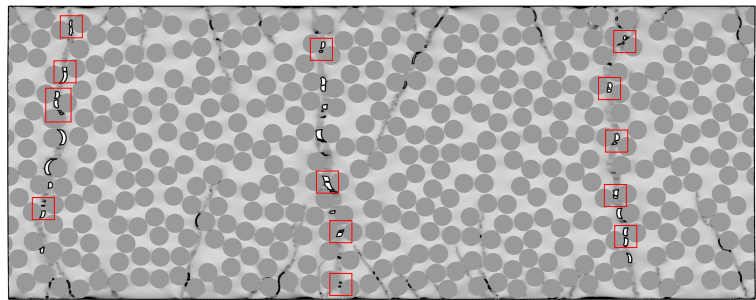

(d) $0.080 \mathrm{~mm}$ embedded $90^{\circ}$ ply.

Fig. 22: Contour plots of the equivalent plastic strain in the matrix of representative RVEs of embedded $90^{\circ}$ plies in a thin-ply sub-laminate at an applied remote strain of $2.0 \%$ (only the $90^{\circ}$ plies are presented) [10]. Identification of the regions where formation of thin necks of matrix material can be observed.

$\phi=\frac{48 \mathcal{G}_{I I c}}{\pi t}$

where $\mathcal{G}_{I I c}$ is the fracture toughness associated with intralaminar fracture of the transverse ply (parallel to the fibre direction) in mode II. Alternatively, the insitu transverse compressive, transverse shear $\left(S_{T}^{i s}\right)$, and

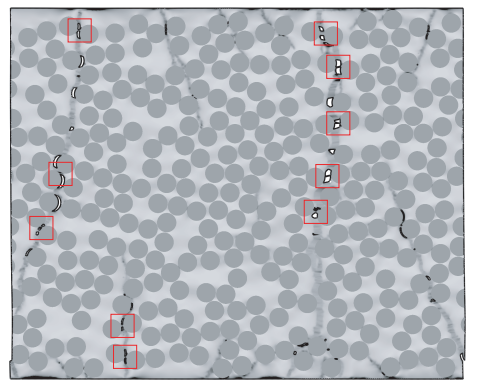

(a) $0.100 \mathrm{~mm}$ embedded $90^{\circ}$ ply.

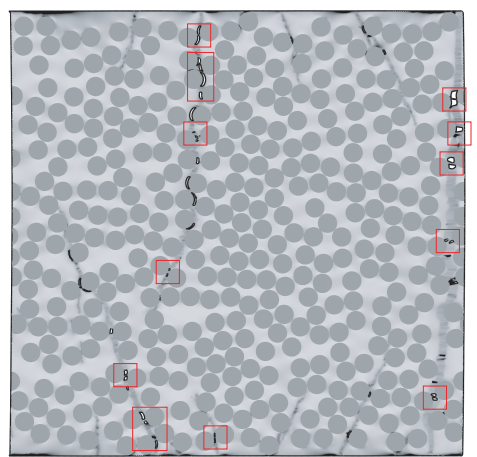

(b) $0.120 \mathrm{~mm}$ embedded $90^{\circ}$ ply.

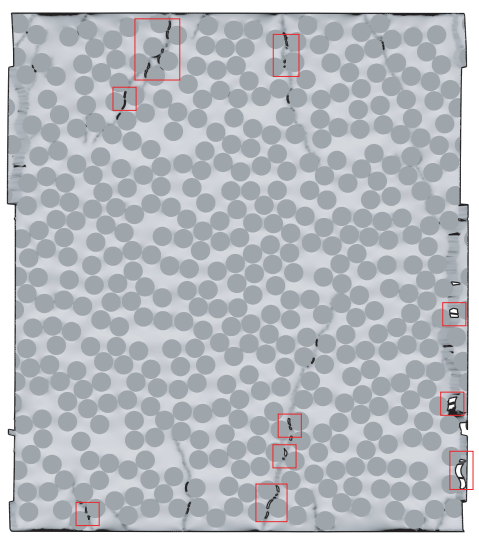

(c) $0.140 \mathrm{~mm}$ embedded $90^{\circ}$ ply.

Fig. 23: Contour plots of the equivalent plastic strain in the matrix of representative RVEs of embedded $90^{\circ}$ plies in a standard-ply sub-laminate at an applied remote strain of $2.0 \%$ (only the $90^{\circ}$ plies are presented) [10]. Identification of the regions where formation of thin necks of matrix material can be observed.

biaxial transverse tensile $\left(Y_{B T}^{i s}\right)$ strengths can be determined using the relations proposed by Camanho et al [38], as explained in Sect. 5. The elastic and strength properties required by the analytical models were determined from separate micro-mechanical analyses using UD RVEs [122] subjected to uniaxial transverse tension and compression, transverse shear, in-plane shear, and 


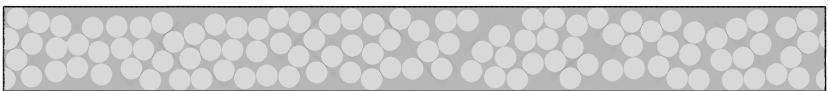

(a) Applied remote strain of $2.0 \%$.

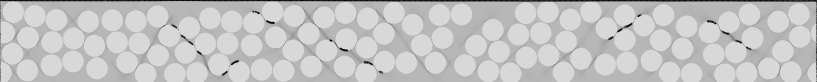

(b) Applied remote strain of $2.5 \%$.

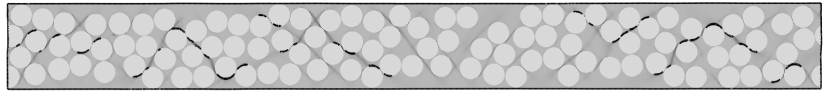

(c) Applied remote strain of $3.0 \%$.

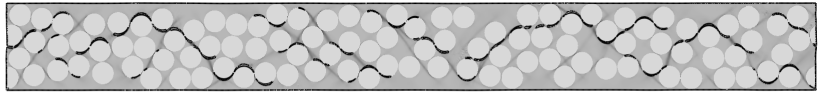

(d) Applied remote strain of $3.5 \%$.

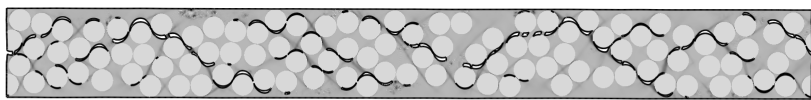

(e) Applied remote strain of $4.0 \%$.

Fig. 24: Contour plots of the equivalent plastic strain in the matrix of a representative RVE of an embedded $0.020 \mathrm{~mm} 90^{\circ}$ ply (only the embedded $90^{\circ}$ ply is presented).

biaxial transverse tension stress states. This included the determination of parameter $\beta$ based on the results from the micro-mechanical computational model of UD RVEs subjected to pure in-plane shear, fitting the polynomial approximation proposed by Hahn and Tsai [86]:

$\gamma_{12}=\frac{1}{G_{12}} \sigma_{12}+\beta \sigma_{12}^{3}$

to the shear stress-shear strain curves obtained with three different RVEs (Fig. 32). The biaxial transverse compressive strength $\left(Y_{B C}\right)$ was estimated as suggested by Vogler et al [189]. The in-situ strengths determined from the micro-mechanical models (discrete points in Figs. 30-31) were obtained based on the applied remote strain corresponding to the development of throughthickness ply failure before onset of secondary damage mechanisms (such as oblique cracking, generalised matrix failure, or push-out).

The analytical and computational micro-mechanics predictions follow the same trends. For the in-situ transverse tensile strength, this is in agreement with experimental observations on standard and thick embedded plies $[23,49,72,79,135,136,150]$, validating both approaches. In compression, it was the first time an in-situ

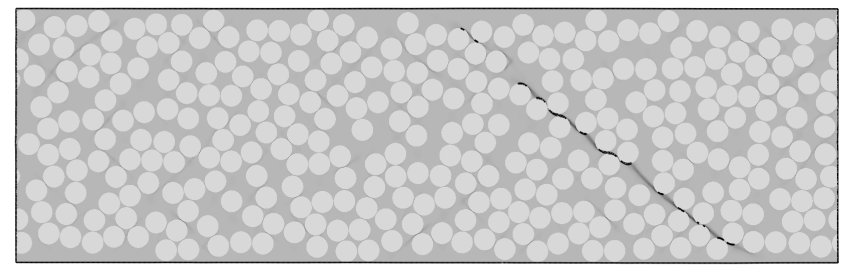

(a) Applied remote strain of $2.0 \%$.

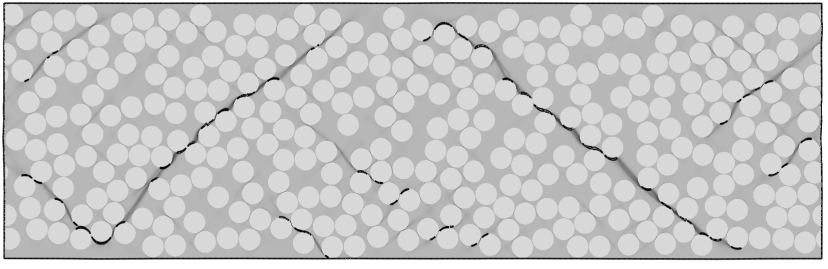

(b) Applied remote strain of $2.5 \%$.

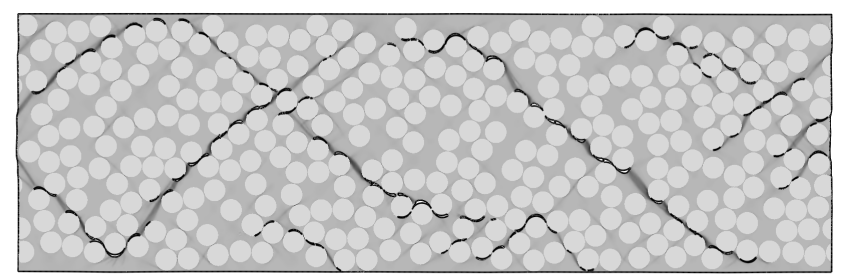

(c) Applied remote strain of $3.0 \%$.

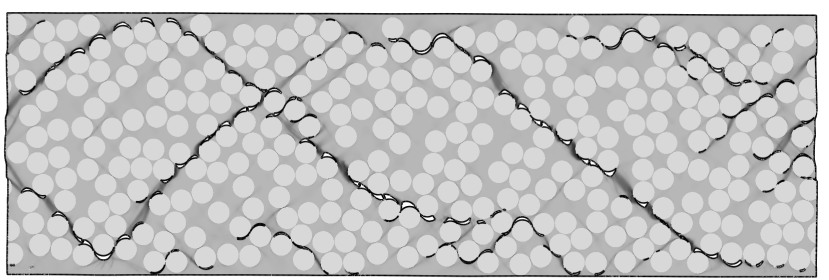

(d) Applied remote strain of $3.5 \%$.

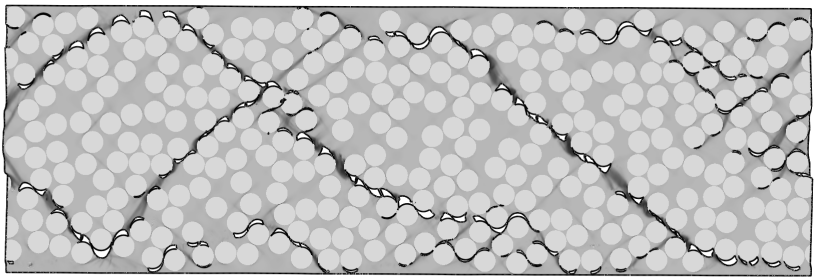

(e) Applied remote strain of $4.0 \%$.

Fig. 25: Contour plots of the equivalent plastic strain in the matrix of a representative RVE of an embedded $0.060 \mathrm{~mm} 90^{\circ}$ ply (only the embedded $90^{\circ}$ ply is presented). 


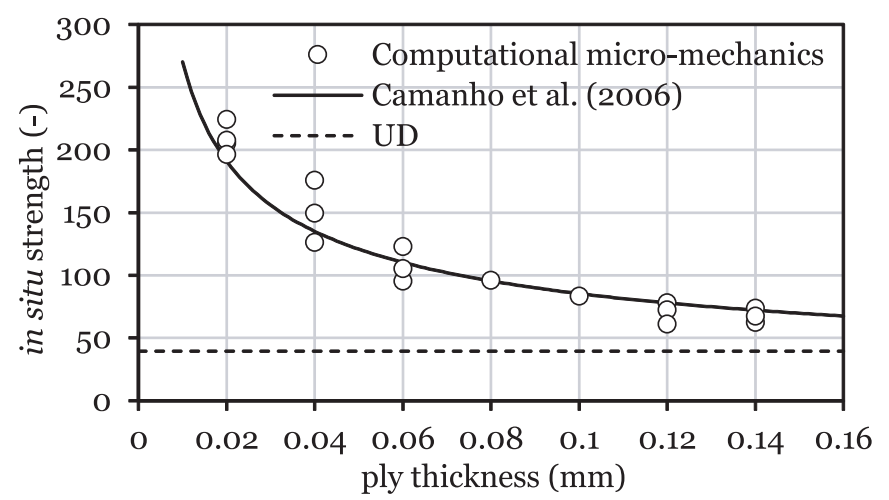

Fig. 30: In-situ transverse tensile strength as a function of the embedded $90^{\circ}$ ply thickness.

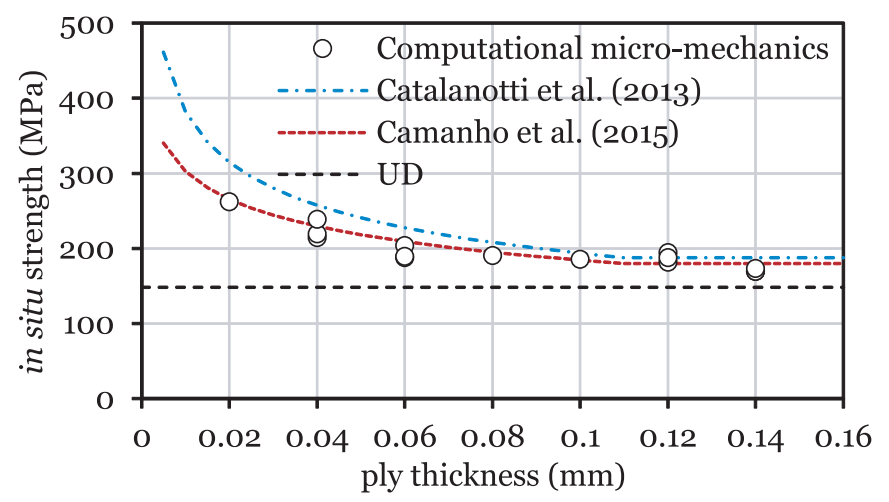

Fig. 31: In-situ transverse compressive strength as a function of the embedded $90^{\circ}$ ply thickness.

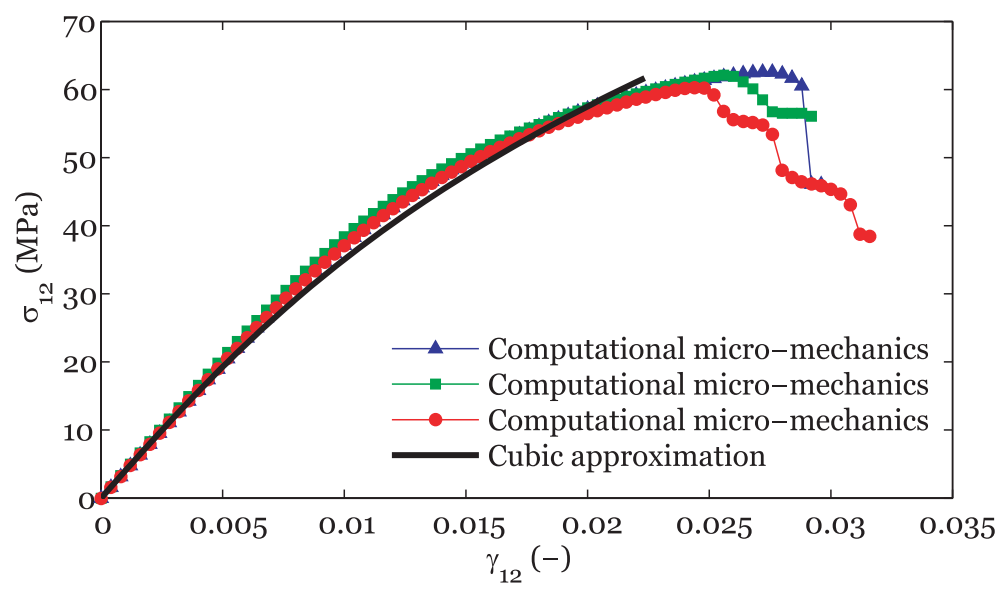

Fig. 32: Shear stress-shear strain curves for three different RVEs, and curve fitting using the cubic approximation proposed by Hahn and Tsai [86].

effect was clearly identified ${ }^{4}$, and the validity of the analytical models proposed in Refs. $[38,47]$ to predict the in-situ transverse compressive strength demonstrated.

\footnotetext{
4 Although there is no direct experimental evidence of the in-situ effect for transverse compression, test results obtained in structural details indicate that ply thickness affects the ply compressive strengths $[5,8,13,14,68,101,197]$.
}

A similar computational micro-mechanics approach was latter presented by Herráez et al [88] to study transverse cracking at the microscale, but employing a simpler constitutive, bi-dimensional model. These authors based their analysis on the maximum homogenised stress in the transverse ply at the onset of damage growth; however, it is not clear if this is an appropriate mea- 


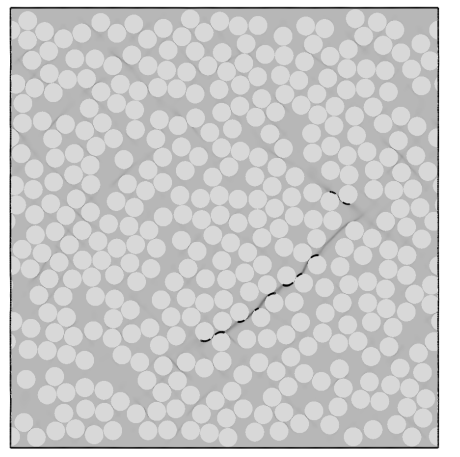

(a) Applied remote strain of $2.0 \%$.

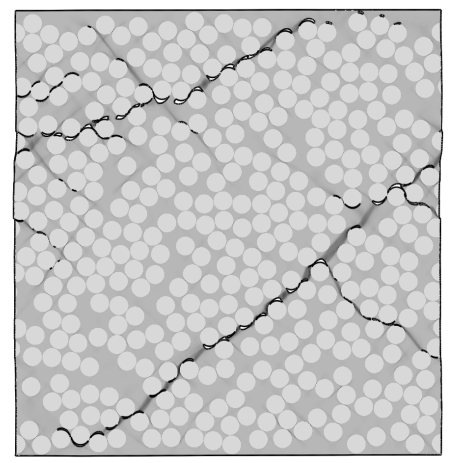

(b) Applied remote strain of $2.5 \%$.

Fig. 26: Contour plots of the equivalent plastic strain in the matrix of a representative RVE of an embedded $0.120 \mathrm{~mm} 90^{\circ}$ ply (only the embedded $90^{\circ}$ ply is presented).

sure of the actual strength of the embedded transverse ply, as the material response during softening is known to depend on both boundary conditions and size of the RVE.

Future developments are focused on the application of the methodology proposed in Refs. [10, 12] to study ply thickness effects on the in-plane and transverse shear strengths of an embedded ply, which are known functions of the ply thickness [33, 38, 47, 132]. Other scenarios of interest include transverse cracking under biaxial tensile and compressive stress states, as well as longitudinal compression and kink band formation [17]. These analyses can further support the understanding of the micro-mechanical behaviour of thin plies and thin-ply laminates subjected to general stress states, overcoming the complexities and limitations of experimental testing on these low grade materials. It is also noted that the present framework can be very helpful in understanding the behaviour of polymer composite laminates subjected to different biaxial or multiaxial loading scenarios, where a fundamental lack of reliable experimental data still exists [77]. There is also great

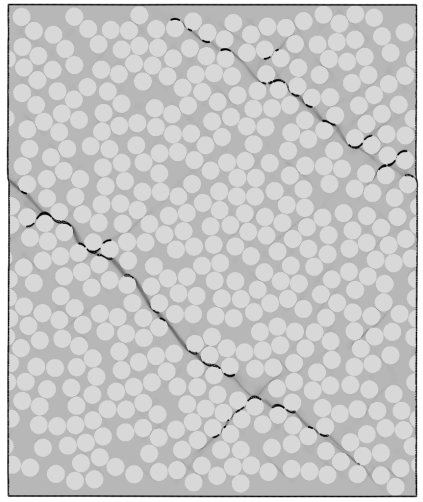

(a) Applied remote strain of $2.0 \%$.

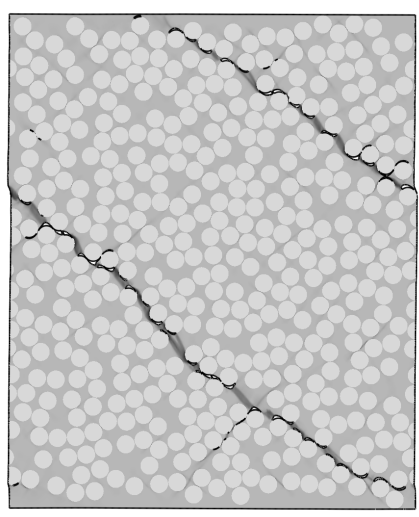

(b) Applied remote strain of $2.5 \%$.

Fig. 27: Contour plots of the equivalent plastic strain in the matrix of a representative RVE of an embedded $0.140 \mathrm{~mm} 90^{\circ}$ ply (only the embedded $90^{\circ}$ ply is presented).

potential for future material tailoring at the microscale, and for the understanding of other important factors on the mechanical response of laminated composites, including: effects of fibre clustering (due to variations in the manufacturing process - study of realistic fibre distributions), effects of intra-bundle and intra-ply hybridisation (e.g. intermingled fibres of different grades or different materials [166]), and effects of new matrix materials (e.g. enhanced resin formulations or thermoplastic matrices).

\section{Ply thickness effects at the mesoscale: failure criteria and in-situ effect}

Due to the very fine level of discretization required by computational micro-mechanics models, they become unsuitable for failure prediction and design of composite structures. For a detailed damage assessment of structural details, a strategy that takes the composite 

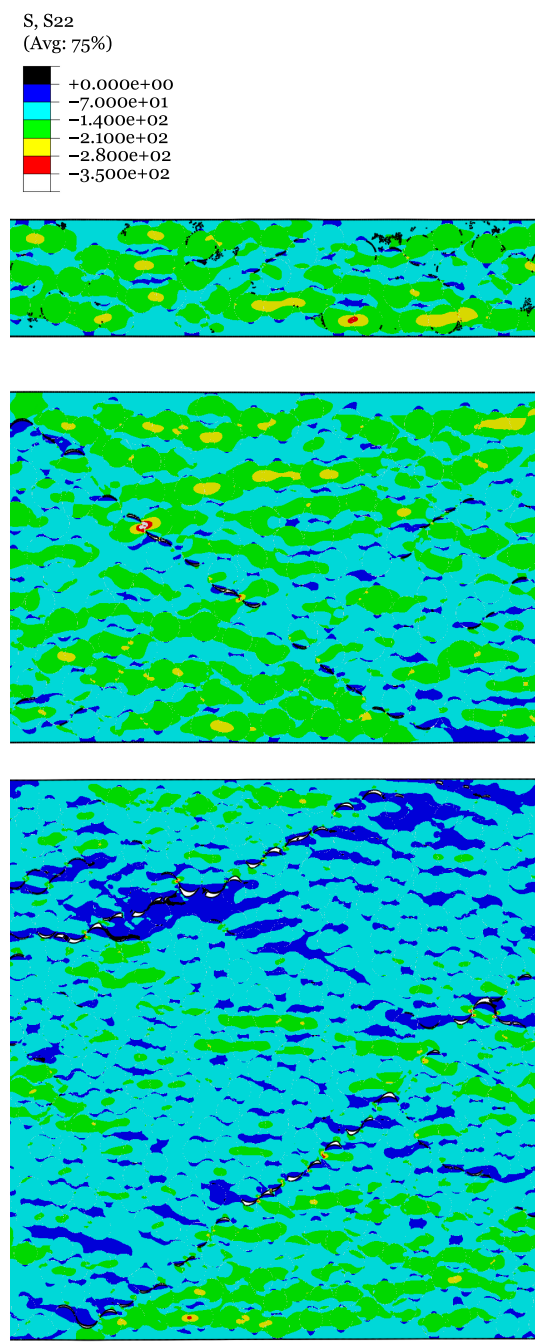

Fig. 29: Transverse stress field $\left(\sigma_{22}\right)$ in damaged embedded $90^{\circ}$ plies subjected to transverse compression, at an applied remote strain of $2.5 \%$ (only the embedded $90^{\circ}$ plies are presented).

plies as the basic homogeneous building blocks becomes more appropriate.

To accurately capture the onset and propagation of ply damage mechanisms at the mesoscale, adequate initiation criteria and damage progression models need to be formulated based on the homogenised stress (or strain) state. Particularly, initiation criteria should be able to capture important aspects that affect the initiation of ply failure, including the in-situ effect. But currently only a few criteria account for ply thickness effects on the ply strengths in multidirectional laminates [38, 47, 50, 63, 71, 138, 157]. For instance, Catalanotti et al [47], based on the ideas presented by Puck and Schürmann [139, 140] and by Dávila et al [63], proposed 3D failure criteria that address general stress states while taking the in-situ effect into account in a consistent way. More recently, Camanho et al [38, 39 ] presented new 3D failure criteria with an invariant quadratic formulation based on structural tensors. To account for the effect of ply thickness, appropriate definitions of the in-situ strengths were consistently derived in the framework of the invariant-based failure criterion for transverse failure mechanisms. Specifically, the criteria presented by Camanho et al $[38,39]$ cover several aspects that are not addressed simultaneously by previous phenomenological failure criteria, including: (1) the increase of the apparent shear strength with moderate values of transverse compression, (2) the detrimental effect of the in-plane shear stresses due to fibre misalignment under longitudinal compressive failure by fibre kinking, and (3) the prediction of failure under hydrostatic pressure. Moreover, the criteria are conceptually simple, and due to an elegant coordinate systemfree formulation, the search for the fracture plane is not necessary, making it easier to implement and more efficient than previous criteria.

\subsection{Invariant-based failure criterion for transverse cracking}

With the aim of distinguishing between transverse and longitudinal failure mechanisms, different criteria were proposed to assess the onset of failure under general stress states. To model transverse damage initiation, the new invariant-based criterion proposed by Camanho et al $[38,39]$ uses structural tensors to represent the material symmetries of the transversely isotropic material instead of symmetry conditions based on a reference coordinate system. This invariant conception enables the description of anisotropy through the use of tensor functions. A preferred direction $\mathbf{a}$ is defined, which corresponds to the fibre direction in UD FRPs $[155,189]$ Taking $x_{1}$ as the fibre direction, the preferred direction $\mathbf{a}$ is given as:

$\mathbf{a}=\left[\begin{array}{lll}1 & 0 & 0\end{array}\right]^{\mathrm{T}}$

The structural tensor $\mathbf{A}$ of transverse isotropy that represents the intrinsic characteristic direction of the material is defined as:

$\mathbf{A}=\mathbf{a} \otimes \mathbf{a}$

According to the proposed invariant formulation [38, 39 ], failure is a function, $f_{M}$, of the stress tensor $\boldsymbol{\sigma}$ and of the structural tensor $\mathbf{A}$ through a set of invariants formulated to identify particular stress states: 
$I_{1}=\frac{1}{2} \operatorname{tr}\left(\boldsymbol{\sigma}^{p}\right)^{2}-\mathbf{a}\left(\boldsymbol{\sigma}^{p}\right)^{2} \mathbf{a}$

$I_{2}=\mathbf{a}\left(\boldsymbol{\sigma}^{p}\right)^{2} \mathbf{a}$

$I_{3}=\operatorname{tr} \boldsymbol{\sigma}-\mathbf{a} \boldsymbol{\sigma} \mathbf{a}$

assuming a decomposition of the stress tensor $\boldsymbol{\sigma}$ in plasticity inducing stresses $\boldsymbol{\sigma}^{p}$ and reaction stresses $\boldsymbol{\sigma}^{r}$ [155]:

$\boldsymbol{\sigma}=\boldsymbol{\sigma}^{p}+\boldsymbol{\sigma}^{r}$

with:

$$
\begin{aligned}
& \boldsymbol{\sigma}^{r}=\frac{1}{2}(\operatorname{tr} \boldsymbol{\sigma}-\mathbf{a} \boldsymbol{\sigma} \mathbf{a}) \mathbf{1}-\frac{1}{2}(\operatorname{tr} \boldsymbol{\sigma}-3 \mathbf{a} \boldsymbol{\sigma} \mathbf{a}) \mathbf{A} \\
& \boldsymbol{\sigma}^{p}=\boldsymbol{\sigma}-\boldsymbol{\sigma}^{r}
\end{aligned}
$$

The reaction stress tensor $\boldsymbol{\sigma}^{r}$ contains the hydrostatic pressure and the projection of the stress tensor onto the preferred direction a. Since the fibre-dominated failure mechanisms are treated separately in the formulation of the failure criteria, the invariants (24) are formulated choosing the plasticity inducing stress tensor $\boldsymbol{\sigma}^{p}$. With this procedure, the invariants $I_{1}$ and $I_{2}$ are directly related, respectively, to transverse shear and in-plane shear loading, whereas the third invariant $I_{3}$ accounts for pressure dependent failure, as experimentally observed in FRPs [90]. The transversely isotropic failure criterion $f_{M}$ reads:

$f_{M}=\alpha_{1} I_{1}+\alpha_{2} I_{2}+\alpha_{3} I_{3}+\alpha_{32} I_{3}^{2} \leq 1$

with:

$\alpha_{3}=\alpha_{3}^{t}, \alpha_{32}=\alpha_{32}^{t}$ if $I_{3}>0, \quad$ and

$\alpha_{3}=\alpha_{3}^{c}, \alpha_{32}=\alpha_{32}^{c}$ if $I_{3} \leq 0$

where the failure parameters $\alpha_{i}$, each related to a particular loading state [189], are given by:

$$
\begin{aligned}
\alpha_{1} & =\frac{1}{S_{T}^{2}} \\
\alpha_{2} & =\frac{1}{S_{L}^{2}} \\
\alpha_{32}^{t} & =\frac{1-\frac{Y_{T}}{2 Y_{B T}}-\alpha_{1} \frac{Y_{T}^{2}}{4}}{Y_{T}^{2}-2 Y_{B T} Y_{T}} \\
\alpha_{3}^{t} & =\frac{1}{2 Y_{B T}}-2 \alpha_{32}^{t} Y_{B T} \\
\alpha_{32}^{c} & =\frac{1-\frac{Y_{C}}{2 Y_{B C}}-\alpha_{1} \frac{Y_{C}^{2}}{4}}{Y_{C}^{2}-2 Y_{B C} Y_{C}} \\
\alpha_{3}^{c} & =\frac{1}{2 Y_{B C}}-2 \alpha_{32}^{c} Y_{B C}
\end{aligned}
$$

where $S_{T}$ and $S_{L}$ are respectively the transverse and inplane shear strengths, $Y_{T}$ and $Y_{C}$ are respectively the transverse tensile and compressive strengths, and $Y_{B T}$ and $Y_{B C}$ are respectively the biaxial transverse tensile and compressive strengths. The distinction concerning $I_{3}>0$ and $I_{3} \leq 0$ in Eq. (28) allows failure under biaxial stress states to be represented by the criterion.

To show the unique features of the criterion proposed by Camanho et al $[38,39]$, and because the range of stress states that can be imposed by means of experimental tests is limited by the complexity of the load introduction systems, the analytical failure envelopes are compared with virtual failure loci generated using computational micro-mechanics $[169,170]$. The elastic and strength properties of the UD composite are obtained from the analysis of RVEs with a random distribution of reinforcements generated using the algorithm proposed by Melro et al [118], and subjected to PBCs [122]. The material behaviour of the constituents is modelled using the framework proposed by Melro et al [121, 122] and described in Sect. 4.

The values obtained from the micro-mechanical analyses of the composite under pure uniaxial, pure biaxial and pure shear loading are used as input data of the transverse failure criterion. Figs. 33-38 show the comparison between the analytical failure envelopes and the virtual failure loci.

Some deviations between the analytical failure envelopes and the micro-mechanical predictions can be observed. These discrepancies are attributed to the random distribution of the reinforcing fibres in the numerical RVEs that leads to some scatter in the numerical simulations, and to the fact that the proposed failure criterion for transverse failure does not distinguish between the in-plane $\left(\sigma_{12}\right)$ and out-of-plane $\left(\sigma_{13}\right)$ longitudinal shear stresses $[38,39]$. Still, the deviations are not large, and all trends reasonably well predicted. 


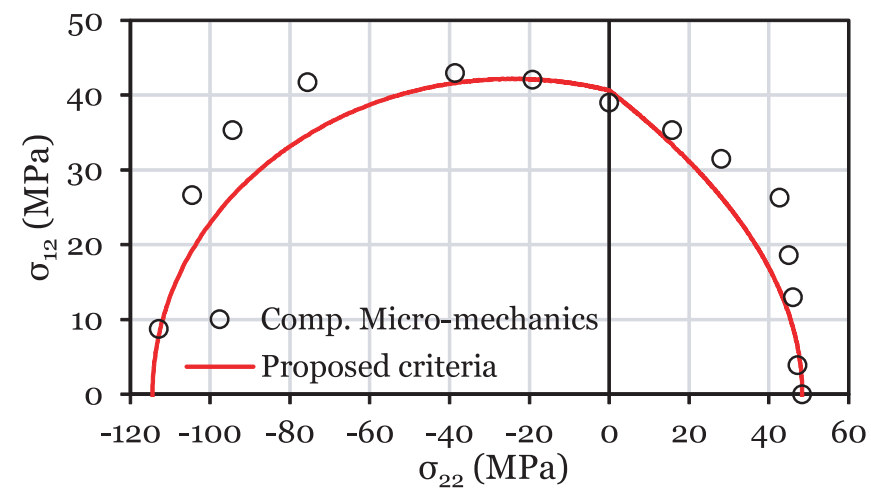

Fig. 33: $\sigma_{22}-\sigma_{12}$ failure envelope and virtual failure loci [38, 39].

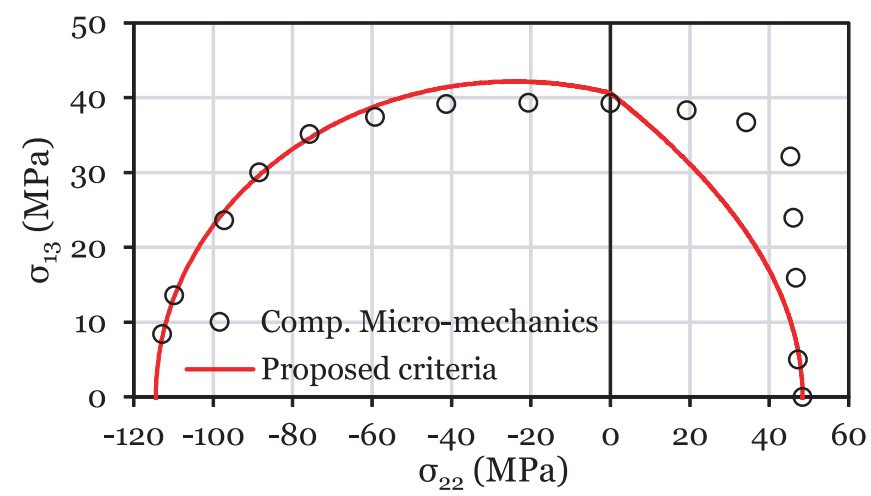

Fig. 34: $\sigma_{22}-\sigma_{13}$ failure envelope and virtual failure loci [38, 39].

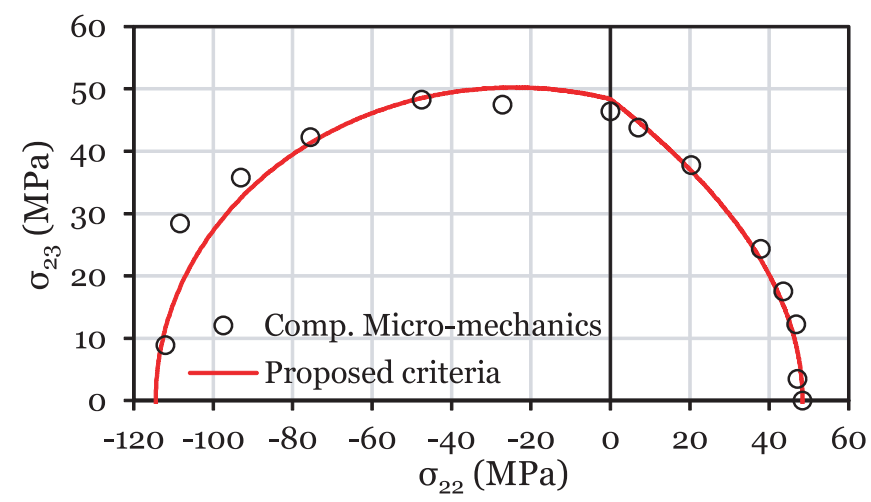

Fig. 35: $\sigma_{22}-\sigma_{23}$ failure envelope and virtual failure loci [38, 39].

In particular, Fig. 38 shows a comparison between the analytical envelopes for the $\sigma_{22}-\sigma_{33}$ stress space obtained with the invariant-based failure criterion [38, 39] and Hashin's failure criteria [87], reportedly the most widely used phenomenological failure criteria for the prediction of intralaminar damage initiation in composite laminates. As can be observed, the biaxial transverse tensile strength is under-predicted by Hashin's failure criteria, while an open failure envelope is obtained for the biaxial transverse compression quadrant, thus mak- ing such failure criteria unsuitable for representing the fracture of composites subjected to complex 3D loading scenarios and hydrostatic pressure. It is important to note that the accurate prediction of failure under these stress states is crucial to predict the mechanical response of very thick laminates (e.g. for applications in wind turbine blades and ship construction) or laminates subjected to complex triaxial stress states (e.g. indentation, low-velocity impact, crushing, or bearing). 


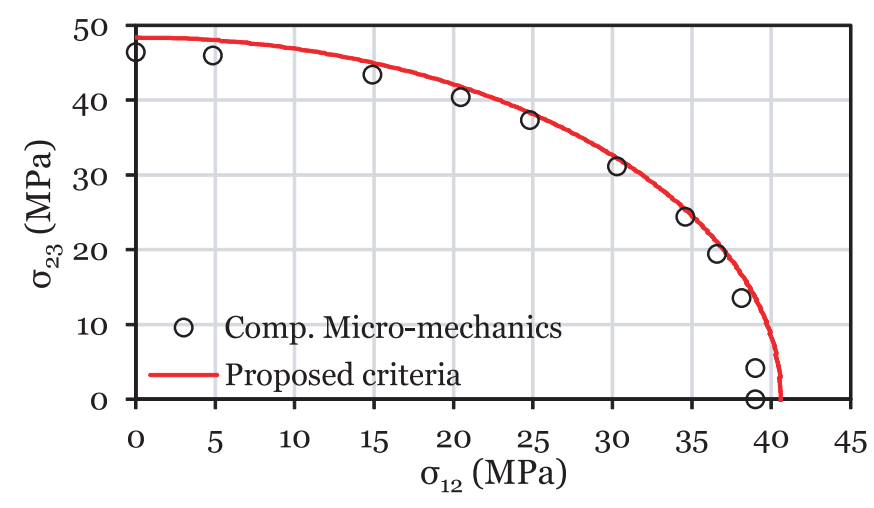

Fig. 36: $\sigma_{12}-\sigma_{23}$ failure envelope and virtual failure loci [38, 39].

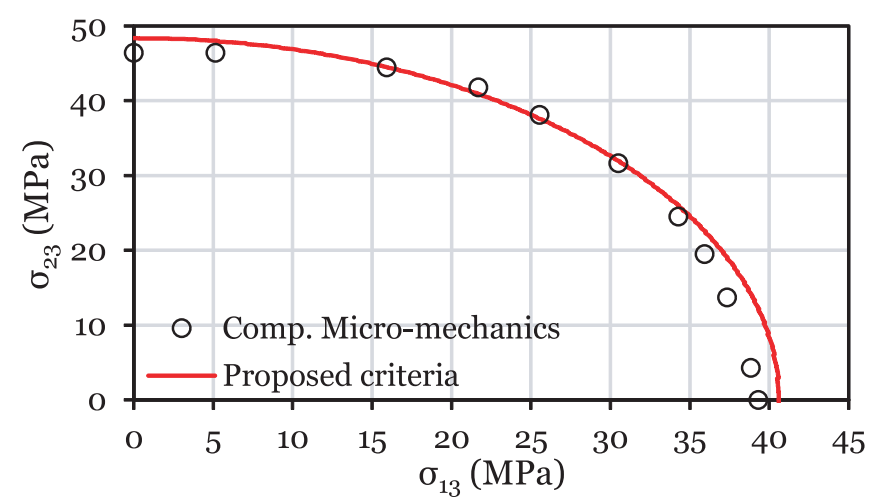

Fig. 37: $\sigma_{13}-\sigma_{23}$ failure envelope and virtual failure loci [38, 39].

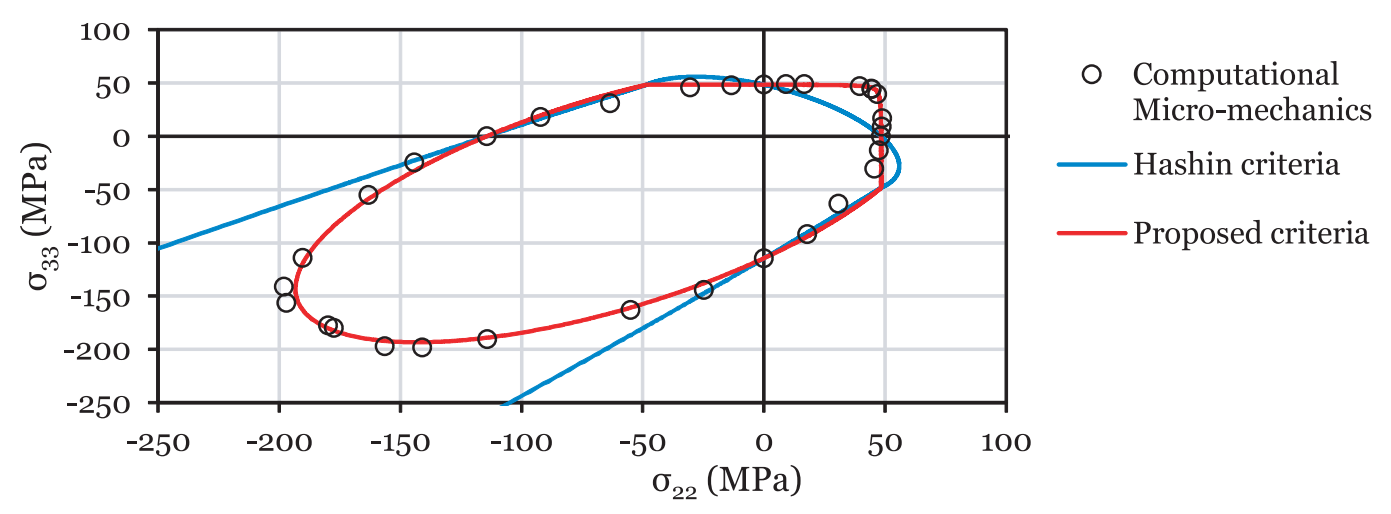

Fig. 38: $\sigma_{22}-\sigma_{33}$ failure envelope and virtual failure loci [38, 39], and comparison with Hashin's failure criterion [87].

\subsubsection{In-situ effect}

To account for the in-situ effect on the transverse ply strengths, and following previous work from Catalanotti et al [47], Camanho et al [38] hypothesised that the slopes in the $\sigma_{22}-\sigma_{12}$ and $\sigma_{22}-\sigma_{23}$ failure envelopes when $\sigma_{22}=0, \eta_{L}$ and $\eta_{T}$ respectively, should remain constant (Fig. 39). In other words, it is assumed that:

$$
\left\{\begin{array}{l}
\eta_{L}^{(+)}=\eta_{L, i s}^{(+)} \\
\eta_{L}^{(-)}=\eta_{L, i s}^{(-)} \\
\eta_{T}^{(+)}=\eta_{T, i s}^{(+)} \\
\eta_{T}^{(-)}=\eta_{T, i s}^{(-)}
\end{array}\right.
$$

where the slopes $\eta_{L}$ and $\eta_{T}$ depend on the sign of the stress component $\sigma_{22}$. Knowing the in-situ transverse tensile $\left(Y_{T}^{i s}\right)$ and in-plane shear $\left(S_{L}^{i s}\right)$ strengths, 
given respectively in Eqs. (15)-(16) and Eqs. (18)-(20) according to the Fracture Mechanics model proposed by Camanho et al [33], and assuming that the biaxial transverse compressive strength $\left(Y_{B C}\right)$ is not an in-situ property [38], the in-situ transverse compressive $\left(Y_{C}^{i s}\right)$, transverse shear $\left(S_{T}^{i s}\right)$, and biaxial transverse tensile $\left(Y_{B T}^{i s}\right)$ strengths are calculated imposing the relations in Eq. (30).

As observed in Figs. 30-31, the predictions of the transverse tensile and compressive ply strengths follow the trends of the computational micro-mechanics analyses of the in-situ effect (Sect. 4), validating the approach proposed by Camanho et al [38] for representation of the delay of transverse matrix cracking at the mesoscale as the ply thickness decreases. Additionally, Fig. 39 shows how the consideration of the in-situ effect modifies the predicted failure envelopes of composite plies in multidirectional laminates, which will have an important role on the strength prediction of composite structures; without such consideration, ply thickness effects at the mesoscale cannot be properly represented, and the unique features of thin-ply laminates properly captured in composite damage simulations.

\subsection{Invariant-based failure criterion for fibre kinking}

Assuming that longitudinal compressive failure of FRPs is originated by local micro-structural defects that trigger a kink band when local matrix cracking occurs in the vicinity of the misaligned, micro-buckled fibres, Camanho et al $[38,39]$ proposed a $3 \mathrm{D}$ kinking model that relies on the invariant-based failure criterion for transverse failure mechanisms (Sect. 5.1). Fig. 40 shows the kinking plane, where the coordinate system $1^{0} 2^{0} 3^{0}$ is aligned with the material axes of the composite, $1^{1} 2^{1} 3^{1}$ is associated with the kinking plane, and $1^{R} 2^{R} 3^{R}$ is associated with the misaligned fibres. The coordinate system $1^{1} 2^{1} 3^{1}$ is obtained rotating the $1^{0} 2^{0} 3^{0}$ frame around the $1^{0}$ axis by an angle $\psi$ (angle of the kinking plane), and the $1^{R} 2^{R} 3^{R}$ coordinate system is obtained rotating the $1^{1} 2^{1} 3^{1}$ frame around the $3^{1}$ axis by an angle $\varphi$ (kinking-angle).

Based on the previous assumptions, kinking failure is predicted using the invariant-based formulation for transverse failure in the misalignment frame $1^{R} 2^{R} 3^{R}$ :

$f_{K}=\alpha_{1} I_{1}+\alpha_{2} I_{2}+\alpha_{3} I_{3}+\alpha_{32} I_{3}^{2} \leq 1$

where the preferred direction $\mathbf{a}^{(0)}$ in the material coordinate system $1^{0} 2^{0} 3^{0}$ is obtained after two successive coordinate system transformations, yielding [38, 39]:

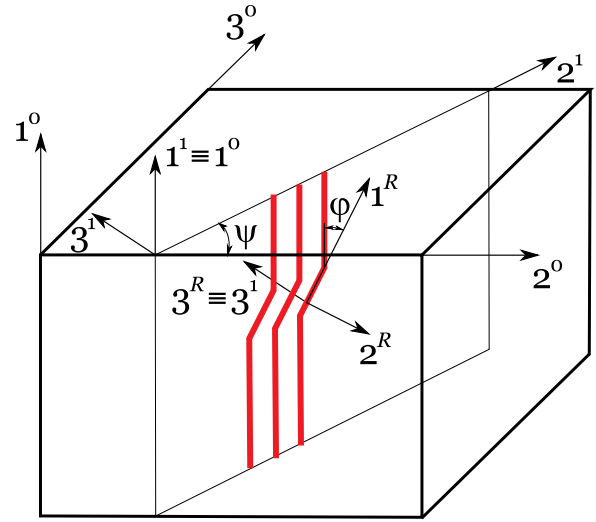

Fig. 40: 3D kinking model (after Camanho et al [38, 39]).

$\mathbf{a}^{(0)}=\left[\begin{array}{c}\cos \varphi \\ \cos \psi \sin \varphi \\ \sin \psi \sin \varphi\end{array}\right]$

The angle of the kinking plane, $\psi$, is the angle that maximises the fibre kinking failure index. Based on the works of Pinho et al [137] and Catalanotti et al [47], a pragmatic expression is considered, assuming that $\psi$ is a function of the shear stresses that act on the 2-3 plane (Fig. 41):

$\psi=\arctan \left(\frac{\sigma_{13}}{\sigma_{12}}\right)$

If the shear stress components $\sigma_{12}$ and $\sigma_{13}$ are equal to zero, the angle of the kinking plane can be calculated by the maximum principal stress that acts on the transversely isotropic plane $[47,137]$ :

$\psi=\frac{1}{2} \arctan \left(\frac{2 \sigma_{23}}{\sigma_{22}-\sigma_{33}}\right)$

The kinking-angle $\varphi$ is given by the sum of a constant initial misalignment angle $\varphi_{0}$ and an angle $\varphi^{R}$ that is originated by the applied shear loading (Fig. 42). According to Camanho et al $[38,39]$, the initial misalignment angle $\varphi_{0}$ can be taken as a representation of the local micro-structural defects from manufacture, or of the intrinsic fibre volume fraction oscillations in the material, and thus a material property. For a material that exhibits linear shear response, the kinking-angle $\varphi$ reads:

$\varphi=\operatorname{sgn}\left\{\sigma_{12}^{(R)}\left(\varphi_{0}, \psi\right)\right\}\left(\varphi_{0}+\frac{\left|\sigma_{12}^{(R)}\left(\varphi_{0}, \psi\right)\right|}{G_{12}}\right)$ 


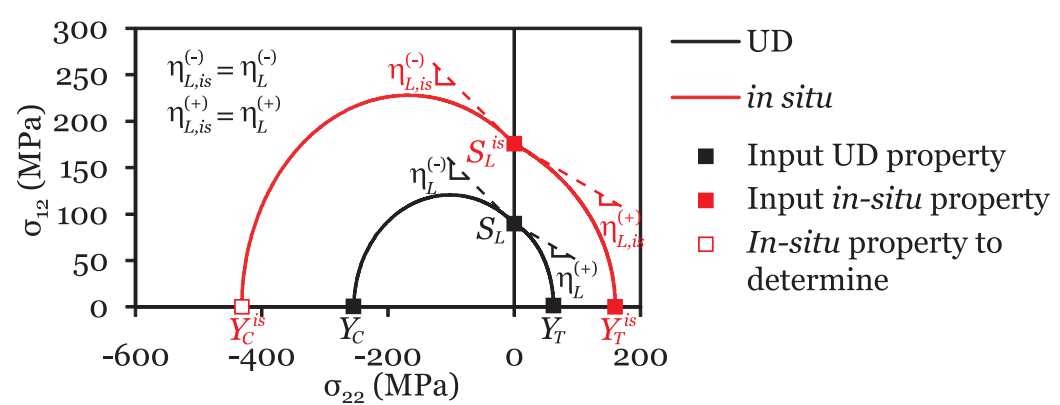

(a) $\sigma_{22}-\sigma_{12}$ failure envelope.
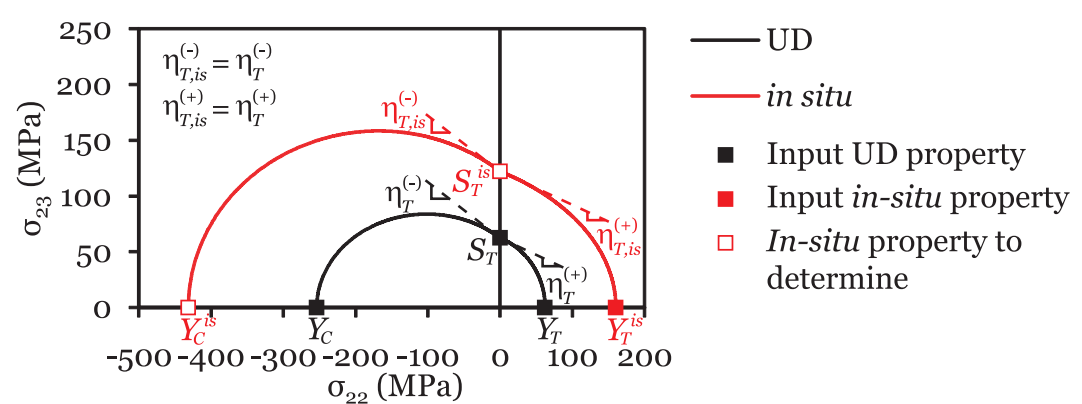

(b) $\sigma_{22}-\sigma_{23}$ failure envelope.

Fig. 39: Definitions of the parameters $\eta_{L}$ and $\eta_{T}$ (after Camanho et al [38]).

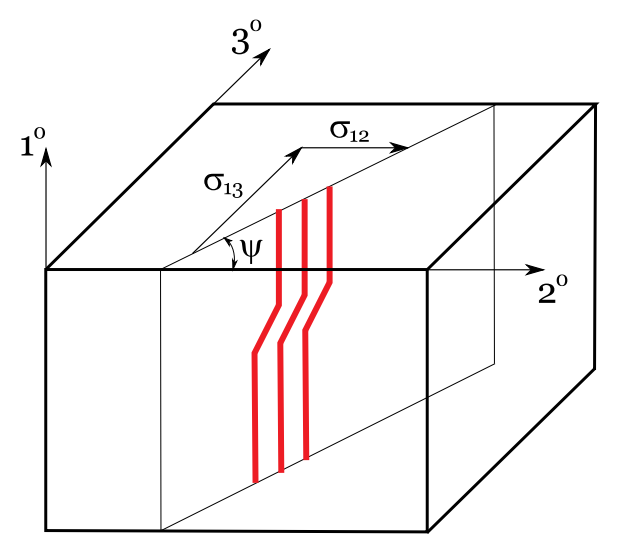

Fig. 41: Kinking plane and involved shear stresses (after Catalanotti et al [47] and Camanho et al [38, 39]).

where $\sigma_{12}^{(R)}\left(\varphi_{0}, \psi\right)$ is the applied shear stress in the misalignment frame, and $\operatorname{sgn}\{x\}$ is the sign of $x$. The shear stress $\sigma_{12}^{(R)}$ is a function of the initial misalignment angle $\varphi_{0}$ and of the angle of the kinking plane $\psi$, and it reads:

$$
\begin{aligned}
\sigma_{12}^{(R)}= & \frac{1}{2}\left(-\sigma_{11}+\sigma_{22} \cos ^{2} \psi+\right. \\
& \left.\sigma_{33} \sin ^{2} \psi+\sigma_{23} \sin 2 \psi\right) \sin 2 \varphi_{0}+ \\
& \left(\sigma_{12} \cos \psi+\sigma_{13} \sin \psi\right) \cos 2 \varphi_{0}
\end{aligned}
$$

The initial misalignment angle $\varphi_{0}$ can be calculated taking the particular case when the material fails under pure longitudinal compression $[38,39]$ :

$$
\varphi_{0}=\varphi_{C}-\frac{\left|X_{C} \sin 2 \varphi_{0}\right|}{2 G_{12}}
$$

where $\varphi_{C}$ is the total misalignment angle under pure longitudinal compression, and the angle:

$\varphi_{C}^{R}=\frac{\left|X_{C} \sin 2 \varphi_{0}\right|}{2 G_{12}}$

is the induced shearing angle $\varphi^{R}$ under pure longitudinal compression, assuming linear shear behaviour. For small initial misalignment angles $\varphi_{0}$, Eq. (37) can be rewritten as:

$\varphi_{0}=\varphi_{C}\left(1+\frac{\left|X_{C}\right|}{G_{12}}\right)^{-1}$

which is an explicit function of $\varphi_{0}$.

Alternatively, assuming nonlinear shear behaviour, and taking the approximation proposed by Hahn and Tsai [86] for the shear stress-shear strain relation in Eq. (21), the kinking angle $\varphi$ and the initial misalignment angle $\varphi_{0}$ are given respectively as [38, 39]: 


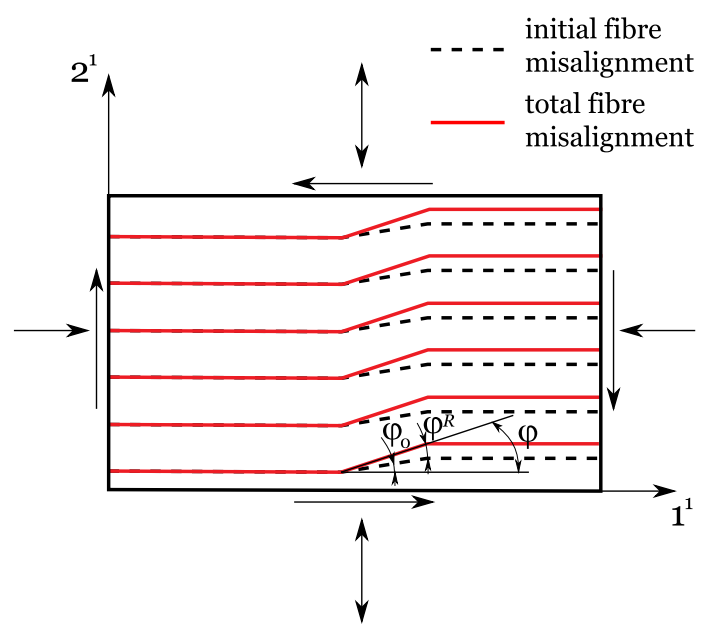

Fig. 42: Misalignment frame (after Camanho et al [38, 39]).

$$
\begin{aligned}
\varphi= & \operatorname{sgn}\left\{\sigma_{12}^{(R)}\left(\varphi_{0}, \psi\right)\right\} \\
& \times\left\{\varphi_{0}+\left|\frac{\sigma_{12}^{(R)}\left(\varphi_{0}, \psi\right)}{G_{12}}+\beta\left[\sigma_{12}^{(R)}\left(\varphi_{0}, \psi\right)\right]^{3}\right|\right\} \\
\varphi_{0}= & \varphi_{C}-\left|\frac{X_{C} \sin 2 \varphi_{0}}{2 G_{12}}+\beta \frac{X_{C}^{3} \sin ^{3} 2 \varphi_{0}}{8}\right|
\end{aligned}
$$

The total misalignment angle $\varphi_{C}$ can be obtained taking failure under pure longitudinal compression (i.e. $\sigma_{11}=X_{C}$ and $\sigma_{i j}=0$ ), and solving the transverse failure criterion (27) for $\varphi=\varphi_{C}$, taking the invariants (24) calculated in the misalignment frame $\mathbf{a}=\mathbf{a}^{(0)}[38$, 39]:

$$
\begin{aligned}
\varphi_{C}= & \frac{1}{2} \arccos \left\{\left[4 \left(\alpha_{1}-4 \alpha_{2}+\alpha_{2}^{2} X_{C}^{2}+\left(\alpha_{3}^{c}\right)^{2}+\right.\right.\right. \\
& \left.2 \alpha_{2} \alpha_{3}^{c} X_{C}+4 \alpha_{32}^{c}\right)^{1 / 2}+\left(\alpha_{1}+4 \alpha_{32}^{c}\right) X_{C}+ \\
& \left.\left.4 \alpha_{3}^{c}\right]\left[\left(\alpha_{1}-4 \alpha_{2}+4 \alpha_{32}^{c}\right) X_{C}\right]^{-1}\right\}
\end{aligned}
$$

An alternative determination of the kinking angle $\varphi$ was also proposed by Camanho et al [38] and Camanho and Arteiro [29] based on observations from Catalanotti et al [47], who represented the imperfections that trigger fibre kinking by a micro-mechanical parameter $\chi$ instead of an initial misalignment angle. In this case, the kinking angle $\varphi$ is obtained as [29]:

$\varphi=\operatorname{sgn}\left\{\sigma_{12}^{(1)}\right\} \gamma_{R}$ where $\operatorname{sgn}\left\{\sigma_{12}^{(1)}\right\}$ is the sign of the shear stress component in the frame of the kinking plane, and $\gamma_{R}$ is the rotation originated by the applied shear loading, which depends on the shear constitutive law. Assuming linear shear behaviour, the following relation was proposed $[29,47]$ :

$\sigma_{12}^{(R)}=\chi \gamma_{R}$

The micro-mechanical parameter $\chi$ can be obtained assuming failure by pure longitudinal compression, reading $[29,47]$ :

$\chi=-\frac{\sin \left(2 \varphi_{C}\right) X_{C}}{2 \varphi_{C}}$

For a generic loading scenario, $\gamma_{R}$ is obtained solving Eq. (44), and then used to determine the kinking angle $\varphi$ using Eq. (43) [29, 47].

Fig. 43 shows the failure envelopes of UD IM7/8552 carbon/epoxy [31, 103, 104] for stress states involving longitudinal failure mechanisms. To predict transverse failure mechanisms and longitudinal tensile failure, the invariant-based failure criterion (27) and a noninteracting maximum allowable strain criterion [29, 38, 39, 47] are used together with the invariant-based failure criterion (31) for kinking failure. Linear shear behaviour is assumed $(\beta=0)$.

When a nonzero transverse stress $\sigma_{22}<0$ or $\sigma_{33}<0$ is combined with a nonzero longitudinal stress $\sigma_{11}<$ 0 , a nonzero initial misalignment angle $\varphi_{0}$ (Fig. 43a) leads to an increase of the apparent axial compressive strength. As explained by Catalanotti et al [47], an increase of the apparent axial compressive strength in these conditions is not physically reasonable; if a compressive load in a transverse direction is applied, the fibres will kink in the plane perpendicular to the load direction, and thus shall not have influence on the onset of fibre kinking. Adopting the alternative methodology to determine the kinking angle $\varphi$ based on the micromechanical parameter $\chi$ (Fig. 43b) overcomes this physical incompatibility, thus becoming the preferred solution to determine the kinking angle $\varphi$ and predict initiation of longitudinal compressive damage mechanics.

Finally, in line with the assumption that longitudinal compressive failure of FRPs occurs from the collapse of the fibres as a result of damage of the supporting matrix, it is interesting to note how the $i n$-situ effect influences longitudinal compressive failure of embedded FRP plies. Fig. 44 shows the $\sigma_{11}-\sigma_{22}$ failure envelopes of an embedded IM7/8552 carbon/epoxy ply for different values of applied transverse compressive stress $\sigma_{33}$. It is noted that, according to the analytical 


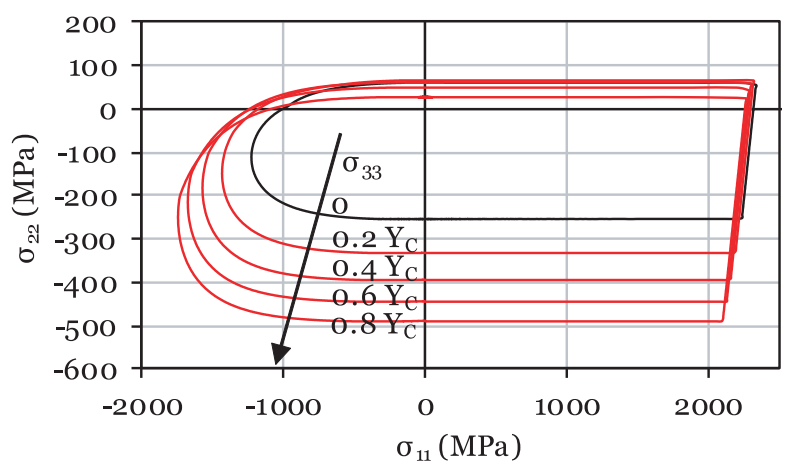

(a) Nonzero initial misalignment angle $\varphi_{0}$ (Eqs. (35)-(37)).

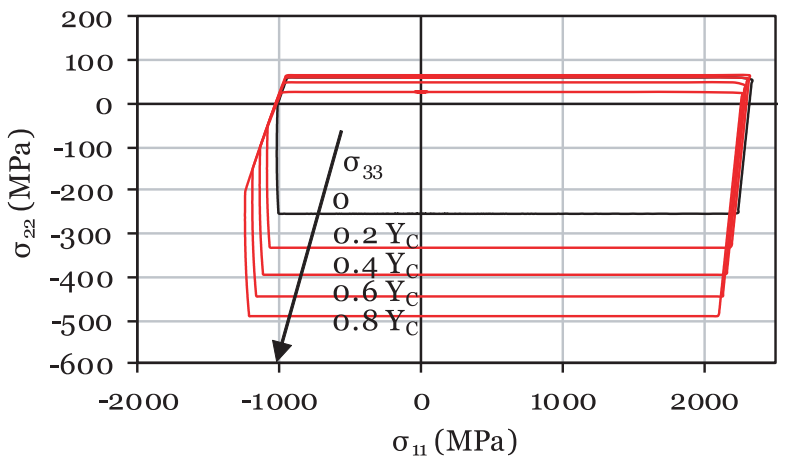

(b) Alternative micro-mechanical parameter $\chi$ (Eqs. (43)-(45)).

Fig. 43: $\sigma_{11}-\sigma_{22}$ failure envelopes of UD IM7/8552 carbon/epoxy for different values of applied transverse compressive stress $\sigma_{33}$.

model, an increase of the transverse tensile and compressive strengths caused by the constraining effect of the adjacent plies improves the overall failure behaviour of the FRP also under combined longitudinal compressive and transverse stress states. This observation highlights the unique potential of thin-ply laminates for applications characterised by complex loading scenarios involving combinations of transverse and longitudinal failure modes.

\section{Structural analysis of thin-ply laminates}

Although application of micro- and meso-mechanical representations of composite damage mechanisms to thin-ply laminates place a crucial role, especially in understanding the unique features of this new class of composite materials and in contributing for improved material development, the design of composite structures with thin plies using representations at these scales has inherent difficulties, such as the increased number of plies, which can be substantially higher than in conventional laminates. But homogenisation and the ab- sence of subcritical damage mechanisms such as matrix cracking and delamination before final failure (Sect. 3) can make design of thin-ply laminates much faster and simpler. In fact, instead of conducting complex ply-byply progressive failure analysis, the equivalent stiffness and strength of a laminate can be calculated directly using very simple analysis tools, such as the classical Laminated Plate Theory (LPT), and closed-form, rapid solutions can be used in the design of composite structures without relying on high safety factors.

\subsection{Failure and mechanical response predictions}

The use of equivalent laminate properties rather than ply-by-ply analysis also has advantages in numerical methods such as the Finite Element Method. By taking the homogenised laminate instead of simulating each ply individually, the overall CPU time and memory needed for simulations can be significantly reduced, especially when the number of layers in the laminate is large. Moreover, the suppression of subcritical damage mechanisms allows simpler models to be used in the nu- 


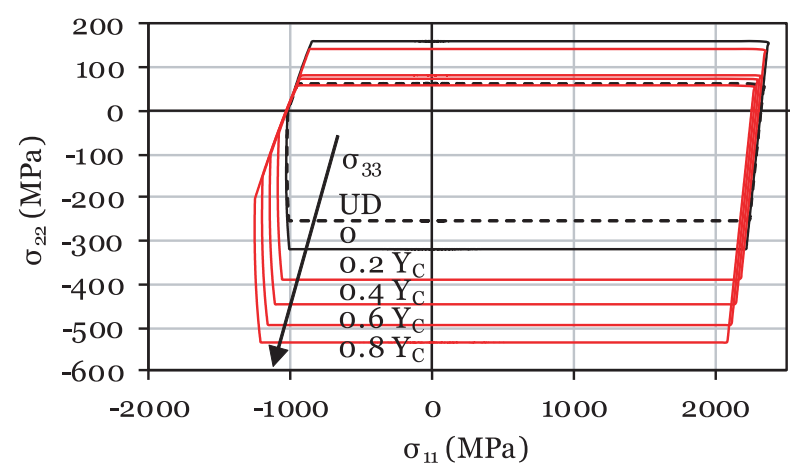

Fig. 44: $\sigma_{11}-\sigma_{22}$ failure envelopes of an embedded IM7/8552 carbon/epoxy ply for different values of applied transverse compressive stress $\sigma_{33}$ obtained using the alternative micro-mechanical parameter $\chi($ Eqs. (43)-(45)). For comparison, the $\sigma_{11}-\sigma_{22}$ failure envelope of a UD IM7/8552 carbon/epoxy lamina is also shown for $\sigma_{33}=0$ (dashed line). The values of $\sigma_{33}$ are given as fractions of the UD transverse compressive strength $Y_{C}$ (as in Fig. 43).

merical strength prediction of thin-ply laminates, avoiding highly nonlinear numerical models such as cohesive interface damage models or ply continuum damage mechanics models. In the case of such simpler, but reliable analysis methodologies, particularly interesting when the design procedures involve optimisation, are added to the intrinsic superior strength and increased design space of thin-ply laminates, better optimised laminates and higher consistency in defining safety factors can be obtained, resulting in weight savings and, consequently, in cost reduction. Therefore, if designed with the appropriate tools, production of composite structures based on thin-ply laminates becomes very competitive.

For instance, Amacher et al [5] applied the classical LPT to predict the strength of thin-ply laminates using only the ply properties, with relative errors within $3 \%$, without implementing stiffness degradation. As discussed earlier, damage progression in thin-ply laminates is drastically reduced, and ultimate failure dominated by the failure strain in the fibres. Thus, the classical FPF analysis is no longer necessary - the gap between matrix-dominated FPF and fibre-dominated $\mathrm{LPF}$ is negligible - making laminate plain strength predictions straightforward.

This unique feature of thin-ply laminates was further exploited by Furtado et al [76]. To predict the laminate elastic properties, instead of LPT, which requires the ply elastic properties measured from at least three independent tests, an invariant-based approach to stiffness [175] that relies on the trace of the in-plane stiffness matrix (Tr) and on a Master Ply concept was used, with relative errors within $7 \%$ (Fig. 45). Only the longitudinal Young's modulus is required using this approach, which is based on the observation that the normalised UD stiffness components, normalised by trace, of sev-
Table 1: Examples of universal laminate factors obtained from the Master Ply using LPT (after Tsai and Melo [176]).

\begin{tabular}{cllll}
\hline Lay-up & $E_{x} / \operatorname{Tr}$ & $E_{y} / \operatorname{Tr}$ & $G_{x y} / \operatorname{Tr}$ & $\nu_{x y}$ \\
\hline Master Ply $-[0]$ & $\mathbf{0 . 8 8 0}$ & $\mathbf{0 . 0 5 2}$ & $\mathbf{0 . 0 3 1}$ & $\mathbf{0 . 3 2 0}$ \\
{$[0 / 90]$} & 0.468 & 0.468 & 0.031 & 0.036 \\
{$[0 / \pm 45 / 90]$} & 0.336 & 0.336 & 0.129 & 0.308 \\
{$\left[0_{7} / \pm 45 / 90\right]$} & 0.662 & 0.175 & 0.070 & 0.310 \\
{$\left[0_{5} / \pm 45_{2} / 90\right]$} & 0.518 & 0.208 & 0.109 & 0.423 \\
{$\left[0_{2} / \pm 45 / 90\right]$} & 0.445 & 0.289 & 0.109 & 0.308 \\
{$\left[0 / \pm 45_{4} / 90\right]$} & 0.217 & 0.217 & 0.187 & 0.552 \\
{$[0 / \pm 45]$} & 0.370 & 0.155 & 0.161 & 0.734 \\
{$[0 / \pm 45 / 0]$} & 0.499 & 0.141 & 0.129 & 0.701 \\
{$[0 / \pm 30]$} & 0.510 & 0.074 & 0.129 & 1.220 \\
{$[0 / \pm 30 / 0]$} & 0.611 & 0.072 & 0.104 & 1.079 \\
{$[ \pm 12.5]$} & 0.764 & 0.053 & 0.066 & 0.913 \\
\hline
\end{tabular}

eral CFRP systems are approximately the same [175]. Based on this, Tsai and Melo [175] defined a Master Ply for CFRPs using the median values of the tracenormalised stiffness properties (Table 1). Additionally, LPT can be used to generate trace-normalised factors for the stiffness components of multidirectional laminates using the Master Ply (Table 1). Because the stiffness of CFRPs along the fibre direction is responsible for about $88 \%$ of the value of trace, it can be determined using only the in-plane longitudinal stiffness component, $E_{1}$ : $\operatorname{Tr}=E_{1} / 0.880$. The trace can then be used to estimate the laminate in-plane elastic constants, $E_{x}$, $E_{y}, G_{x y}$ and $\nu_{x y}$, from one elastic property and from the Universal Laminate Factors.

To simplify the strength prediction of composite laminates, instead of FPF or LPF analysis based on LPT, Furtado et al [76] employed an invariant-based approach to strength based on the concept of Omni Strain 

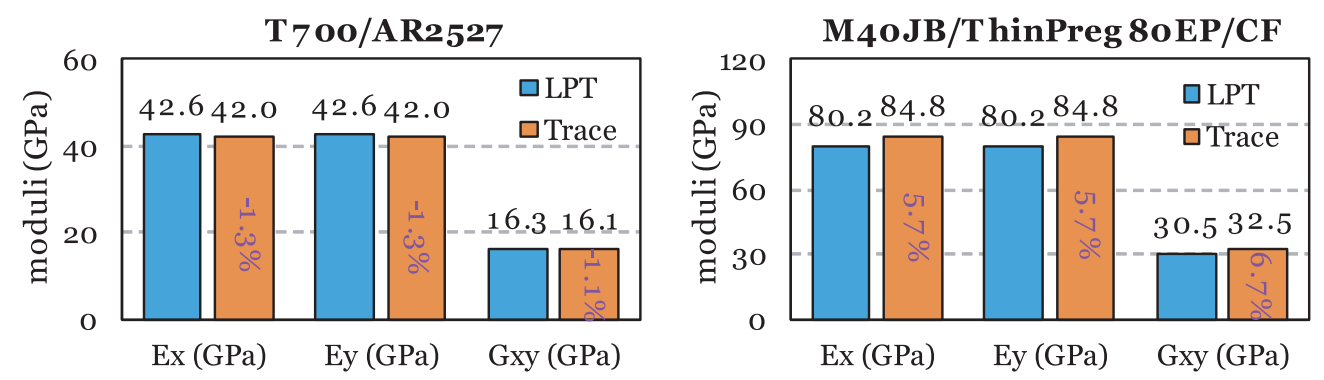

Fig. 45: Examples of predictions of the elastic properties of quasi-isotropic laminates of different thin-ply carbon/epoxy systems using LPT and the Trace theory (after Furtado et al [76]). Relative errors in percentage.

Failure Envelopes [175] and on the Unit Circle failure criterion [177]. Following Tsai and Melo [175], Omni Strain Failure Envelopes for a laminate with many ply orientations can be defined by selecting the controlling ply in each orientation of the strain space $^{5}$. Superimposing the envelopes of the constituent plies, an Omni Strain Failure Envelope can be selected as the inner envelope that covers all controlling plies (Fig. 46), defining a material property that is independent of laminate lay-up configuration.

Due to the fact that the LPF Omni Strain Failure Envelopes of CFRPs are invariably controlled by the longitudinal failure of the $0^{\circ}$ and $90^{\circ}$ plies, they can be approximated by a Unit Circle in the normalised principal strain space using the uniaxial tensile and compressive strains-to-failure ( $\varepsilon_{1 T}$ and $\varepsilon_{1 C}$ respectively) as normalising factors (Fig. 47) [177]. The Unit Circle failure envelope is inscribed in the LPF Omni Strain Failure Envelope [177], and can be uniquely defined from the longitudinal tensile and compressive strains-to-failure of a UD ply. Assuming that LPF is fibre-dominated, as in thin-ply laminates, Unit Circle failure envelopes can be generated without relying on the strengths associated with matrix-dominated failure modes. Hence, ply characterisation can be reduced from several tests on different lamina configurations to just two tests of a $0^{\circ}$ coupon: longitudinal tension and longitudinal compression. Fig. 48 shows a comparison between the predictions of the laminate tensile and compressive unnotched strengths ( $X_{T}^{L}$ and $X_{C}^{L}$ respectively) obtained with the Unit Circle failure criterion and the experimental results reported in the literature for quasi-isotropic laminates of different thin-ply carbon/epoxy systems. Relative errors within $10 \%$ can be observed.

It is noted that, to generate the predictions shown in Figs. 45 and 48 , only the stiffness $\left(E_{1}\right)$ and the tensile

\footnotetext{
5 The use of strain space is justified by the fact that, in this case, failure envelopes are invariant [175]; in other words, in strain space, the shapes of the failure envelopes are independent of the presence of other plies.
}

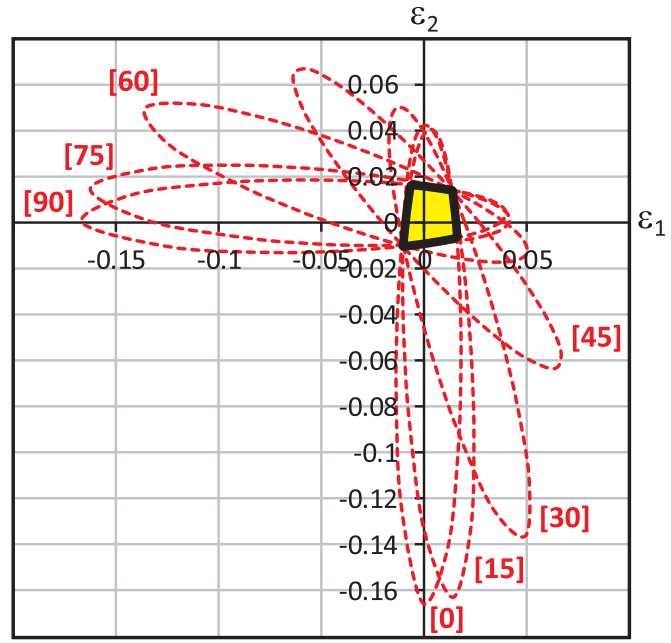

Fig. 46: LPF (degraded) Omni Strain Failure Envelope for IM7/8552, obtained using the Tsai-Wu failure criterion (interaction term $F_{12}^{*}=-1 / 2$ ) in strain space. Property degradation was only applied to the matrixdominated elastic properties $\left(E_{2}, G_{12}\right.$ and $\left.\nu_{12}\right)$, to the interaction term $\left(F_{12}^{*}\right)$, and to the longitudinal compressive strength $\left(X_{C}\right)$, using a matrix degradation factor $E_{m}^{*}=0.15$ and an exponent degradation factor for the longitudinal compressive strength $n=0.1$ (after Furtado et al [76]).

and compressive strengths $\left(X_{T}\right.$ and $X_{C}$ respectively) of the $0^{\circ}$ ply were required [76], resulting in relatively accurate predictions with the minimum number of independent ply properties.

Also motivated by the inherent delamination and matrix cracking suppression capability of thin-ply laminates, Fuller and Wisnom [73] proposed a simple analytical modelling approach for thin-ply angle-ply laminates based solely on the plasticity of the matrix. These authors [74] were able to exploit the damage suppression characteristics of thin-ply laminates and obtain highly nonlinear stress-strain responses using angle-ply 

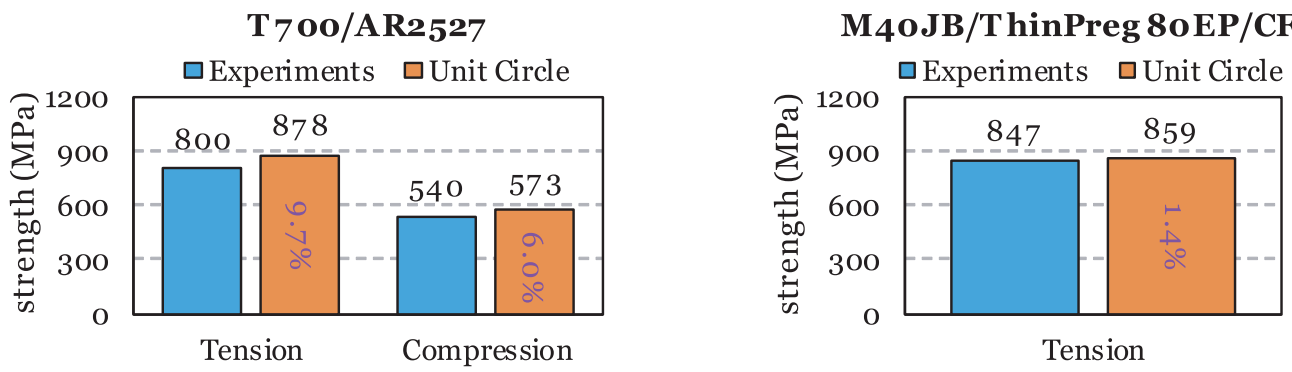

Fig. 48: Examples of failure predictions for quasi-isotropic laminates of different thin-ply carbon/epoxy systems obtained using the Unit Circle failure criterion, and comparison with experimental results from the literature (after Furtado et al [76]). Relative errors in percentage.

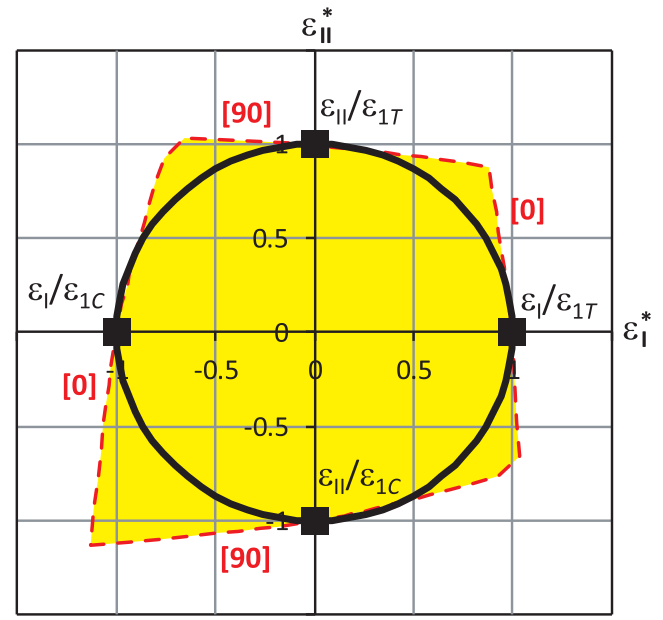

Fig. 47: LPF Omni Strain Failure Envelope for IM7/8552 and Unit Circle failure criterion in the normalised principal strain space (after Furtado et al [76]).

lay-ups, resulting in a new class of high-performance ductile carbon composites that do not rely on complex, costly and time consuming production or tailoring techniques and can be readily obtained from products available in the market. Although valid only for in-plane uniaxial tensile loading, the analysis tool proposed in Ref. [73] allows fast analysis of this new class of composite materials, particularly suitable for preliminary design and optimisation.

To obtain fast predictions of the onset of delaminations at the free edges of laminated composites under tension, either induced by matrix cracks or by the high interlaminar stresses at the free edges, Guillamet et al [84] presented a methodology based on an energybased criterion for matrix cracking-induced delamination (MCID), and on a simplified FE model with cohesive elements. In spite of facing some difficulties in obtaining accurate predictions of free-edge delamina- tion in sub-laminates with thin plies, attributed to the fact that the proposed methodology considers independently MCID and delaminations induced by free-edge interlaminar stresses (which in reality interact - both phenomena occur at relatively high applied strains), this tool, due to its simplicity, can still be useful for predicting the onset of delamination at the free edges of general laminates, while taking into account the effect of ply thickness and ply position in the laminate, with minimum computational effort.

Olsson [132], with the aim of contributing for the development of modelling strategies for thin-ply weaves, presented an analytical model to assess large mass impact response and damage growth in thin-ply composite laminates. The model was formulated taking into account damage due to ply shear cracking, delamination, bending failure and membrane failure. Based on the predictions of the proposed model and on experimental evidence, Olsson [132] suggested that, whereas delamination occurs early in conventional laminates, causing a change to membrane dominated behaviour and negligible bending strains, thin-ply laminates show higher resistance to delamination, resulting in bendingdominated compressive fibre failure. Experimental observation suggests that delamination in impacted thinply laminates is generated by fibre fracture, rather than being the cause of it. An additional factor pointed out by Olsson [132] is related to the effect of higher insitu transverse shear strengths in thin-ply laminates. Olsson [132] suggested that the transverse shear cracks that typically occur in laminates with plies of standard thickness, which can deflect into delaminations, tend to shift to longitudinal shear cracks in thin-ply laminates. These longitudinal shear cracks should induce intralaminar crack growth that is likely to be associated with a higher toughness due to bridging and a more tortuous crack path. This may have an effect on the global impact response of thin-ply laminates too. 


\subsection{Notched response predictions}

In the presence of stress concentrations, such as holes or through-thickness cracks, the nonuniform stress (and strain) gradients can make failure analysis of composite laminates rather complex. However, in thin-ply laminates, the ability to accommodate more plies means that macro-mechanical homogenisation is much easier to achieve; thus, thin-ply laminates can be represented as a homogenised quasi-brittle material, making macroscopic models formulated at the laminate level ideal for the analysis of their notched response.

\subsubsection{Coupled energy-stress Finite Fracture Mechanics criteria}

Analytical coupled energy-stress FFMs criteria [36, 56, $106,114,116]$ have been successfully applied to the prediction of the notched response $[9,76,143]$ and large damage capability [11] of thin-ply laminates. According to these criteria, failure is the result of the propagation of kinematically admissible cracks with finite sizes. In a notched plate subjected to a uniaxial remote stress parallel to the $x$-axis (Fig. 49), failure occurs when both stress-based and energy-based criteria are simultaneously satisfied:

$$
\left\{\begin{array}{l}
\frac{1}{l_{c}} \int_{a_{0}}^{a_{0}+l_{c}} \sigma_{x x}(0, y) \mathrm{d} y=X^{L} \\
\frac{1}{l_{c}} \int_{a_{0}}^{a_{0}+l_{c}} \mathcal{G}_{I}(a) \mathrm{d} a=\mathcal{G}_{I c}
\end{array}\right.
$$

where $2 a_{0}$ is the notch length (in open-hole plates, $a_{0}=$ $R$, where $R$ is the hole radius), $\sigma_{x x}(0, y)$ is the stress distribution along the $y$-axis, $X^{L}$ is the laminate unnotched strength, $\mathcal{G}_{I}(a)$ is the mode I energy release rate, $\mathcal{G}_{I c}$ is the mode I laminate fracture toughness, and $l_{c}$ is the crack extension at failure [36]. Thus, analytical predictions of the notched strength of laminated composite plates can be obtained without requiring empirical adjusting parameters [191, 193], but only the laminate unnotched strength $X^{L}$, the laminate fracture toughness $\mathcal{G}_{I c}$, the ply elastic properties, and the solutions for $\sigma_{x x}(0, y)$ and $\mathcal{G}_{I}(a)$.

Although the system of equations (46) provides good estimations of the notched response of general composite laminates [9, 36, 68, 143], Arteiro et al [11] showed that significant improvements in the predictions for a wider range of notch sizes can be obtained by taking the crack resistance curve of the laminate into account:

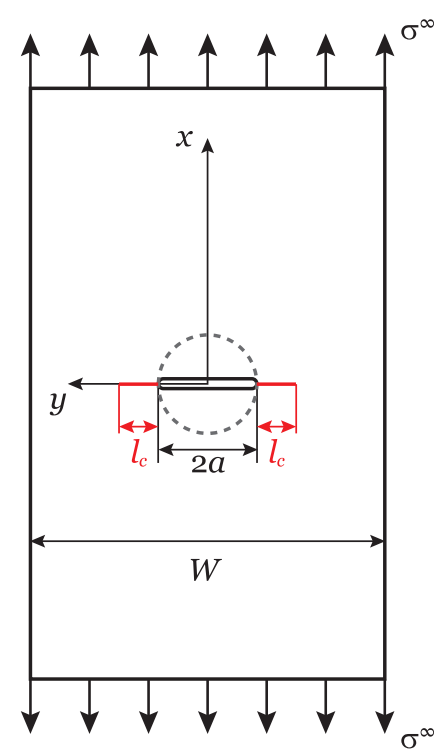

Fig. 49: Notched laminated composite plate.

$$
\left\{\begin{array}{l}
\frac{1}{l_{c}} \int_{a_{0}}^{a_{0}+l_{c}} \sigma_{x x}(0, y) \mathrm{d} y=X^{L} \\
\int_{a_{0}}^{a_{0}+l_{c}} \mathcal{G}_{I}(a) \mathrm{d} a=\int_{0}^{l_{c}} \mathcal{R}(\Delta a) \mathrm{d} \Delta a
\end{array}\right.
$$

where $\mathcal{R}(\Delta a)$ is the crack resistance curve (or $\mathcal{R}$-curve) of the laminate. In this case, instead of the laminate fracture toughness $\mathcal{G}_{I c}$, identification of the laminate $\mathcal{R}$-curve is required $[11,46,48]$.

Figs. 50-53 show the predictions of the notched tensile and compressive strengths of different thin-ply composite laminates obtained with the coupled FFMs criteria ("Analytical - laminate properties"), together with the experimental results available in the literature $[8$, $11,75]$. Notched strength predictions with relative errors within $11 \%$ were obtained in open-hole tension (Figs. 50a-51a), open-hole compression (Figs. 50b-51b), and centre-notched tension specimens (Fig. 52) with a dry ply areal weight of $75 \mathrm{~g} / \mathrm{m}^{2}$. Interestingly, in laminates with ultra-thin plies, with a dry ply areal weight of $30 \mathrm{~g} / \mathrm{m}^{2}$, the relative errors of the FFMs predictions are below $3 \%$ (Fig. 53), validating not only the analytical coupled criteria [36], but also the observation that the strength of thin-ply laminates subjected to nonsmooth stress fields can be accurately predicted using simple tools based on the homogenised laminate properties.

However, these homogenised laminate properties required by the coupled FFMs criteria need to be experimentally determined every time the lay-up of the 


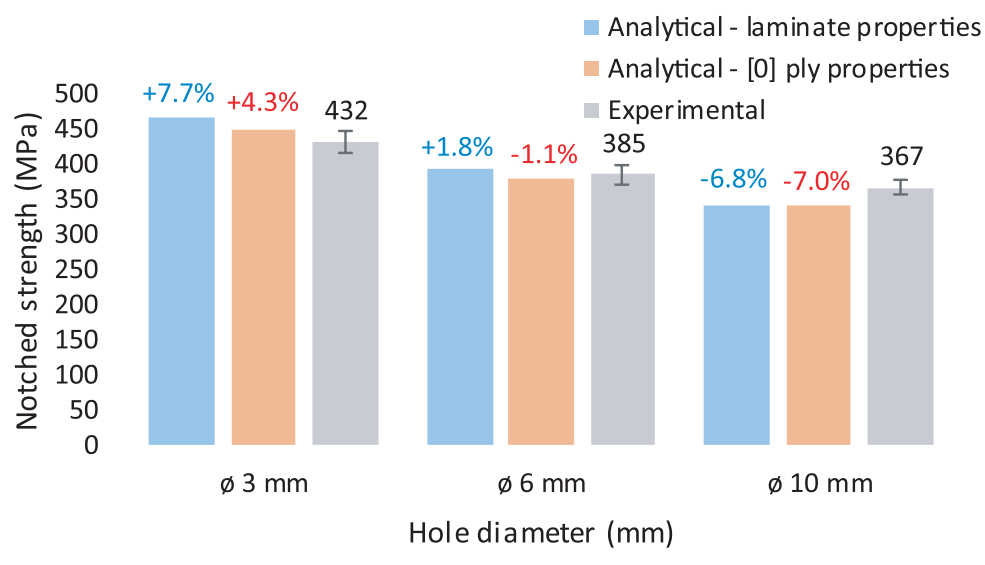

(a) Open-hole tension.

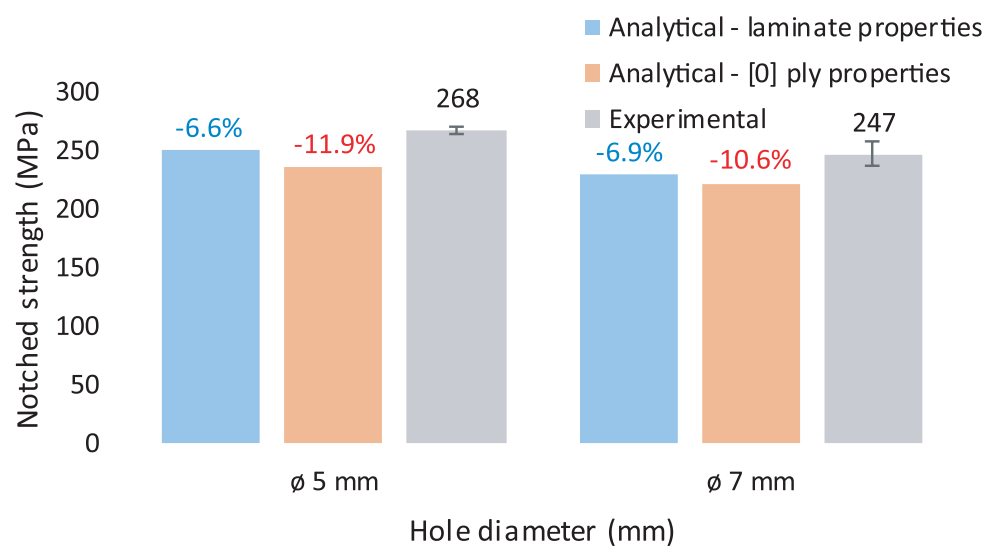

(b) Open-hole compression.

Fig. 50: Notched strength predictions and experimental results of a $[(0 /-45) /(90 / 45)]_{6 \mathrm{~T}}$ T700/AR2527 carbon/epoxy laminate [8], with dry ply areal weight $75 \mathrm{~g} / \mathrm{m}^{2}$. Open-hole specimens with constant width-to-hole diameter ratio $W /(2 R)=4$.

laminate changes, rendering the analysis too costly in terms of testing requirements. Instead, the possibility to take the ply properties determined from tests at the lamina level and the lay-up as inputs makes the analytical model far more attractive. Bearing this is mind, Furtado et al [76] proposed a framework that combines the analytical FFMs criteria with the invariant-based approaches to stiffness and strength proposed by Tsai and Melo [175, 177], and an analytical model that predicts the laminate fracture toughness from that of the $0^{\circ}$ ply [30]. This framework provides laminate notched strength predictions based on the minimum number of independent ply properties: the Young's modulus, the strength, and the $\mathcal{R}$-curve (or fracture toughness) of the $0^{\circ}$ ply. The notched tensile and compressive strength predictions of this framework for different thin-ply composite systems and laminates are also shown in Figs. 50-
53 ("Analytical - [0] ply properties"), together with the predictions obtained using the properties measured directly on the laminate, and the comparison with the experimental results. Although in some cases the relative errors are slightly higher than obtained when using the laminate properties measured directly on laminate coupons, in general the predictions have an accuracy within what is typically sought for preliminary design and optimisation, with the added benefit that the number of material tests required is minimal and the lay-up selection endless, bringing down the amount of tests and material quantity required to design a composite structure, with huge benefits in terms of time and cost reduction at the design stage. 


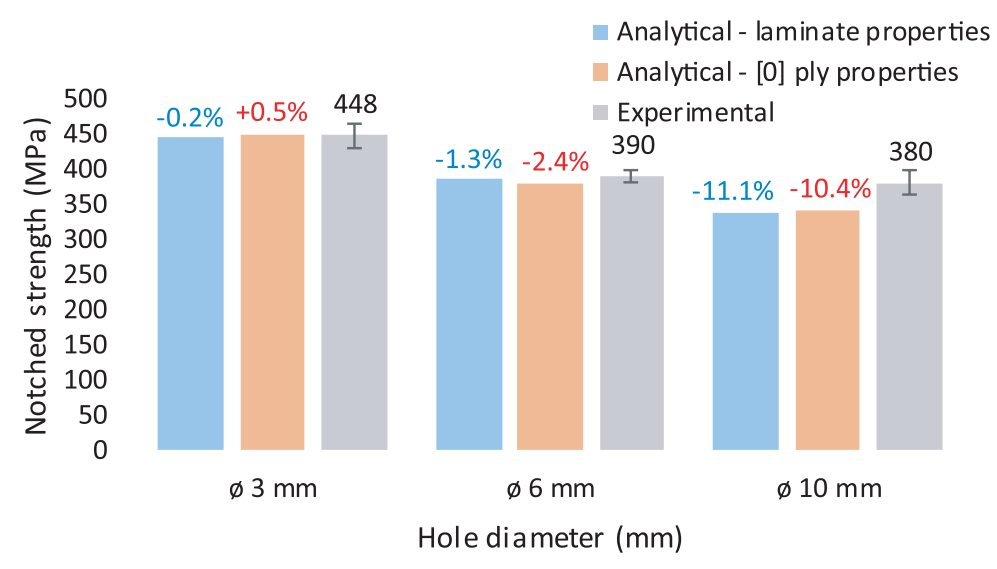

(a) Open-hole tension.

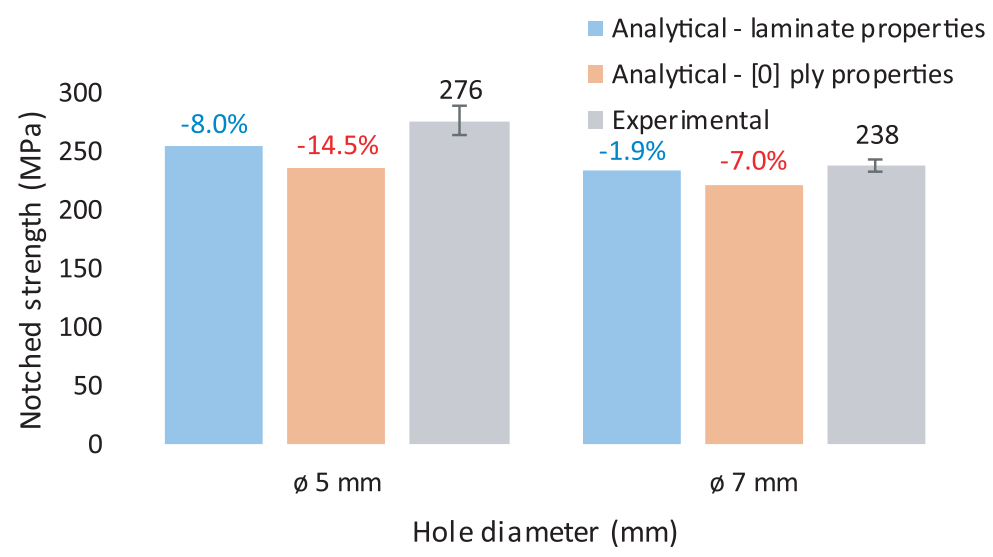

(b) Open-hole compression.

Fig. 51: Notched strength predictions and experimental results of a $[(0 /-45) /(45 / 0) /(90 / 45) /(-45 / 90)]_{\mathrm{S}}$ T700/AR2527 carbon/epoxy laminate [8], with dry ply areal weight $75 \mathrm{~g} / \mathrm{m}^{2}$. Open-hole specimens with constant width-to-hole diameter ratio $W /(2 R)=4$.

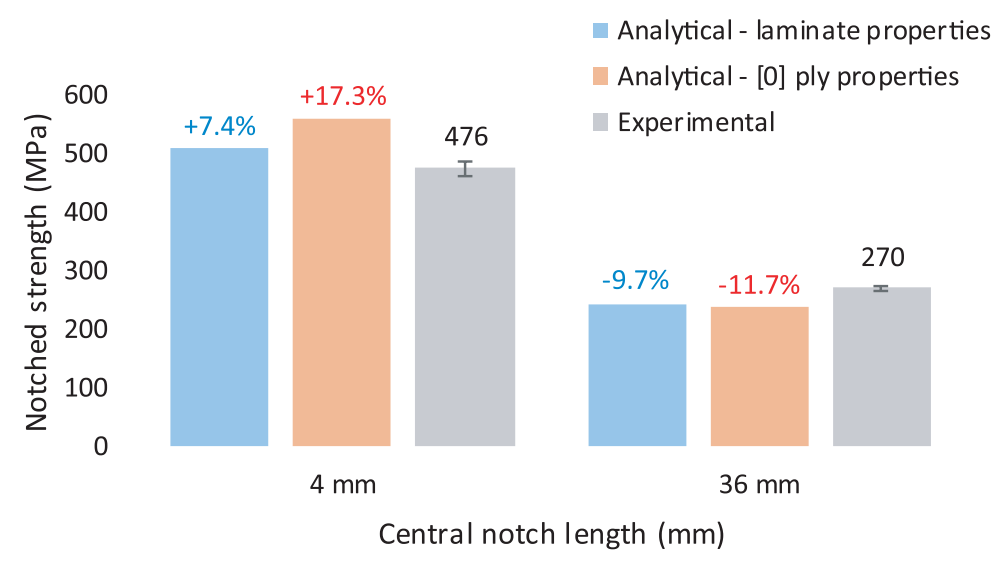

Fig. 52: Notched tensile strength predictions and experimental results of a $[(0 /-45) /(45 / 0) /(90 / 45) /(-45 / 90)]_{\mathrm{S}}$ T700/AR2527 carbon/epoxy laminate [11], with dry ply areal weight $75 \mathrm{~g} / \mathrm{m}^{2}$. Centre-notched specimens with constant width-to-notch length ratio $W /\left(2 a_{0}\right)=7.5$. 


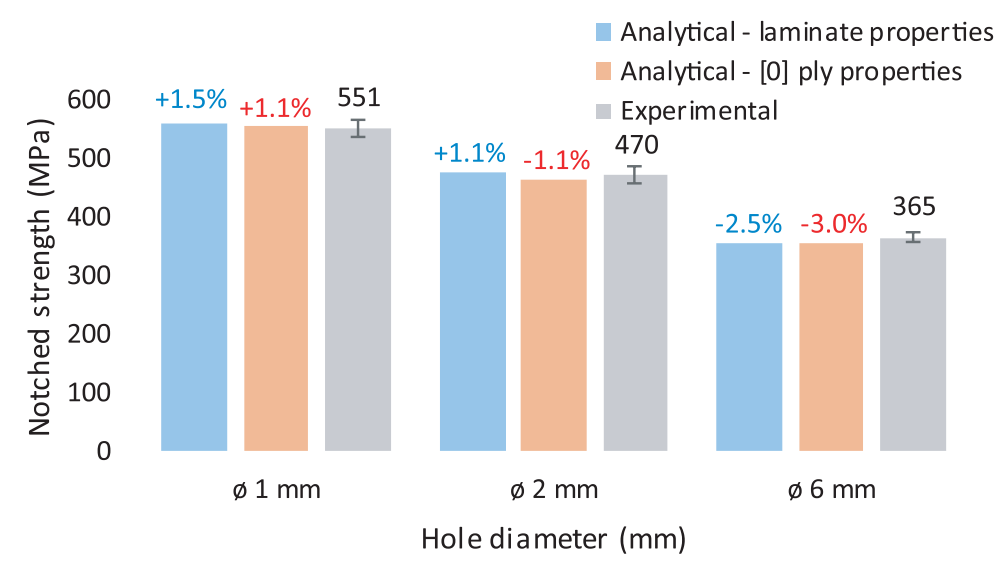

Fig. 53: Notched tensile strength predictions and experimental results of a $[45 / 90 /-45 / 0]_{10 \mathrm{~S}}$ M40JB/ThinPreg 80EP/CF carbon/epoxy laminate [75], with dry ply areal weight $30 \mathrm{~g} / \mathrm{m}^{2}$. Open-hole specimens with constant width-to-hole diameter ratio $W /(2 R)=6$.

\subsubsection{Phase field approach of brittle fracture}

In spite of providing an attractive solution for laminate failure analysis, when it comes to more general geometries or loading scenarios, analytical criteria cannot adequately handle the structural problem, as the availability of closed-form solutions of the specific stress fields and energy release rates is rather limited. Moreover, analytical models such as the coupled FFMs criteria do not provide information about damage extension and crack paths before failure, or about the loaddisplacement history, which can be important in the assessment of the structural integrity of composite panels or structures. These limitations can only be overcome using numerical methods, such as those based on FEA. To tackle the unique features of thin-ply laminates while taking advantage of laminate homogenisation and well defined crack paths, intrinsic to this class of composite materials, Reinoso et al [143] proposed the application of a PF approach of brittle fracture to the failure analysis and strength prediction of openhole thin-ply laminates subjected to tensile loading using a $\mathrm{FE}$ discretization based on a general nonlinear enhanced assumed solid shell formulation [145].

Unlike alternative continuum damage models or discrete damage mechanics methods, the diffusive crack modelling of the $\mathrm{PF}$ approach encompasses a spatially smooth continuum formulation, while avoiding the explicit representation of kinematic discontinuities, allowing the simulation of very complex crack patterns without resorting to special features. The PF approach can be understood as a particular type of gradient enhanced (nonlocal) method for brittle fracture, based on a smeared crack representation over a zone of width $l$ (Fig. 54).
Denoting $\mathbf{X}$ and $\mathbf{x}$ as the reference and current position vectors, and $\mathfrak{d}$ a scalar-valued function with $\mathfrak{d}=0$ and $\mathfrak{d}=1$ identifying the intact and the cracked states, respectively, following the assumptions of PF modelling techniques [123, 124], the surface integrals defined on sharp crack surfaces can be replaced by volume integrals as follows:

$\int_{\Gamma_{c}} \mathcal{G}_{c} \mathrm{~d} \Gamma \approx \int_{\mathcal{B}_{0}} \mathcal{G}_{c} \gamma(\mathfrak{d}, \nabla \mathbf{X} \mathfrak{d}) \mathrm{d} \Omega$

where $\mathcal{G}_{c}$ is the fracture toughness according to the Griffith fracture theory, and $\gamma\left(\mathfrak{d}, \nabla_{\mathbf{X}} \mathfrak{d}\right)$ identifies the socalled crack surface density functional per unit volume of the solid. A common form for $\gamma\left(\mathfrak{d}, \nabla_{\mathbf{X}} \mathfrak{d}\right)$ is given by the second order Allen-Cahn functional [89]:

$\gamma\left(\mathfrak{d}, \nabla_{\mathbf{X}} \mathfrak{d}\right)=\frac{1}{2 l} \mathfrak{d}^{2}+\frac{l}{2}|\nabla \mathbf{X} \mathfrak{d}|^{2}$

where the characteristic length parameter $l$ controls the regularisation band of the model, converging to the sharp crack surface $\Gamma_{c}$ for the limit $l \rightarrow 0$ (Fig. 55) in the spirit of the so-called $\Gamma$-convergence [25].

To model fracture of thin-ply laminates, the $\mathrm{PF}$ approach is implemented in a nonlinear enhanced assumed solid shell formulation. As stressed by Reinoso et al [143], the adoption of this formulation is especially suitable for the analysis of thin-ply composite panels and structures, as the application of these components are typically in the form of plates or shells. Moreover, it takes direct advantage of laminate homogenisation, which is an intrinsic feature of this class of composite systems. 


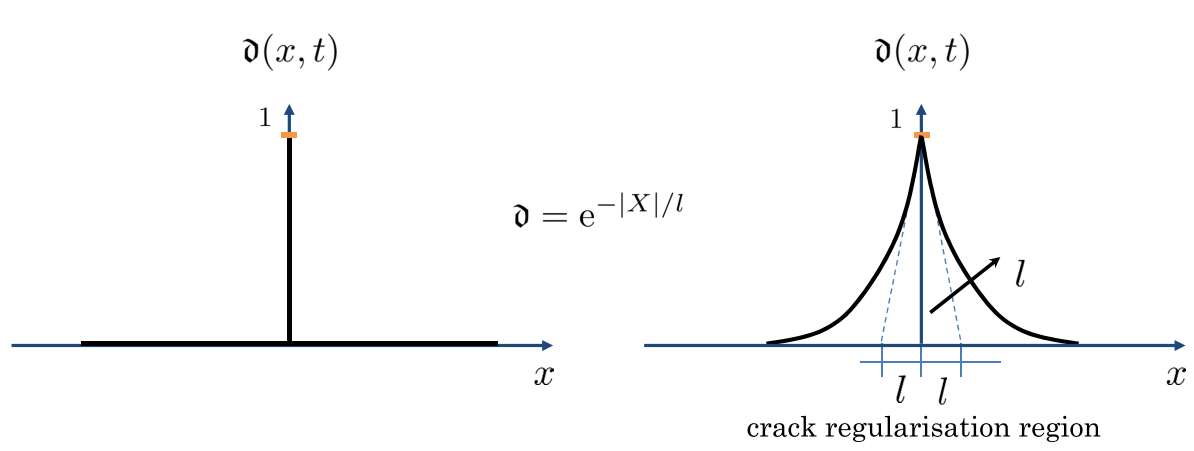

Fig. 54: Sharp and diffusive crack representations. (Left) Sharp crack at $x=0$. (Right) Diffusive crack at $x=0$ confining the regularisation to the region characterised by the length scale $l$ (after Reinoso et al [145]).

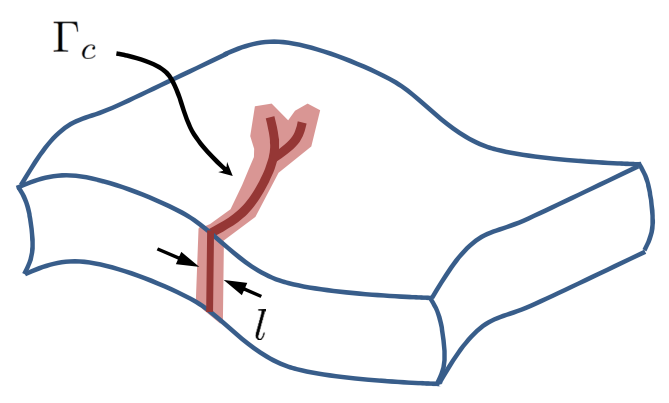

Fig. 55: Shell body where fracture is considered through the phase field concept on the surface $\Gamma_{c}$ (after Reinoso et al [145]).

Following this approach, the position vector of any material point, $\mathbf{X}$, can be expressed by points of the top $\mathbf{X}_{t}\left(\xi^{1}, \xi^{2}\right)$ and bottom surfaces $\mathbf{X}_{b}\left(\xi^{1}, \xi^{2}\right)$ of the shell. This representation can be expressed, respectively, in the reference $\mathcal{B}_{0}$ and current $\mathcal{B}_{t}$ configurations as [143]:

$\mathbf{X}(\boldsymbol{\xi})=\frac{1}{2}\left(1+\xi^{3}\right) \mathbf{X}_{t}\left(\xi^{1}, \xi^{2}\right)+\frac{1}{2}\left(1-\xi^{3}\right) \mathbf{X}_{b}\left(\xi^{1}, \xi^{2}\right)$

$\mathbf{x}(\boldsymbol{\xi})=\frac{1}{2}\left(1+\xi^{3}\right) \mathbf{x}_{t}\left(\xi^{1}, \xi^{2}\right)+\frac{1}{2}\left(1-\xi^{3}\right) \mathbf{x}_{b}\left(\xi^{1}, \xi^{2}\right)$

The corresponding parametric space is defined as:

$\mathcal{A}:=\left\{\boldsymbol{\xi}=\left(\xi^{1}, \xi^{2}, \xi^{3}\right) \in \mathbb{R}^{3} \mid-1 \leq \xi^{i} \leq+1, i=1,2,3\right\}$

where $\left(\xi^{1}, \xi^{2}\right)$ stand for the in-plane directions and $\xi^{3}$ is the thickness direction.

Reinoso et al [143] also adopted the previous kinematic ansatz for the phase field parametrisation within the shell body: $\mathfrak{d}(\boldsymbol{\xi})=\frac{1}{2}\left(1+\xi^{3}\right) \mathfrak{d}_{t}\left(\xi^{1}, \xi^{2}\right)+\frac{1}{2}\left(1-\xi^{3}\right) \mathfrak{d}_{b}\left(\xi^{1}, \xi^{2}\right)$

where $\mathfrak{d}_{t}$ and $\mathfrak{d}_{b}$ denote respectively the phase field variables of the top and bottom surfaces of the shell. This assumption allows a linear approximation of the phase field variable over the shell thickness, especially suitable for bending dominated applications where damage states at the top and bottom surfaces are not necessarily uniform [145].

It is worth noting that the solid shell model adopted by Reinoso et al [143] allows a fully 3D description of the strain field to be simulated, overcoming the limitations posed by plane stress assumptions as in standard Kirchhoff-Lover or Reissner-Mindlin shell formulations. To avoid locking pathologies, a 7-parameter shell model [22] was also envisaged through the advocation of the enhanced assumed strain concept [152], using an additive decomposition of the Green-Lagrange strain tensor $\mathbf{E}$, i.e. $\mathbf{E}=\mathbf{E}^{u}+\tilde{\mathbf{E}}$, where $\mathbf{E}^{u}$ and $\tilde{\mathbf{E}}$ are respectively its compatible and incompatible counterparts [22]. The adopted formulation relies on the exploitation of the multi-field $\mathrm{Hu}$-Washizu variational principle expressed as the stationarity of the following functional of a possibly cracked body [143]:

$$
\begin{aligned}
\Pi(\mathbf{S}, \tilde{\mathbf{E}}, \mathbf{u}, \mathfrak{d}) & =\int_{\mathcal{B}_{0}} \mathfrak{g}(\mathfrak{d}) \Psi\left(\mathbf{E}^{u}, \tilde{\mathbf{E}}\right) \mathrm{d} \Omega-\int_{\mathcal{B}_{0}} \mathbf{S}: \tilde{\mathbf{E}} \mathrm{d} \Omega \\
& +\int_{\mathcal{B}_{0}} \frac{\mathcal{G}_{c} l}{2}\left(\frac{\mathfrak{d}^{2}}{l^{2}}+\left|\nabla_{\mathbf{X}} \mathfrak{d}\right|^{2}\right) \mathrm{d} \Omega+\Pi_{\text {ext }}
\end{aligned}
$$

where the displacement field $(\mathbf{u})$, the incompatible strain tensor $(\tilde{\mathbf{E}})$, the second Piola-Kirchhoff stress tensor $(\mathbf{S})$ and the phase field variable $(\mathfrak{d})$ are the independent variables, and $\Pi_{\text {ext }}$ denotes the contribution due to the prescribed external actions. In Eq. (54), $\mathfrak{g}(\mathfrak{d})=$ $[1-\mathfrak{d}]^{2}+\mathcal{K}$ is the so-called degradation function that 
affects the current stiffness along the loading process, and the parameter $\mathcal{K} \approx 0$ stands for a residual positive parameter that prevents numerical instabilities due to fully degraded material response [123]. It is noted that the degradation function $\mathfrak{g}$ affects the free-energy function, whereas the third integral in Eq. (54) identifies the term associated with the energy dissipation due to fracture. It can be also observed that the variational form encompasses an energy competition between the deformation and the fracture dissipation terms.

The definitions of the second Piola-Kirchhoff stress tensor $(\mathbf{S})$ and of the driving force of the phase field $(\mathcal{H})$ adopted by Reinoso et al [143] are:

$\mathbf{S}:=\frac{\partial \bar{\Psi}\left(\mathbf{E}^{u}, \tilde{\mathbf{E}}, \mathfrak{d}\right)}{\partial \mathbf{E}}$, and

$\mathcal{H}:=\frac{\partial \bar{\Psi}\left(\mathbf{E}^{u}, \tilde{\mathbf{E}}, \mathfrak{d}\right)}{\partial \mathfrak{d}}$, with

$\bar{\Psi}\left(\mathbf{E}^{u}, \tilde{\mathbf{E}}, \mathfrak{d}\right)=\mathfrak{g}(\mathfrak{d}) \Psi\left(\mathbf{E}^{u}, \tilde{\mathbf{E}}\right)$

In line with Reinoso et al [143], the stress field can be eliminated from the variational form given in Eq. (54) through imposition of the orthogonality condition between the interpolation spaces of the stress and incompatible strain fields [152], leading to the following residual equations of the corresponding multi-field problem:

$\mathcal{R}^{u}(\mathbf{u}, \delta \mathbf{u}, \tilde{\mathbf{E}}, \mathfrak{d})=\mathcal{R}_{\text {int }}^{u}-\mathcal{R}_{\text {ext }}^{u}$

$=\int_{\mathcal{B}_{0}} \mathfrak{g}(\mathfrak{d})\left[\frac{\partial \Psi}{\partial \mathbf{E}}: \frac{\partial \mathbf{E}^{u}}{\partial \mathbf{u}} \delta \mathbf{u}\right] \mathrm{d} \Omega+\delta \Pi_{\text {ext }}(\mathbf{u})=0$, $\forall \delta \mathbf{u} \in \mathfrak{V}^{u}$

$\mathcal{R}^{\tilde{E}}(\mathbf{u}, \tilde{\mathbf{E}}, \delta \tilde{\mathbf{E}}, \mathfrak{d})=\int_{\mathcal{B}_{0}} \mathfrak{g}(\mathfrak{d})\left[\frac{\partial \Psi}{\partial \mathbf{E}}: \delta \tilde{\mathbf{E}}\right] \mathrm{d} \Omega=0$,

$$
\forall \delta \tilde{\mathbf{E}} \in \mathfrak{V}^{\tilde{E}}
$$

$\mathcal{R}^{\mathfrak{d}}(\mathbf{u}, \tilde{\mathbf{E}}, \mathfrak{d}, \delta \mathfrak{d})=\int_{\mathcal{B}_{0}}-2(1-\mathfrak{d}) \delta \mathfrak{d} \Psi\left(\mathbf{E}^{u}, \tilde{\mathbf{E}}\right) \mathrm{d} \Omega$

$$
\begin{aligned}
+\int_{\mathcal{B}_{0}} \mathcal{G}_{c} l\left[\frac{1}{l^{2}} \mathfrak{d} \delta \mathfrak{d}+\nabla_{\mathbf{X}} \mathfrak{d} \cdot \nabla_{\mathbf{X}}(\delta \mathfrak{d})\right] \mathrm{d} \Omega & =0, \\
& \forall \delta \mathfrak{d} \in \mathfrak{V}^{\mathfrak{d}}
\end{aligned}
$$

$\mathcal{R}^{u}(\mathbf{u}, \delta \mathbf{u}, \tilde{\mathbf{E}}, \mathfrak{d}), \mathcal{R}^{\tilde{E}}(\mathbf{u}, \tilde{\mathbf{E}}, \delta \tilde{\mathbf{E}}, \mathfrak{d})$ and $\mathcal{R}^{\mathfrak{d}}(\mathbf{u}, \tilde{\mathbf{E}}, \mathfrak{d}, \delta \mathfrak{d})$ are respectively the residual vectors corresponding to the kinematic field, the incompatible strains and the phase field. $\mathfrak{V}^{u}=\left\{\delta \mathbf{u} \in\left[H^{1}\left(\mathcal{B}_{0}\right)\right]: \delta \mathbf{u}=\mathbf{0}\right.$ on $\left.\partial \mathcal{B}_{0, u}\right\}, \mathfrak{V}^{\tilde{E}}=$ $\left[L_{2}\left(\mathcal{B}_{0}\right)\right]$ and $\mathfrak{V}^{\mathfrak{d}}=\left\{\delta \mathfrak{d} \in \mathcal{H}^{1}\left(\mathcal{B}_{0}\right) \mid \delta \mathfrak{d}=0\right.$ on $\left.\Gamma_{c}\right\}$ denote the space of admissible displacement variations $(\delta \mathbf{u})$, the space of admissible enhanced strain modes $(\delta \tilde{\mathbf{E}})$ and the space of admissible test functions for the phase field $(\delta \mathfrak{d})$, respectively. To solve the coupled nonlinear residual equations given in Eqs. (58)-(60), a standard incremental-iterative Newton-Raphson scheme was employed, adopting a fully coupled formulation [145].

To perform the finite element discretization, the reference and current configurations of the shell can be interpolated through standard trilinear shape functions $N^{I}(\mathbf{N}(\boldsymbol{\xi})$ in matrix notation) via the isoparametric concept [143]:

$$
\begin{aligned}
\mathbf{X} & =\sum_{I=1}^{n_{n}} N^{I}(\boldsymbol{\xi}) \mathbf{X}_{I}=\mathbf{N}(\boldsymbol{\xi}) \widetilde{\mathbf{X}} \\
\mathbf{X} & =\sum_{I=1}^{n_{n}} N^{I}(\boldsymbol{\xi}) \mathbf{x}_{I}=\mathbf{N}(\boldsymbol{\xi}) \widetilde{\mathbf{x}}
\end{aligned}
$$

where $\mathbf{X}_{I}$ and $\mathbf{x}_{I}$ denote the discrete nodal values that are collected into the respective vectors $\widetilde{\mathbf{X}}$ and $\widetilde{\mathbf{x}}$, and $n_{n}=8$ is the number of nodes at the element level. Accordingly, the displacement and the phase field variable $(\mathbf{u}, \mathfrak{d})$, their respective variations $(\delta \mathbf{u}, \delta \mathfrak{d})$ and their increments $(\Delta \mathbf{u}, \Delta \mathfrak{d})$ are approximated as [143]:

$$
\begin{aligned}
& \mathbf{u} \approx \mathbf{N}(\boldsymbol{\xi}) \mathbf{d} \\
& \delta \mathbf{u} \approx \mathbf{N}(\boldsymbol{\xi}) \delta \mathbf{d} \\
& \Delta \mathbf{u} \approx \mathbf{N}(\boldsymbol{\xi}) \Delta \mathbf{d}
\end{aligned}
$$

and:

$$
\begin{aligned}
& \mathfrak{d}=\mathbf{N}(\boldsymbol{\xi}) \overline{\mathfrak{d}} \\
& \delta \mathfrak{d}=\mathbf{N}(\boldsymbol{\xi}) \delta \overline{\mathfrak{d}} \\
& \Delta \mathfrak{d}=\mathbf{N}(\boldsymbol{\xi}) \Delta \overline{\mathfrak{d}}
\end{aligned}
$$

where $\mathbf{d}$ and $\overline{\mathfrak{d}}$ are the vectors containing the nodal displacements and phase field variables at the element level. The incompatible strains $\tilde{\mathbf{E}}$ are interpolated at the element level by means of an operator $\mathbf{M}(\boldsymbol{\xi})$ according to the scheme [143]:

$$
\begin{aligned}
& \tilde{\mathbf{E}} \approx \mathbf{M}(\boldsymbol{\xi}) \boldsymbol{\varsigma} \\
& \delta \tilde{\mathbf{E}} \approx \mathbf{M}(\boldsymbol{\xi}) \delta \boldsymbol{\varsigma} \\
& \Delta \tilde{\mathbf{E}} \approx \mathbf{M}(\boldsymbol{\xi}) \Delta \boldsymbol{\varsigma}
\end{aligned}
$$

where $\delta \tilde{\mathbf{E}}$ and $\Delta \tilde{\mathbf{E}}$ stand for the variation and increment of the incompatible strains, respectively. To alleviate Poisson thickness and volumetric locking effects, Reinoso et al [143] adopted the following interpolation operator in the local parametric setting, $\tilde{\mathbf{M}}(\boldsymbol{\xi})$ : 


$$
\tilde{\mathbf{M}}(\boldsymbol{\xi})=\left[\begin{array}{ccccccc}
\xi^{1} & 0 & 0 & 0 & 0 & 0 & 0 \\
0 & \xi^{2} & 0 & 0 & 0 & 0 & 0 \\
0 & 0 & \xi^{3} & \xi^{1} \xi^{3} & \xi^{2} \xi^{3} & 0 & 0 \\
0 & 0 & 0 & 0 & 0 & \xi^{1} & \xi^{2} \\
0 & 0 & 0 & 0 & 0 & 0 & 0 \\
0 & 0 & 0 & 0 & 0 & 0 & 0
\end{array}\right] .
$$

which is transformed to the global Cartesian setting complying with the patch test [143]:

$\tilde{\mathbf{E}}=\left[\frac{\operatorname{det} \mathbf{J}_{0}}{\operatorname{det} \mathbf{J}}\right] \mathbf{T}_{0} \tilde{\mathbf{M}}(\boldsymbol{\xi}) \varsigma=\mathbf{M}(\boldsymbol{\xi}) \boldsymbol{\varsigma}$

where $\mathbf{G}_{i}(\boldsymbol{\xi}):=\partial \mathbf{X}(\boldsymbol{\xi}) / \partial \xi^{i}$ is the co-variant basis in the reference configuration, $\mathbf{J}=\left[\mathbf{G}_{1}, \mathbf{G}_{2}, \mathbf{G}_{3}\right]$ and $\mathbf{J}_{0}=$ $\left[\mathbf{G}_{1(0)}, \mathbf{G}_{2(0)}, \mathbf{G}_{3(0)}\right]$ stand respectively for the Jacobian and the corresponding evaluation at the element centre, and the components of the transformation matrix $\mathbf{T}_{0}$ are $T_{0}^{i j}=\mathbf{G}^{i} \cdot \mathbf{G}_{(0)}^{j}[102,142]$.

To integrate the previous formulation into a nonlinear FE solution scheme, Reinoso et al [143] opted for a linearisation of the residuals in Eqs. (58)-(60) through the directional derivative concept:

$$
\begin{aligned}
\hat{L}\left[\mathbf{R}^{d}\right](\mathbf{d}, \delta \mathbf{d}, \Delta \mathbf{d}, \overline{\mathfrak{d}}, \Delta \overline{\mathfrak{d}}, \varsigma, \Delta \boldsymbol{\varsigma}) & =\mathbf{R}^{d}(\mathbf{d}, \delta \mathbf{d}, \overline{\mathfrak{d}}, \boldsymbol{\varsigma}) \\
& +\Delta_{\mathbf{d}} \mathbf{R}^{d} \Delta \mathbf{d} \\
& +\Delta_{\overline{\mathfrak{d}}} \mathbf{R}^{d} \Delta \overline{\mathfrak{d}} \\
& +\Delta_{\boldsymbol{\varsigma}} \mathbf{R}^{d} \Delta \boldsymbol{\varsigma} \\
\hat{L}\left[\mathbf{R}^{\varsigma}\right](\mathbf{d}, \Delta \mathbf{d}, \overline{\mathfrak{d}}, \Delta \overline{\mathfrak{d}}, \boldsymbol{\varsigma}, \delta \varsigma, \Delta \boldsymbol{\varsigma}) & =\mathbf{R}^{\varsigma}(\mathbf{d}, \overline{\mathfrak{d}}, \boldsymbol{\varsigma}, \delta \varsigma) \\
& +\Delta_{\mathbf{d}} \mathbf{R}^{\varsigma} \Delta \mathbf{d} \\
& +\Delta_{\overline{\mathfrak{d}}} \mathbf{R}^{\varsigma} \Delta \overline{\mathfrak{d}} \\
& +\Delta_{\boldsymbol{\varsigma}} \mathbf{R}^{\varsigma} \Delta \boldsymbol{\varsigma} \\
\hat{L}\left[\mathbf{R}^{\mathfrak{d}}\right](\mathbf{d}, \overline{\mathfrak{d}}, \delta \overline{\mathfrak{d}}, \Delta \overline{\mathfrak{d}}, \varsigma, \delta \varsigma, \Delta \boldsymbol{\varsigma}) & =\mathbf{R}^{\mathfrak{d}}(\mathbf{d}, \overline{\mathfrak{d}}, \delta \overline{\mathfrak{d}}, \varsigma) \\
& +\Delta_{\mathbf{d}} \mathbf{R}^{\mathfrak{d}} \Delta \mathbf{d} \\
& +\Delta_{\overline{\mathfrak{d}}} \mathbf{R}^{\mathfrak{d}} \Delta \overline{\mathfrak{d}} \\
& +\Delta_{\boldsymbol{\varsigma}} \mathbf{R}^{\mathfrak{d}} \Delta \varsigma
\end{aligned}
$$

where $\Delta_{*}[\bullet]$ is the directional derivative operator with respect to the field $*$. Consequently, the coupled system of equations can be written in matrix form as [143]:

$$
\left[\begin{array}{lll}
\mathbf{k}_{d d} & \mathbf{k}_{d \mathfrak{d}} & \mathbf{k}_{d \varsigma} \\
\mathbf{k}_{\mathrm{d} d} & \mathbf{k}_{\mathfrak{d} \mathfrak{d}} & \mathbf{k}_{\mathfrak{d} \varsigma} \\
\mathbf{k}_{\varsigma d} & \mathbf{k}_{\varsigma \mathfrak{d}} & \mathbf{k}_{\varsigma \varsigma}
\end{array}\right]\left[\begin{array}{c}
\Delta \mathbf{d} \\
\Delta \overline{\mathfrak{d}} \\
\Delta \varsigma
\end{array}\right]=\left[\begin{array}{c}
\mathbf{R}_{\text {ext }}^{d} \\
\mathbf{0} \\
\mathbf{0}
\end{array}\right]-\left[\begin{array}{l}
\mathbf{R}_{\text {int }}^{d} \\
\mathbf{R}_{\text {int }}^{\mathfrak{o}} \\
\mathbf{R}_{\text {int }}^{\varsigma}
\end{array}\right]
$$

Finally, the enhancing strains can be eliminated from the system of equations (71) by means of a standard condensation procedure, yielding [143]: $\left[\begin{array}{ll}\mathbf{k}_{d d}^{*} & \mathbf{k}_{d \mathfrak{d}}^{*} \\ \mathbf{k}_{\mathfrak{d} d}^{*} & \mathbf{k}_{\mathfrak{d} \mathfrak{d}}^{*}\end{array}\right]\left[\begin{array}{c}\Delta \mathbf{d} \\ \Delta \overline{\mathfrak{d}}\end{array}\right]=\left[\begin{array}{c}\mathbf{R}_{\text {ext }}^{d} \\ \mathbf{0}\end{array}\right]-\left[\begin{array}{l}\mathbf{R}_{\text {int }}^{d *} \\ \mathbf{R}_{\text {int }}^{\mathfrak{D} *}\end{array}\right]$

where the modified residuals and tangent matrices are given as [143]:

$$
\begin{aligned}
& \mathbf{k}_{d d}^{*}=\mathbf{k}_{d d}-\mathbf{k}_{d \varsigma} \mathbf{k}_{\varsigma \varsigma}^{-1} \mathbf{k}_{\varsigma d} \\
& \mathbf{k}_{d \mathfrak{d}}^{*}=\mathbf{k}_{d \mathfrak{d}}-\mathbf{k}_{d \varsigma} \mathbf{k}_{\varsigma \varsigma}^{-1} \mathbf{k}_{\varsigma \mathfrak{d}} \\
& \mathbf{k}_{\mathfrak{d} d}^{*}=\mathbf{k}_{\mathfrak{d} d}-\mathbf{k}_{\mathfrak{d} \varsigma} \mathbf{k}_{\varsigma \varsigma}^{-1} \mathbf{k}_{\varsigma d} \\
& \mathbf{k}_{\mathfrak{d} \mathfrak{d}}^{*}=\mathbf{k}_{\mathfrak{d} \mathfrak{d}}-\mathbf{k}_{\mathfrak{d} \varsigma} \mathbf{k}_{\varsigma \varsigma}^{-1} \mathbf{k}_{\varsigma \mathfrak{d}} \\
& \mathbf{R}_{\text {int }}^{d *}=\mathbf{R}_{\text {int }}^{d}-\mathbf{k}_{d \varsigma} \mathbf{k}_{\varsigma \varsigma}^{-1} \mathbf{R}_{\mathrm{int}}^{\varsigma} \\
& \mathbf{R}_{\mathrm{int}}^{\mathfrak{d} *}=\mathbf{R}_{\mathrm{int}}^{\mathfrak{D}}-\mathbf{k}_{\mathfrak{d} \varsigma} \mathbf{k}_{\varsigma \varsigma}^{-1} \mathbf{R}_{\mathrm{int}}^{\varsigma}
\end{aligned}
$$

This numerical technique was implemented into the purpose FE codes ABAQUS and FEAP, and used to predict failure of thin-ply T700/AR2527 carbon/epoxy $[(0 /-45) /(90 / 45)]_{6 \mathrm{~T}}$ open-hole coupons loaded in tension. From the mechanical point of view, a KirchhoffSaint-Venant constitutive formulation was adopted using a homogenised material formulation at laminate level. Complying with standard derivations [143], the tangent material tensor $\mathbb{C}=\partial_{\varepsilon \varepsilon} \Psi(\varepsilon)$, where $\Psi(\varepsilon)$ is the Helmholtz free energy function, is given, in the convective curvilinear setting, as:

$\mathbb{C}=\mathbb{C}^{i j k l} \mathbf{G}_{i} \otimes \mathbf{G}_{j} \otimes \mathbf{G}_{k} \otimes \mathbf{G}_{l}$

where $\mathbb{C}^{i j k l}$ are the contravariant components. Following Miehe et al [123, 124], a positive-negative decomposition of the free energy density was adopted by Reinoso et al [143]:

$\psi(\varepsilon, \mathfrak{d})=\mathfrak{g}(\mathfrak{d}) \psi_{+}^{e}(\varepsilon)+\psi_{-}^{e}(\varepsilon)$

with:

$$
\begin{aligned}
\psi_{+}^{e}(\varepsilon) & =\frac{\lambda}{2}\left(\langle\operatorname{tr}[\varepsilon]\rangle_{+}\right)^{2}+\mu \operatorname{tr}\left[\varepsilon_{+}^{2}\right] \\
\psi_{-}^{e}(\varepsilon) & =\frac{\lambda}{2}\left(\langle\operatorname{tr}[\varepsilon]\rangle_{-}\right)^{2}+\mu \operatorname{tr}\left[\varepsilon_{-}^{2}\right]
\end{aligned}
$$

where $\boldsymbol{\varepsilon}$ is the small strain tensor, $\operatorname{tr}[\bullet]$ is the trace operator, $\varepsilon=\varepsilon_{+}+\varepsilon_{-}$stand for the positive and negative parts of $\varepsilon$, and $\lambda$ and $\mu$ are the Lamé constants. The spectral decomposition of the positive part of the strain tensor is given as [143]:

$$
\varepsilon_{+}=\sum_{i=1}^{n_{\text {dim }}}\left\langle\varepsilon^{i}\right\rangle_{+} \mathbf{n}_{\varepsilon}^{i} \otimes \mathbf{n}_{\varepsilon}^{i}
$$


where $\varepsilon^{i}$ and $\mathbf{n}_{\varepsilon}^{i}$ are the eigenvalues and the eigenvectors of the strain tensor and $\langle\bullet\rangle_{+}=(\bullet+|\bullet|) / 2$.

Fig. 56 shows the results of the predicted remote stress-displacement relation for the $[(0 /-45) /(90 / 45)]_{6 \mathrm{~T}}$ T700/AR2527 carbon/epoxy open-hole specimens and the comparison with the experimental data [8]. These predictions were obtained setting the regularisation parameter of the $\mathrm{PF}$ model to $l=0.2 \mathrm{~mm}$. This value was chosen in such a way that at the final imposed displacement (replicating the experimental data), the simulations trigger fully degraded states around the stress concentrator. It is worth mentioning that one of the main characteristics of the PF approach is the fact that it precludes the use of any specific stress-based strength criterion for damage onset and growth, since it is based on the direct competition between the strain and fracture energy terms. However, the length scale parameter $l$ has a strong influence on the strength prediction as discussed in Refs. [24, 108, 128], being still an open question of notable importance in practice.

The open-hole plates were discretised using approximately 7,000 solid shell elements with standard mesh refinement around the hole, where failure events are expected to take place. The principal constraint with respect to the mesh size is related with the fact that at least two elements within $l$ are needed to obtain a reliable regularisation [133].

The predictions shown in Fig. 56 (dashed lines) provide a satisfactory agreement with the experimental results for the notched tensile strengths (with relative errors below 5\%), and reasonable agreement with the experimental load-displacement measures. Unlike analytical models such as the coupled FFMs criteria, not only estimations of the ultimate strength can be obtained, but also the loading history (Fig. 56) and the corresponding crack pattern (Fig. 57). Small discrepancies of the numerical estimations with respect to the specimen stiffness can be observed, which can be attributed to the adoption of a homogenised constitutive model at laminate level. The crack pattern resembles a brittle type of net-section failure mode perpendicular to the loading direction. As expected, macrocracking starts around the notches and evolves symmetrically towards the laminate straight free edges, in agreement with the experimental observations reported in Ref. [8].

Finally, it is noted that the PF method proposed by Reinoso et al [143] can be employed in a straightforward manner to the failure prediction of homogenised composite laminates independently of the geometric characteristics of the specimen and loading conditions, and at the same time provide valuable information regarding the crack initiation load, growth path and ultimate strength. However, it is recognised that the computa- tional effort is usually high, in contrast with analytical methods such as the FFMs model. Moreover, the role of the length scale $l$ needs to be better understood, not only the effect on the predicted crack initiation load, but also on the compromise between the accuracy and computational cost of the method. Other important features that can potentially improve and expand the applicability of the PF method is the extension to compressive failure modes, the adoption of an orthotropic/anisotropic PF formulation (e.g. Refs. [53, 85, $126,168]$ ), the introduction of phenomenological failure criteria (e.g. Refs. [125, 156]), and the introduction of a cohesive-type damage propagation law [186, 187] to more accurately capture bridging effects in thin-ply laminates [11].

It is also worth noting that, although application and validation of the macro-mechanical tools proposed in Sect. 6.2 to uniaxial load cases is straightforward even for highly orthotropic laminates, there are still open questions regarding the characterisation of a laminate fracture toughness under mode II and mixed-mode loading, and the implementation of constitutive relations that can account for the variation of the laminate fracture toughness with the applied stress state (mode mixity) and as the lay-up changes (e.g. when the crack path changes direction in a non-isotropic laminate). These issues are crucial for extension of any fracture mechanics-based macro-mechanical tool (analytical or numerical) to general laminates and loading scenarios.

\section{Conclusions and future research directions}

With the aim of reducing the cost and time required for introduction of new, optimised composite systems in the industry, an appropriate combination of testing and analysis relying more and more on the latter is very important. This article presents a comprehensive coverage of different analysis models formulated at different length-scales and their application to the understanding and prediction of the mechanical response of a new class of composite materials — thin-ply laminates.

Thin-ply laminates exhibit unique features that make composite materials and structures stronger, and consequently thinner and lighter. Among these features, higher resistance to matrix cracking, lower interlaminar stresses and, consequently, higher delamination resistance, and laminate homogenisation have been highlighted here due to their impact on the formulation of composite analysis models.

Analysis models at the lower length-scales were introduced here with the aim of understanding the nature of the features originated at the scale of the constituents. Computational micro-mechanics was used to 

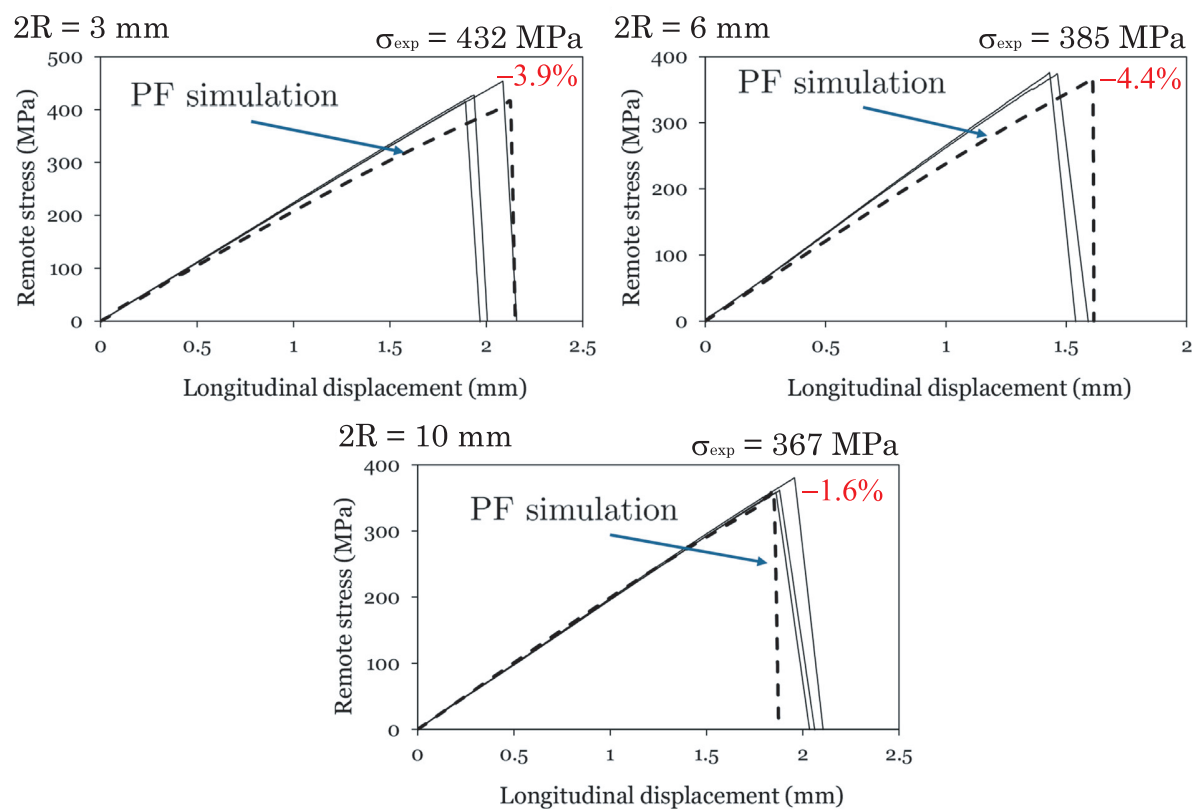

Fig. 56: Experimental-numerical correlation of the remote stress-displacement relations of $[(0 /-45) /(90 / 45)]_{6 \mathrm{~T}}$ T700/AR2527 carbon/epoxy open-hole specimens loaded in tension (after Reinoso et al [143]). The dry ply areal weight is $75 \mathrm{~g} / \mathrm{m}^{2}$. The hole diameters are $2 R=3 \mathrm{~mm}, 2 R=6 \mathrm{~mm}, 2 R=10 \mathrm{~mm}$. All specimens had a constant width-to-hole diameter ratio $W /(2 R)=4$. Experimental results correspond to the solid lines, and the numerical data to the dashed lines. The relative errors related to the average tensile notched strength are shown in red.

support the understanding of the in-situ effect on the normal transverse strengths of thin plies. The proposed framework $[10,12,121,122]$ provided a detailed representation of the failure mechanisms involved in the development of transverse matrix cracks, from the onset of fibre-matrix decohesion to through-thickness crack penetration. The framework was also able to perfectly capture matrix cracking constraining in embedded plies, and subsequent delay of through-thickness crack penetration with decreasing ply thickness, in agreement with detailed experimental evidence [148]. An in-situ effect on the uniaxial transverse tensile and compressive strengths was clearly observed, with excellent correlation with the available analytical models [33, 38, 47, 67].

Due to their size (large number of elements and degrees of freedom) and consequently long running times, micro-mechanical models are not suitable for failure prediction and design of composite laminates and structures. For detailed damage assessment, meso-models that take the laminate layers as the basic homogeneous building blocks are usually employed. However, these models are not able to accurately predict damage onset and ply thickness effects in multidirectional laminates unless they take the in-situ effect on the ply strengths into account. Here, new 3D failure criteria with an invariant quadratic formulation based on structural tensors is proposed [39], together with appropriate defi- nitions of the in-situ strengths [38], validated against computational micro-mechanics simulations. In addition, these criteria cover important aspects such as the increase of the apparent shear strength with moderate values of transverse compression, the detrimental effect of the in-plane shear stresses due to fibre misalignment under longitudinal compressive failure by fibre kinking, and the prediction of failure under hydrostatic pressure, which are not addressed simultaneously by previous phenomenological failure criteria.

Finally, because the design of composite structures with thin plies using representations at the micro- or mesoscales has inherent computational limitations, such as the large number of plies that need to be discretised, alternative models formulated at the laminate scale were presented here to predict ultimate failure of thin-ply laminates. Laminate homogenisation and the absence of subcritical damage mechanisms such as matrix cracking and delamination before final failure support the application and validity of these models. In fact, simple analytical solutions based on LPT [174] or on invariant omni strain failure envelopes $[175,177]$ provide predictions of the unnotched strength of smooth thin-ply laminates with relative errors below $10 \%[5$, 76]. Similarly simple models have also been successfully applied in the prediction of the nonlinear behaviour of thin-ply angle-ply laminates [73], of the onset of delami- 


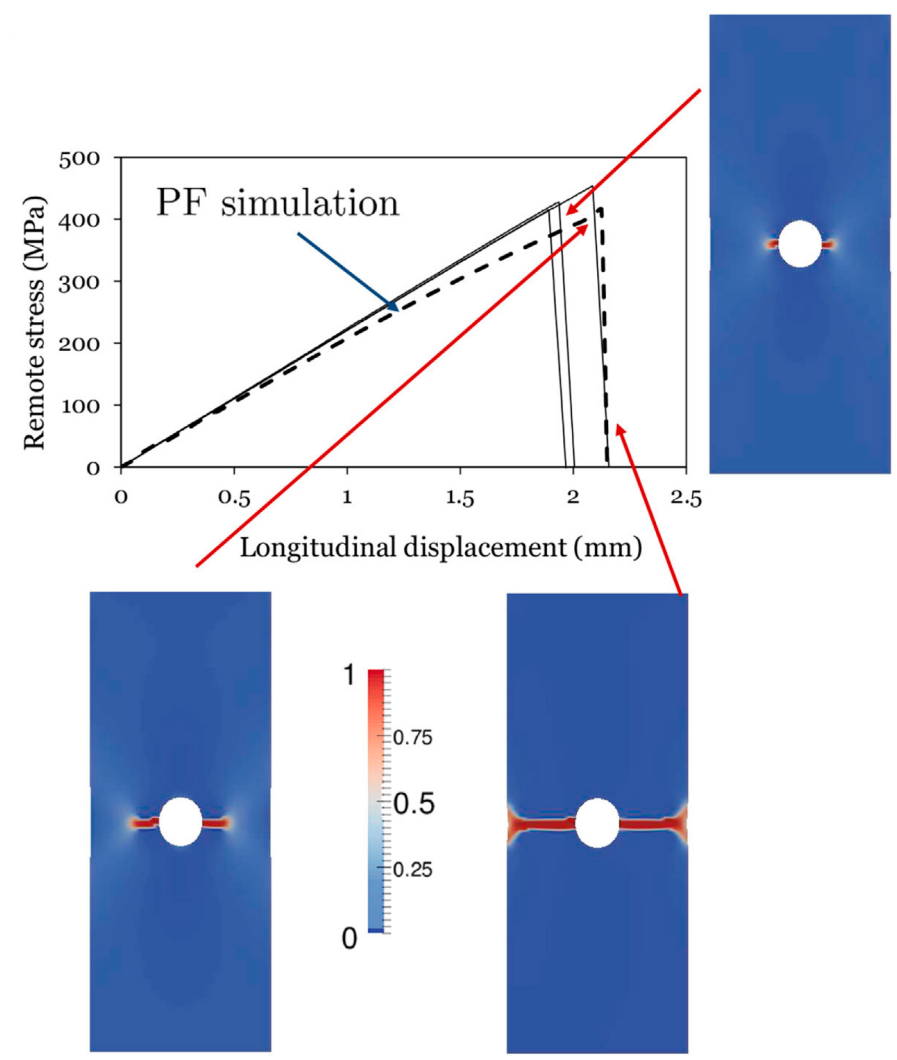

Fig. 57: Experimental-numerical correlation of the remote stress-displacement relation and crack pattern at different stages of a $[(0 /-45) /(90 / 45)]_{6 \mathrm{~T}}$ T700/AR2527 carbon/epoxy open-hole specimen loaded in tension, with a hole diameter $2 R=3 \mathrm{~mm}$ and width-to-hole diameter ratio $W /(2 R)=4$ (after Reinoso et al [143]). Experimental results correspond to the solid lines, and the numerical data to the dashed lines.

nations at the free edges of thin-ply laminates [84], or to assess large mass impact response and damage growth in thin-ply composites. To predict failure of notched laminated plates, coupled energy-stress FFMs criteria $[36,56,106,114,116]$ were proposed when the stress field and energy release rate for the geometry and loading conditions under analysis are suitable for representation by closed-form solutions. Validation against experimental tests on open-hole and centre-notched thinply laminates $[8,11,75]$ leads to relative errors within what is typically sought for preliminary design and optimisation of composite structures [9, 11, 143]. Accurate predictions of the notched response of thin-ply laminates were also obtained using only material properties related to the $0^{\circ}$ ply — the longitudinal Young's modulus, the unnotched strength, and the $\mathcal{R}$-curve (or fracture toughness) [76]. For more complex scenarios, a PF approach to brittle fracture was proposed [143]. Unlike analytical failure criteria, the PF method can be employed in a straightforward manner to the failure prediction of homogenised composite laminates independently of the geometric characteristics of the speci- men and loading conditions, and at the same time provided valuable information regarding the crack initiation load, growth path and ultimate strength. Current limitations that hamper further application of this approach to the prediction of the fracture behaviour of thin-ply composite structures are its usually high computational cost, the lack of a comprehensive understanding of the role of the length parameter $l$ (although Tanné et al [164] has provided a first step in this direction), and the lack of additional features such as the prediction of compressive failure modes, the adoption of an orthotropic/anisotropic PF formulation, the introduction of phenomenological damage initiation criteria, or the introduction of a cohesive-type damage propagation law. Note also the combination with alternative techniques such as the cohesive approach, which is especially suitable for heterogeneous structures [42, $43,133,134]$. However, the extension of the previous fracture macro-mechanical tools to more general loading scenarios is dependent on an accurate characterisation of the composite fracture toughness, not only in mode I, but also in mode II and mixed-mode loading. In 
addition, the formulation of constitutive relations that account for the variation of a laminate fracture toughness with the applied stress state (mode mixity) and as the lay-up changes (e.g. when the crack path changes direction in a non-isotropic laminate) is currently missing.

The tools proposed herein have been used to enhance the understanding and the predictive capability of the structural response of thin-ply laminated composites, providing a case study that shows the potential for application of tools with different levels of complexity and formulated at different length-scales to study features whose experimental observation is either impossible or requires complex and time-consuming procedures, allowing the development of analysis methods that can exploit these features and improve the available modelling strategies. However, currently, these tools remain uncoupled. In the future, combination of these tools into integrated bottom-up virtual testing frameworks or by means of multi-scale analysis methods could make application and interpretation of these models easier, more reliable, and more effective. In fact, in spite of all great recent developments, there is still a remarkable way through for a wider and more efficient application of the tools described, particularly regarding a broader industrial contextualisation of the proposed models for easier and more efficient design of composite structures. Among possible future developments, a thorough validation of the micro-mechanical analyses and the development of more efficient numerical procedures (e.g. using reduced-order models) that allow faster computations suitable of in-silico material design in an industrial context, the development of strategies for faster meso-mechanical simulations and their generalised application on virtual testing and virtual certification, the extension of current laminate analysis models to account for general loading scenarios on laminates with any material symmetry, and the integration of these models into hierarchical or concurrent multi-scale frameworks are just few examples of subjects that require further consideration in the application of advanced analysis methods to enhance the development of new FRP systems.

\section{Conflict of interest}

On behalf of all authors, the corresponding author states that there is no conflict of interest.

\section{References}

1. Abdalla MM, Setoodeh S, Gürdal Z (2007) Design of variable stiffness composite panels for maximum fundamental frequency using lamination parameters. Compos Struct 81:283-291

2. Abisset E, Daghia F, Ladevèze P (2011) On the validation of a damage mesomodel for laminated composites by means of open-hole tensile tests on quasi-isotropic laminates. Compos Part A-Appl S 42:1515-1524

3. Aboudi J, Arnold SM, Bednarcyk BA (2013) Micromechanics of Composite Materials: A Generalized Multiscale Analysis Approach. Elsevier, Amsterdam

4. Achard V, Bouvet C, Castanié B, Chirol C (2014) Discrete ply modelling of open hole tensile tests. Compos Struct 113:369-381

5. Amacher R, Cugnoni J, Botsis J, Sorensen L, Smith W, Dransfeld C (2014) Thin ply composites: Experimental characterization and modeling of size-effects. Compos Sci Technol 101:121-132

6. Areias P, Rabczuk T, Camanho PP (2013) Initially rigid cohesive laws and fracture based on edge rotations. Comput Mech 52:931-947

7. Arteiro A (2016) Structural mechanics of thin-ply laminated composites. PhD thesis, Faculdade de Engenharia, Universidade do Porto, Porto

8. Arteiro A, Catalanotti G, Xavier J, Camanho PP (2013) Notched response of non-crimp fabric thinply laminates. Compos Sci Technol 79:97-114

9. Arteiro A, Catalanotti G, Xavier J, Camanho PP (2013) Notched response of non-crimp fabric thin-ply laminates: Analysis methods. Compos Sci Technol 88:165-171

10. Arteiro A, Catalanotti G, Melro AR, Linde P, Camanho PP (2014) Micro-mechanical analysis of the in situ effect in polymer composite laminates. Compos Struct 116:827-840

11. Arteiro A, Catalanotti G, Xavier J, Camanho PP (2014) Large damage capability of non-crimp fabric thin-ply laminates. Compos Part A-Appl S 63:110-122

12. Arteiro A, Catalanotti G, Melro AR, Linde P, Camanho PP (2015) Micro-mechanical analysis of the effect of ply thickness on the transverse compressive strength of polymer composites. Compos Part A-Appl S 79:127-137

13. Arteiro A, Catalanotti G, Xavier J, Linde P, Camanho PP (2017) Effect of tow thickness on the structural response of aerospace-grade spread-tow fabrics. Compos Struct 179:208-223 
14. Arteiro A, Catalanotti G, Xavier J, Linde P, Camanho PP (2018) A strategy to improve the structural performance of non-crimp fabric thin-ply laminates. Compos Struct 188:438-449

15. Aymerich F, Pani C, Priolo P (2007) Damage response of stitched cross-ply laminates under impact loadings. Engng Fract Mech 74:500-514

16. Bäcklund J, Aronsson CG (1986) Tensile fracture of laminates with holes. J Compos Mater 20:259286

17. Bai X, Bessa MA, Melro AR, Camanho PP, Guo L, Liu WK (2015) High-fidelity micro-scale modeling of the thermo-visco-plastic behavior of carbon fiber polymer matrix composites. Compos Struct 134:132-141

18. Bažant ZP, Oh BH (1983) Crack band theory for fracture of concrete. Mater Struct 16(93):155-177

19. Belytschko T, Song JH (2010) Coarse-graining of multiscale crack propagation. Int J Numer Meth Engng 81:537-563

20. Benzeggagh M, Kenane M (1996) Measurement of mixed-mode delamination fracture toughness of unidirectional glass/epoxy composites with mixed-mode bending apparatus. Compos Sci Technol 56:439-449

21. Berthelot JM (2003) Transverse cracking and delamination in cross-ply glass-fiber and carbonfiber reinforced plastic laminates: Static and fatigue loading. Appl Mech Rev 56(1):111-147

22. Bischoff M, Ramm E (1997) Shear deformable shell elements for large strains and rotations. Int J Numer Meth Engng 40:4427-4449

23. Boniface L, Smith PA, Bader MG (1997) Transverse ply cracking in cross-ply CFRP laminates - Initiation or propagation controlled? J Compos Mater 31(11):1080-1112

24. Borden MJ, Verhoosel CV, Scott MA, Hughes TJR, Landis CM (2012) A phase-field description of dynamic brittle fracture. Comput Method Appl M 217-220:77-95

25. Bourdin B, Francfort GA, Marigo JJ (2008) The variational approach to fracture. J Elasticity 91 (13):5-148

26. Bouvet C, Rivallant S, Barrau JJ (2012) Low velocity impact modeling in composite laminates capturing permanent indentation. Compos Sci Technol 72:1977-1988

27. Buryachenko VA, Pagano NJ, Kim RY, Spowart JE (2003) Quantitative description and numerical simulation of random microstructures of composites and their effective elastic moduli. Int J Solids Struct 40:47-72
28. Camanho PP (1999) Application of numerical methods to the strength prediction of mechanically fastened joints in composite laminates. PhD thesis, Centre for Composite Materials, Imperial College of Science, Technology and Medicine, London

29. Camanho PP, Arteiro A (2017) Analysis Models for Polymer Composites Across Different Length Scales: Fifty Years of Progress and Achievement of the Science, Development, and Applications, Springer International Publishing, Cham, chap 9, pp 199-279

30. Camanho PP, Catalanotti G (2011) On the relation between the mode I fracture toughness of a composite laminate and that of a $0^{\circ}$ ply: Analytical model and experimental validation. Engng Fract Mech 78:2535-2546

31. Camanho PP, Lambert M (2006) A design methodology for mechanically fastened joints in laminated composite materials. Compos Sci Technol 66:3004-3020

32. Camanho PP, Dávila CG, de Moura MF (2003) Numerical simulation of mixed-mode progressive delamination in composite materials. J Compos Mater 37(16):1415-1438

33. Camanho PP, Dávila CG, Pinho ST, Iannucci L, Robinson P (2006) Prediction of in situ strengths and matrix cracking in composites under transverse tension and in-plane shear. Compos Part AAppl S 37:165-176

34. Camanho PP, Maimí P, Dávila CG (2007) Prediction of size effects in notched laminates using continuum damage mechanics. Compos Sci Technol 67:2715-2727

35. Camanho PP, Arteiro A, Turon A, Costa J, Guillamet G (2012) Structural integrity of thin-ply laminates. JEC Compos Mag 71:49-50

36. Camanho PP, Erçin GH, Catalanotti G, Mahdi S, Linde P (2012) A finite fracture mechanics model for the prediction of the open-hole strength of composite laminates. Compos Part A-Appl S 43:1219-1225

37. Camanho PP, Bessa MA, Catalanotti G, Vogler M, Rolfes R (2013) Modeling the inelastic deformation and fracture of polymer composites Part II: Smeared crack model. Mech Mater 59:3649

38. Camanho PP, Arteiro A, Catalanotti G, Melro AR, Vogler M (2015) Three-dimensional invariantbased failure criteria for transversely isotropic fibre-reinforced composites. In: Camanho PP, Hallett SR (eds) Numerical Modelling of Failure in Advanced Composite Materials, Woodhead Pub- 
lishing, Cambridge, chap 5, pp 111-150

39. Camanho PP, Arteiro A, Melro AR, Catalanotti G, Vogler M (2015) Three-dimensional invariantbased failure criteria for fibre-reinforced composites. Int J Solids Struct 55:92-107

40. Canal LP, González C, Molina-Aldareguía JM, Segurado J, Llorca J (2012) Application of digital image correlation at the microscale in fiberreinforced composites. Compos Part A-Appl S 43:1630-1638

41. Canal LP, González C, Segurado J, Llorca J (2012) Intraply fracture of fiber reinforced composites: Microscopic mechanisms and modeling. Compos Sci Technol 72:1223-1232

42. Carollo V, Reinoso J, Paggi M (2017) A 3D finite strain model for intralayer and interlayer crack simulation coupling the phase field approach and cohesive zone model. Compos Struct 182:636-651

43. Carollo V, Reinoso J, Paggi M (2018) Modeling complex crack paths in ceramic laminates: a novel variational framework combining the phase field method of fracture and the cohesive zone model. J Eur Ceram Soc, https://doi.org/10.1016/j.jeurceramsoc.2018.01.035

44. Carrere N, Laurin F, Maire JF (2012) Micromechanical-based hybrid mesoscopic 3D approach for non-linear progressive failure analysis of composite structures. J Compos Mater 46(19-20):2389-2415

45. Catalanotti G (2016) On the generation of RVEbased models of composites reinforced with long fibres or spherical particles. Compos Struct 138:8495

46. Catalanotti G, Camanho PP (2013) A semianalytical method to predict net-tension failure of mechanically fastened joints in composite laminates. Compos Sci Technol 76:69-76

47. Catalanotti G, Camanho PP, Marques AT (2013) Three-dimensional failure criteria for fiberreinforced laminates. Compos Struct 95:63-79

48. Catalanotti G, Arteiro A, Hayati M, Camanho PP (2014) Determination of the mode I crack resistance curve of polymer composites using the sizeeffect law. Engng Fract Mech 118:49-65

49. Chang FK, Chen MH (1987) The in situ ply shear strength distribution in graphite/epoxy laminated composites. J Compos Mater 21:708-733

50. Chang KY, Liu S, Chang FK (1991) Damage tolerance of laminated composites containing an open hole subjected to tensile loadings. J Compos Mater 25:274-301

51. Chen BY, Pinho ST, Carvalho NVD, Baiz PM, Tay TE (2014) A floating node method for the modelling of discontinuities in composites. Engng Fract Mech 127:104-134

52. Chen BY, Tay TE, Pinho ST, Tan VBC (2016) Modelling the tensile failure of composites with the floating node method. Comput Method Appl M 308:414-442

53. Clayton JD, Knap J (2015) Phase field modeling of directional fracture in anisotropic polycrystals. Comp Mater Sci 98:158-169

54. CMH-17-1G (2012) Composite Materials Handbook, vol 1 of 6: Polymer Matrix Composites: Guidelines for Characterization of Structural Materials. SAE International

55. CMH-17-3G (2012) Composite Materials Handbook, vol 3 of 6: Polymer Matrix Composites: Materials Usage, Design and Analysis. SAE International

56. Cornetti P, Pugno N, Carpinteri A, Taylor D (2006) Finite fracture mechanics: A coupled stress and energy failure criterion. Engng Fract Mech 73:2021-2033

57. Cousigné O, Moncayo D, Coutellier D, Camanho P, Naceur H, Hampel S (2013) Development of a new nonlinear numerical material model for woven composite materials accounting for permanent deformation and damage. Compos Struct 106:601614

58. Cousigné O, Moncayo D, Coutellier D, Camanho P, Naceur H (2014) Numerical modeling of nonlinearity, plasticity and damage in CFRP-woven composites for crash simulations. Compos Struct 115:75-88

59. Cuntze RG (2006) Efficient 3D and 2D failure conditions for UD laminae and their application within the verification of the laminate design. Compos Sci Technol 66:1081-1096

60. Czél G, Wisnom MR (2013) Demonstration of pseudo-ductility in high performance glass/epoxy composites by hybridisation with thin-ply carbon prepreg. Compos Part A-Appl S 52:23-30

61. Daniel IM, Ishai O (2008) Engineering Mechanics of Composite Materials. Oxford University Press, Oxford

62. Dávila CG, Camanho PP (2003) Analysis of the effects of residual strains and defects on skin/stiffner debonding using decohesion elements. Tech. Rep. AIAA Paper 2003-1465, NASA Langley Research Center, Hampton, Virginia

63. Dávila CG, Camanho PP, Rose CA (2005) Failure criteria for FRP laminates. J Compos Mater 39(4):323-345

64. Dávila CG, Camanho PP, Turon A (2008) Effective simulation of delamination in aeronautical 
structures using shells and cohesive elements. J Aircraft 45(2):663-672

65. Dávila CG, Rose CA, Iarve EV (2014) Modeling fracture and complex crack networks in laminated composites. In: Mantič V (ed) Mathematical Methods and Models in Composites, Computational and Experimental Methods in Structures, Aliabadi FMH, Series editor, vol 5, Imperial College Press, London, chap 8, pp 297-347

66. Diao H, Bismarck A, Robinson P, Wisnom MR (2014) Production of continuous intermingled $\mathrm{CF} / \mathrm{GF}$ hybrid composite via fibre tow spreading technology. In: Proceedings of ECCM16, Seville, pp 1-8

67. Dvorak GJ, Laws N (1987) Analysis of progressive matrix cracking in composite laminates II. First ply failure. J Compos Mater 21:309-329

68. Erçin GH, Camanho PP, Xavier J, Catalanotti G, Mahdi S, Linde P (2013) Size effects on the tensile and compressive failure of notched composite laminates. Compos Struct 96:736-744

69. Eriksson I, Aronsson CG (1990) Strength of tensile loaded graphite epoxy laminates containing cracks, open and filled holes. J Compos Mater 24:456-482

70. Feder J (1980) Random sequential adsorption. J Theor Biol 87:237-254

71. Flaggs DL (1985) Prediction of tensile matrix failure in composite laminates. J Compos Mater 19:29-50

72. Flaggs DL, Kural MH (1982) Experimental determination of the in situ transverse lamina strength in graphite/epoxy laminates. J Compos Mater 16:103-116

73. Fuller J, Wisnom MR (2015) Exploration of the potential for pseudo-ductility in thin ply CFRP angle-ply laminates via an analytical method. Compos Sci Technol 112:8-15

74. Fuller J, Wisnom MR (2015) Pseudo-ductility and damage suppression in thin ply CFRP angle-ply laminates. Compos Part A-Appl S 69:64-71

75. Furtado C, Arteiro A, Catalanotti G, Xavier J, Camanho PP (2016) Selective ply-level hybridisation for improved notched response of composite laminates. Compos Struct 145:1-14

76. Furtado C, Arteiro A, Bessa MA, Wardle BL, Camanho PP (2017) Prediction of size effects in open-hole laminates using only the Young's modulus, the strength, and the $\mathcal{R}$-curve of the $0^{\circ}$ ply. Compos Part A-Appl S 101:306-317

77. Gan KW, Wisnom MR, Hallett SR (2014) Effect of high through-thickness compressive stress on fibre direction tensile strength of carbon/epoxy composite laminates. Compos Sci Technol 90:1-8

78. García IG, Mantič V, Blázquez A, París F (2014) Transverse crack onset and growth in cross-ply $[0 / 90]_{s}$ laminates under tension. Application of a coupled stress and energy criterion. Int J Solids Struct 51:3844-3856

79. Garrett KW, Bailey JE (1977) Multiple transverse fracture in $90^{\circ}$ cross-ply laminates of a glass fibrereinforced polyester. J Mater Sci 12:157-168

80. Gay D, Hoa SV (2007) Composite Materials: Design and Applications, 2nd edn. CRC Press, Taylor and Francis Group, Boca Raton

81. González C, Llorca J (2007) Mechanical behavior of unidirectional fiber-reinforced polymers under transverse compression: Microscopic mechanisms and modeling. Compos Sci Technol 67:2795-2806

82. González EV, Maimí P, Sainz de Aja JR, Cruz P, Camanho PP (2014) Effects of interply hybridization on the damage resistance and tolerance of composite laminates. Compos Struct 108:319-331

83. Guillamet G, Turon A, Costa J, Renart J, Linde P, Mayugo JA (2014) Damage occurrence at edges of non-crimp-fabric thin-ply laminates under off-axis uniaxial loading. Compos Sci Technol 98:44-50

84. Guillamet G, Turon A, Costa J, Linde P (2016) A quick procedure to predict free-edge delamination in thin-ply laminates under tension. Engng Fract Mech 168:28-39

85. Gültekin O, Dal H, Holzapfel GA (2016) A phase-field approach to model fracture of arterial walls: Theory and finite element analysis. Comput Method Appl M 312:542-566

86. Hahn HT, Tsai SW (1973) Nonlinear elastic shear behavior of unidirectional composite laminae. J Compos Mater 7(1):102-118

87. Hashin Z (1980) Failure criteria for unidirectional fibre composites. J Appl Mech 47:329-334

88. Herráez M, Mora D, Naya F, Lopes CS, González C, Llorca J (2015) Transverse cracking of crossply laminates: A computational micromechanics perspective. Compos Sci Technol 110:196-204

89. Hesch C, Weinberg K (2014) Thermodynamically consistent algorithms for a finite-deformation phase field approach to fracture. Int J Numer Meth Engng 99(12):906-924

90. Hine PJ, Duckett RA, Kaddour AS, Hinton MJ, Wells GM (2005) The effect of hydrostatic pressure on the mechanical properties of glass fibre/epoxy unidirectional composites. Compos Part A-Appl S 36:279-289

91. Hinton MJ, Kaddour AS, Soden PD (2004) A further assessment of the predictive capabilities of current failure theories for composite laminates: 
comparison with experimental evidence. Compos Sci Technol 64:549-558

92. Hinton MJ, Kaddour AS, Soden PD (2004) Evaluation of failure prediction in composite laminates: background to 'part C' of the exercise. Compos Sci Technol 64:321-327

93. Hobbiebrunken T, Hojo M, Adachi T, De Jong C, Fiedler B (2006) Evaluation of interfacial strength in $\mathrm{CF} /$ epoxies using FEM and in-situ experiments. Compos Part A-Appl S 37:2248-2256

94. Iarve EV, Gurvich MR, Mollenhauer DH, Rose CA, Dávila CG (2011) Mesh-independent matrix cracking and delamination modeling in laminated composites. Int J Numer Meth Engng 88:749-773

95. Jacques S, De Baere I, Van Paepegem W (2014) Application of periodic boundary conditions on multiple part finite element meshes for the mesoscale homogenization of textile fabric composites. Compos Sci Technol 92:41-54

96. Jalalvand M, Wisnom MR, Hosseini-Toudeshky H, Mohammadi B (2014) Experimental and numerical study of oblique transverse cracking in cross-ply laminates under tension. Compos Part A-Appl S 67:140-148

97. Jiang WG, Hallett SR, Green BG, Wisnom MR (2007) A concise interface constitutive law for analysis of delamination and splitting in composite materials and its application to scaled notched tensile specimens. Int J Numer Meth Engng 69:1982-1995

98. Jodrey WS, Tory EM (1985) Computer simulation of close random packing of equal spheres. Phys Rev A 32(4):2347

99. Kawabe K (2008) New spreading technology for carbon fiber tow and its application to composite materials. Sen-i Gakkaishi 64(8):262-267, in Japanese

100. Kawabe K, Matsuo T, Maekawa Z (1998) New technology for opening various reinforcing fiber tows. J Soc Mat Sci Jpn 47(7):727-734, in Japanese

101. Kawabe K, Sasayama H, Kageyama K, Ogata N (2008) Effect of ply thickness on compressive properties in multidirectionally laminated composites. J Jpn Soc Compos Mater 34:173-181, in Japanese

102. Klinkel S, Wagner W (1997) A geometrical nonlinear brick element based on the EAS-method. Int J Numer Meth Engng 40:4529-4545

103. Koerber H, Camanho PP (2011) High strain rate characterisation of unidirectional carbonepoxy IM7-8552 in longitudinal compression. Compos Part A-Appl S 42:462-470
104. Koerber H, Xavier J, Camanho PP (2010) High strain rate characterisation of unidirectional carbon-epoxy IM7-8552 in transverse compression and in-plane shear using digital image correlation. Mech Mater 42:1004-1019

105. Laurin F, Carrere N, Huchette C, Maire JF (2012) A multiscale hybrid approach for damage and final failure predictions of composite structures. J Compos Mater 47(20-21):2713-2747

106. Leguillon D (2002) Strength or toughness? A criterion for crack onset at a notch. Eur J Mech A-Solid 21:61-72

107. Ling D, Yang Q, Cox B (2009) An augmented finite element method for modeling arbitrary discontinuities in composites. Int J Fracture 156:5373

108. Liu G, Li Q, Msekh MA, Zuo Z (2016) Abaqus implementation of monolithic and staggered schemes for quasi-static and dynamic fracture phase-field model. Comp Mater Sci 121:35-47

109. Lopes CS, Gürdal Z, Camanho PP (2008) Variable-stiffness composite panels: Buckling and first-ply failure improvements over straight-fibre laminates. Comput Struct 86:897-907

110. Lopes CS, Sábada S, González C, Llorca J, Camanho PP (2016) Physically-sound simulation of low-velocity impact on fiber reinforced laminates. Int J Impact Eng 92:3-17

111. Maimí P, Camanho PP, Mayugo JA, Dávila CG (2007) A continuum damage model for composite laminates: Part I - Constitutive model. Mech Mater 39:897-908

112. Maimí P, Camanho PP, Mayugo JA, Dávila CG (2007) A continuum damage model for composite laminates: Part II - Computational implementation and validation. Mech Mater 39:909-919

113. Maimí P, González EV, Camanho PP (2014) Comment to the paper 'Analysis of progressive matrix cracking in composite laminates II. First ply failure'. J Compos Mater 48(9):1139-1141

114. Mantič V (2009) Interface crack onset at a circular cylindrical inclusion under a remote transverse tension. Application of a coupled stress and energy criterion. Int J Solids Struct 46(6):1287-1304

115. Mar JW, Lin KY (1977) Fracture mechanics correlation for tensile failure of filamentary composites with holes. J Aircraft 14:703-704

116. Martin E, Leguillon D, Carrère N (2012) A coupled strength and toughness criterion for the prediction of the open hole tensile strength of a composite plate. Int J Solids Struct 49:3915-3922

117. Mayugo JA, Camanho PP, Maimí P, Dávila CG (2010) Analytical modelling of transverse matrix 
cracking of $\left\{ \pm \theta / 90^{n}\right\}^{s}$ composite laminates under multiaxial loading. Mech Adv Mater Struc 17:237245

118. Melro AR, Camanho PP, Pinho ST (2008) Generation of random distribution of fibres in longfibre reinforced composites. Compos Sci Technol 68:2092-2102

119. Melro AR, Camanho PP, Pinho ST (2012) Influence of geometrical parameters on the elastic response of unidirectional composite materials. Compos Struct 94:3223-3231

120. Melro AR, Camanho PP, Pires FMA, Pinho ST (2012) Numerical simulation of the non-linear deformation of 5 -harness satin weaves. Comp Mater Sci 61:116-126

121. Melro AR, Camanho PP, Pires FMA, Pinho ST (2013) Micromechanical analysis of polymer composites reinforced by unidirectional fibres: Part I - Constitutive modelling. Int J Solids Struct 50:1897-1905

122. Melro AR, Camanho PP, Pires FMA, Pinho ST (2013) Micromechanical analysis of polymer composites reinforced by unidirectional fibres: Part II - Micromechanical analyses. Int J Solids Struct 50:1906-1915

123. Miehe C, Hofacker M, Welschinger F (2010) A phase field model for rate-independent crack propagation: Robust algorithmic implementation based on operator splits. Comput Method Appl M 199(45-48):2765-2778

124. Miehe C, Welschinger F, Hofacker M (2010) Thermodynamically consistent phase-field models of fracture: Variational principles and multi-field FE implementations. Int J Numer Meth Engng 83(10):1273-1311

125. Miehe C, Schänzel LM, Ulmer H (2015) Phase field modeling of fracture in multi-physics problems. Part I. Balance of crack surface and failure criteria for brittle crack propagation in thermoelastic solids. Comput Method Appl M 294:449485

126. Mozaffari N, Voyiadjis GZ (2015) Phase field based nonlocal anisotropic damage mechanics model. Physica D 308:11-25

127. Nash NH, Young TM, McGrail PT, Stanley WF (2015) Inclusion of a thermoplastic phase to improve impact and post-impact performances of carbon fibre reinforced thermosetting composites - A review. Mater Design 85:582-597

128. Nguyen TT, Yvonnet J, Bornert M, Chateau C, Sab K, Romani R, Le Roy R (2016) On the choice of parameters in the phase field method for simulating crack initiation with experimental valida- tion. Int J Fracture 197(2):213-226

129. Ogihara S, Takeda N, Kobayashi A (1997) Experimental characterization of microscopic failure process under quasi-static tension in interleaved and toughness-improved CFRP cross-ply laminates. Compos Sci Technol 57:267-275

130. Oh JH, Jin KK, Ha SK (2006) Interfacial strain distribution of a unidirectional composite with randomly distributed fibers under transverse loading. J Compos Mater 40(9):759-778

131. Okereke MI, Akpoyomare OI (2013) A virtual framework for prediction of full-field elastic response of unidirectional composites. Comp Mater Sci 70:82-99

132. Olsson R (2015) Analytical prediction of damage due to large mass impact on thin ply composites. Compos Part A-Appl S 72:184-191

133. Paggi M, Reinoso J (2017) Revisiting the problem of a crack impinging on an interface: A modeling framework for the interaction between the phase field approach for brittle fracture and the interface cohesive zone model. Comput Method Appl M 321:145-172

134. Paggi M, Corrado M, Reinoso J (2004) Fracture of solar-grade anisotropic polycrystalline Silicon: A combined phase fieldcohesive zone model approach. Comput Method Appl M 330:123-148

135. Parvizi A, Bailey JE (1978) On multiple transverse cracking in glass fibre epoxy cross-ply laminates. J Mater Sci 13:2131-2136

136. Parvizi A, Garrett KW, Bailey JE (1978) Constrained cracking in glass fibre-reinforced epoxy cross-ply laminates. J Mater Sci 13:195-201

137. Pinho ST, Iannucci L, Robinson P (2006) Physically-based failure models and criteria for laminated fibre-reinforced composites with emphasis on fibre kinking: Part I: Development. Compos Part A-Appl S 37:63-73

138. Pinho ST, Iannucci L, Robinson P (2012) Material and structural response of polymer-matrix fibrereinforced composites. J Compos Mater 46(19 20):2313-2341

139. Puck A, Schürmann H (1998) Failure analysis of FRP laminates by means of physically based phenomenological models. Compos Sci Technol 58:1045-1067

140. Puck A, Schürmann H (2002) Failure analysis of FRP laminates by means of physically based phenomenological models. Compos Sci Technol 62:1633-1662

141. Pyrz R (1994) Quantitative description of the microstructure of composites. Part I: Morphology of unidirectional composite systems. Compos Sci 
Technol 50(2):197-208

142. Reinoso J, Blázquez A (2016) Application and finite element implementation of 7-parameter shell element for geometrically nonlinear analysis of layered CFRP composites. Compos Struct 139:263276

143. Reinoso J, Arteiro A, Paggi M, Camanho PP (2017) Strength prediction of notched thin ply laminates using finite fracture mechanics and the phase field approach. Compos Sci Technol 150:205-216

144. Reinoso J, Catalanotti G, Blázquez A, Areias P, Camanho PP, París F (2017) A consistent anisotropic damage model for laminated fiberreinforced composites using the $3 \mathrm{D}$-version of the Puck failure criterion. Int J Solids Struct 126$127: 37-53$

145. Reinoso J, Paggi M, Linder C (2017) Phase field modeling of brittle fracture for enhanced assumed strain shells at large deformations: formulation and finite element implementation. Comput Mech 59:981-1001

146. Rolfes R, Ernst G, Vogler M, Hühne C (2008) Material and failure models for textile composites. In: Camanho PP, Dávila CG, Pinho ST, Remmers JJC (eds) Mechanical Response of Composites, Computational Methods in Applied Sciences, vol 10, Springer, Dordrecht, chap 2, pp 27-56

147. Saito H, Morita M, Kawabe K, Kanesaki M, Takeuchi H, Tanaka M, Kimpara I (2011) Effect of ply-thickness on impact damage morphology in CFRP laminates. J Reinf Plast Comp 30:10971106

148. Saito H, Takeuchi H, Kimpara I (2012) Experimental evaluation of the damage growth restraining in $90^{\circ}$ layer of thin-ply CFRP cross-ply laminates. Adv Compos Mater 21:57-66

149. Saito H, Takeuchi H, Kimpara I (2014) A study of crack suppression mechanism of thin-ply carbonfiber-reinforced polymer laminate with mesoscopic numerical simulation. J Compos Mater 48(17):2085-2096

150. Sebaey TA, Costa J, Maimí P, Batista Y, Blanco N, Mayugo JA (2014) Measurement of the in situ transverse tensile strength of composite plies by means of the real time monitoring of microcracking. Compos Part B-Eng 65:40-46

151. Sihn S, Kim RY, Kawabe K, Tsai SW (2007) Experimental studies of thin-ply laminated composites. Compos Sci Technol 67:996-1008

152. Simo JC, Armero F (1992) Geometrically nonlinear enhanced strain mixed methods and the method of incompatible modes. Int J Numer Meth
Engng 33:1413-1449

153. Soden PD, Kaddour AS, Hinton MJ (2004) Recommendations for designers and researchers resulting from the world-wide failure exercise. Compos Sci Technol 64:589-604

154. Song K, Li Y, Rose CA (2011) Continuum damage mechanics models for the analysis of progressive failure in open-hole tension laminates. Tech. Rep. NF1676L-12382, NASA Langley Research Center, Hampton, Virginia

155. Spencer AJM (1987) Kinematic constraints, constitutive equations and failure rules for anisotropic materials. In: Boehler JP (ed) Applications of Tensor Functions in Solid Mechanics, CISM Courses and Lectures - No. 292, Springer - Verlag, Wien, chap 10, pp 187-201

156. Strobl M, Seelig T (2016) On constitutive assumptions in phase field approaches to brittle fracture. Procedia Structural Integrity 2:3705-3712

157. Sun CT, Tao J (1998) Prediction of failure envelopes and stress/strain behaviour of composite laminates. Compos Sci Technol 58:1125-1136

158. Swolfs Y, Gorbatikh L, Romanov V, Orlova S, Lomov SV, Verpoest I (2013) Stress concentrations in an impregnated fibre bundle with random fibre packing. Compos Sci Technol 74:113-120

159. Swolfs Y, Gorbatikh L, Verpoest I (2013) Stress concentrations in hybrid unidirectional fibrereinforced composites with random fibre packings. Compos Sci Technol 85:10-16

160. Swolfs Y, McMeeking RM, Verpoest I, Gorbatikh L (2015) Matrix cracks around fibre breaks and their effect on stress redistribution and failure development in unidirectional composites. Compos Sci Technol 108:16-22

161. Swolfs Y, McMeeking RM, Verpoest I, Gorbatikh L (2015) The effect of fibre dispersion on initial failure strain and cluster development in unidirectional carbon/glass hybrid composites. Compos Part A-Appl S 69:279-287

162. Swolfs Y, Verpoest I, Gorbatikh L (2015) Issues in strength models for unidirectional fibre-reinforced composites related to Weibull distributions, fibre packings and boundary effects. Compos Sci Technol 114:42-49

163. Swolfs Y, Verpoest I, Gorbatikh L (2016) Maximising the hybrid effect in unidirectional hybrid composites. Mater Design 93:39-45

164. Tanné E, Li T, Bourdin B, Marigo J, Maurini C (2018) Crack nucleation in variational phasefield models of brittle fracture. J Mech Phys Solids 110:80-99 
165. Tao J, Sun CT (1998) Influence of ply orientation on delamination in composite laminates. J Compos Mater 32(21):1933-1947

166. Tavares RP, Melro AR, Bessa MA, Turon A, Liu WK, Camanho PP (2016) Mechanics of hybrid polymer composites: analytical and computational study. Comput Mech 57:405-421

167. Tavares RP, Otero F, Turon A, Camanho PP (2017) Effective simulation of the mechanics of longitudinal tensile failure of unidirectional polymer composites. Int J Fracture 208:269-285

168. Teichtmeister S, Miehe C (2015) Phase-field modeling of fracture in anisotropic media. Proc Appl Math Mech 15:159-160

169. Totry E, González C, Llorca J (2008) Failure locus of fiber-reinforced composites under transverse compression and out-of-plane shear. Compos Sci Technol 68:829-839

170. Totry E, González C, Llorca J (2008) Prediction of the failure locus of $\mathrm{C} / \mathrm{PEEK}$ composites under transverse compression and longitudinal shear through computational mechanics. Compos Sci Technol 68:3128-3136

171. Totry E, Molina-Aldareguía JM, González C, Llorca J (2010) Effect of fiber, matrix and interface properties on the in-plane shear deformation of carbon-fiber reinforced composites. Compos Sci Technol 70:970-980

172. Trias D (2005) Analysis and simulation of transverse random fracture of long fibre reinforced composites. PhD thesis, Universitat de Girona, Escola Politècnica Superior, Girona

173. Trias D, Costa J, Mayugo JA, Hurtado JE (2006) Random models versus periodic models for fiber reinforced composites. Comp Mater Sci 38:316324

174. Tsai SW (2008) Strength and Life of Composites. Composites Design Group, Department of Aeronautics and Astronautics, Stanford University

175. Tsai SW, Melo JDD (2014) An invariantbased theory of composites. Compos Sci Technol 100:237-243

176. Tsai SW, Melo JDD (2015) Composite Materials Design and Testing - Unlocking mystery with invariants. Composites Design Group, Department of Aeronautics and Astronautics, Stanford University, Stanford

177. Tsai SW, Melo JDD (2016) A unit circle failure criterion for carbon fiber reinforced polymer composites. Compos Sci Technol 123:71-78

178. van der Meer FP, Dávila CG (2013) Cohesive modeling of transverse cracking in laminates under in-plane loading with a single layer of elements per ply. Int J Solids Struct 50:3308-3318

179. Van der Meer FP, Sluys LJ (2009) A phantom node formulation with mixed mode cohesive law for splitting in laminates. Int J Fract 158:107-124

180. Van der Meer FP, Sluys LJ (2010) Meshindependent modeling of both distributed and discrete matrix cracking in interaction with delamination in composites. Engng Fract Mech 77:719 735

181. Varandas LF, Arteiro A, Bessa MA, Melro AR, Catalanotti G (2017) The effect of throughthickness compressive stress on mode II interlaminar crack propagation: A computational micromechanics approach. Compos Struct 182:326-334

182. Varna J, Berglund LA, Ericson ML (1997) Transverse single-fibre test for interfacial debonding in composites: 2. Modelling. Compos Part A-Appl S 28A:317-326

183. Vaughan TJ, McCarthy CT (2010) A combined experimental numerical approach for generating statistically equivalent fibre distributions for high strength laminated composite materials. Compos Sci Technol 70:291-297

184. Vaughan TJ, McCarthy CT (2011) A micromechanical study on the effect of intra-ply properties on transverse shear fracture in fibre reinforced composites. Compos Part A-Appl S 42:1217-1228

185. Vaughan TJ, McCarthy CT (2011) Micromechanical modelling of the transverse damage behaviour in fibre reinforced composites. Compos Sci Technol 71:388-396

186. Verhoosel CV, de Borst R (2013) A phase-field model for cohesive fracture. Int $\mathrm{J}$ Numer Meth Engng 96:43-62

187. Vignollet J, May S, de Borst R, Verhoosel CV (2014) Phase-field models for brittle and cohesive fracture. Meccanica 49:2587-2601

188. Violeau D, Ladevèze P, Lubineau G (2009) Micromodel-based simulations for laminated composites. Compos Sci Technol 69:1364-1371

189. Vogler M, Rolfes R, Camanho PP (2013) Modeling the inelastic deformation and fracture of polymer composites - Part I: Plasticity model. Mech Mater 59:50-64

190. Vogler TJ, Kyriakides S (2001) On the initiation and growth of kink bands in fiber composites: Part I. experiments. Int J Solids Struct 38:2639-2651

191. Waddoups ME, Eisenmann JR, Kaminski BE (1971) Macroscopic fracture mechanics of advanced composite materials. J Compos Mater $5: 446-454$

192. Walker TH, Avery WB, Ilcewicz LB, Poe, Jr CC, Harris CE (1991) Tension fracture of laminates 
for transport fuselage. Part I: material screening. In: Soderquist JR, Neri LM, Bohon HL (eds) Proceedings of the 9th DoD/NASA/FAA conference on fibrous composites in structural design, Lake Tahoe, Nevada, vol II, pp 747-787

193. Whitney JM, Nuismer RJ (1974) Stress fracture criteria for laminated composites containing stress concentrations. J Compos Mater 8:253-265

194. Wisnom MR (2010) Modelling discrete failures in composites with interface elements. Compos Part A-Appl S 41:795-805

195. Wongsto A, Li S (2005) Micromechanical FE analysis of UD fibre-reinforced composites with fibres distributed at random over the transverse crosssection. Compos Part A-Appl S 36:1246-1266

196. Yang S, Tewari A, Gokhale AM (1997) Modeling of non-uniform spatial arrangement of fibers in a ceramic matrix composite. Acta Mater 45(7):3059-3069

197. Yokozeki T, Aoki Y, Ogasawara T (2008) Experimental characterization of strength and damage resistance properties of thin-ply carbon fiber/toughened epoxy laminates. Compos Struct 82:382-389

198. Zobeiry N, Forghani A, McGregor C, Vaziri R, Poursartip A (2008) Progressive damage modeling of composite materials under both tensile and compressive loading regimes. In: Camanho PP, Dávila CG, Pinho ST, Remmers JJC (eds) Mechanical Response of Composites, Computational Methods in Applied Sciences, vol 10, Springer, Dordrecht, chap 9, pp 179-195 